MONICA GOES EBOLI

TRANSFORMAÇÃO DE REDES DE PETRI COLORIDAS EM PROCESSOS DE DECISÃO MARKOVIANOS COM PROBABILIDADES IMPRECISAS

São Paulo

2010 
MONICA GOES EBOLI

\section{TRANSFORMAÇÃO DE REDES DE PETRI COLORIDAS EM PROCESSOS DE DECISÃO MARKOVIANOS COM PROBABILIDADES IMPRECISAS}

Dissertação a ser apresentada à Escola Politécnica da Universidade de São Paulo para a obtenção do título de mestre em engenharia

Área de Concentração:

Engenharia de controle e automação mecânica

Orientador:

Prof.Dr.Fabio Gagliardi Cozman

São Paulo 


\section{DEDICATÓRIA}

Dedico este trabalho a minha família (Lúcia, Oscar, Stella e Juliana) e a meu marido Eduardo. 


\section{AGRADECIMENTOS}

Obrigada ao meu orientador Fábio pelos constantes questionamentos e orientação.

Ao querido Eduardo pelo carinho, compreensão e ajuda dedicados e vitais para a conclusão deste projeto.

A minha família pelo suporte e compreensão nos momentos difíceis. 
Learning, a mere hoard of gold kept by a devil. William Shakespeare 


\section{RESUMO}

Este trabalho foi motivado pela necessidade de considerar comportamento estocástico durante o planejamento da produção de sistemas de manufatura, ou seja, o que produzir e em que ordem. Estes sistemas possuem um comportamento estocástico geralmente não considerado no planejamento da produção. O principal objetivo deste trabalho foi obter um método que modelasse sistemas de manufatura e representasse seu comportamento estocástico durante o planejamento de produção destes sistemas. Como os métodos que eram ideais para planejamento não forneciam a modelagem adequada dos sistemas, e os com modelagem adequada não forneciam a capacidade de planejamento necessária, decidiu-se combinar dois métodos para atingir o objetivo desejado. Decidiu-se modelar os sistemas em rede de Petri e convertê-los em processos de decisão markovianos, e então realizar o planejamento com o ultimo. Para que fosse possível modelar as probabilidades envolvidas nos processos, foi proposto um tipo especial de rede de Petri, nomeada rede de Petri fatorada. Utilizando este tipo de rede de Petri, foi desenvolvido o método de conversão em processos de decisão markovianos. A conversão ocorreu com sucesso, conforme testes que mostraram que planos podem ser produzidos utilizando-se algoritmos de ponta para processos de decisão markovianos.

Palavras-chave: Processos de decisão markovianos. Processos de decisão markovianos com probabilidades imprecisas. Rede de Petri colorida. Processo de decisão markoviano fatorado. 


\begin{abstract}
The present work was motivated by the need to consider stochastic behavior when planning the production mix in a manufacturing system. These systems are exposed to stochastic behavior that is usually not considered during production planning. The main goal of this work was to obtain a method to model manufacturing systems and to represent their stochastic behavior when planning the production for these systems. Because the methods that were suitable for planning were not adequate for modeling the systems and viceversa, two methods were combined to achieve the main goal. It was decided to model the systems in Petri nets and to convert them into Markov decision processes, to do the planning with the latter. In order to represent probabilities in the process, a special type of Petri nets, named Factored Petri nets, were proposed. Using this kind of Petri nets, a conversion method into Markov decision processes was developed. The conversion is successful as tests showed that plans can be produced within seconds using state-of-art algorithms for Markov decision processes.
\end{abstract}

Keywords: Markov decision process. Markov decision process with imprecise probabilities. Colored Petri nets. Factored markov decision process. 


\section{LISTA DE ILUSTRAÇÕES}

Figura 1 - Representação de elementos de redes de Petri: lugar, transição, arco e marca.

Figura 2 - Exemplo de representação com rede de Petri. 23

Figura 3 - Exemplo de elementos de rede de Petri a)Antes do disparo da transição b)Após o disparo da transição

Figura 4 - a)Transição desabilitada b)Transição desabilitada c)Transição habilitada

Figura 5 - a) Transição desabilitada por pós condições b) Transição habilitada26

Figura 6 - a)Transição desabilitada por pré-condições b)Transição desabilitada por pós-condições c)Transição habilitada

Figura 7 - Exemplos de conflito por recursos e por lugares ............................ 28

Figura 8 - Exemplo de conflito resolvido com random switch .......................... 28

Figura 9 - Exemplo de rede lugar-transição com marcas indistintas................. 30

Figura 10 - Exemplo de rede de Petri colorida com arcos indicando marcas. .. 30

Figura 11 - Exemplo de rede de Petri colorida com variáveis nos arcos orientados.

Figura 12 - Representação gráfica da evolução dos estados do exemplo de fórmula um

Figura 13 - llustração do exemplo de dois tanques

Figura 14 - Representação dos estados do MDPIP e evoluções no modo tradicional do exemplo dos dois tanques.

Figura 15 - Representação da evolução das variáveis de estado do MDPIP no modo fatorado do exemplo de dois tanques.

Figura 16 - Segundo exemplo de representação gráfica de rede de Petri seguindo restrições. 53

Figura 17 - Exemplo de restrição de probabilidades superiores mínimas........ 60

Figura 18 - Rede de Petri para exemplo de listagem de variáveis em MDP..... 62 
Figura 19 - Rede de Petri para exemplo de listagem de ações em MDP. ........ 63

Figura 20 - Rede de Petri para exemplo de dependência entre variáveis. ....... 65

Figura 21 - Rede de Petri para exemplo do que é transições de saída para cálculo de probabilidades de estado futuro. ................................... 68

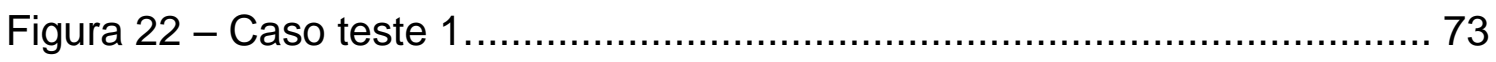

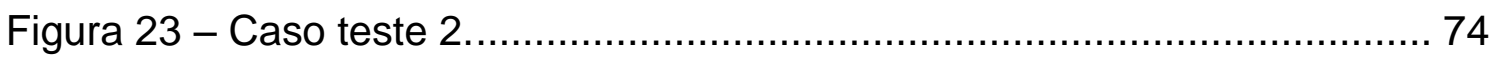

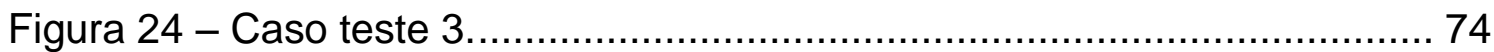

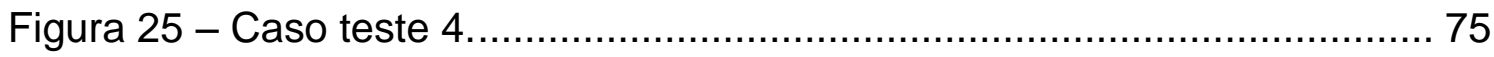

Figura 1A - llustração do exemplo do tanque com sensores ............................. ii

Figura 2A - Layout de input do valor das probabilidades ................................vi

Figura 1C - Rede de Petri para exemplo de dependência entre variáveis...... xxiii

Figura 1D - Entrada da rede de Petri no programa ................................... xxxiv

Figura 2D - Entrada das tabelas de probabilidades no programa ................ xxxiv 


\section{LISTA DE TABELAS}

Tabela 1 - Tabela de probabilidades e recompensas do exemplo de fórmula um

Tabela 2 - Probabilidades e recompensas do exemplo de fórmula um com intervalos de probabilidades.

Tabela 3 - Exemplo de definição dos estados dos sistemas e suas recompensas.

Tabela 4 - Tabela de probabilidades do exemplo de MDP de tanques não fatorado

Tabela 5 - Tabela de probabilidades do tanque 1 do exemplo de MDP de tanques fatorado.

Tabela 6 - Tabela de probabilidades do tanque 2 do exemplo de MDP de tanques fatorado.

Tabela 7 - Tabela de probabilidades de transições em conflito de uma rede de Petri fatorada.

Tabela 8 - Tabela reduzida de probabilidades de transições em conflito de redes de Petri fatoradas.

Tabela 9 - Tabela de probabilidades do primeiro grupo de conflito do exemplo de rede de Petri fatorada da Figura 16.

Tabela 10 - Tabela de probabilidades do segundo grupo de conflito para exemplo de rede de Petri fatorada da Figura 16.

Tabela 11 - Exemplo de tabela de recompensas do exemplo de rede de Petri fatorada da Figura 15

Tabela 12 - Tabela de probabilidades imprecisas do conflito de uma rede de Petri fatorada com probabilidades imprecisas para o exemplo da Figura 15 
Tabela 13 - Tabela de probabilidades do primeiro grupo de conflitos para o exemplo de rede de Petri fatorada com probabilidades imprecisas da Figura 16

Tabela 14 - Tabela de probabilidades do segundo grupo de conflitos para o exemplo de rede de Petri fatorada com probabilidades imprecisas da Figura 16 59

Tabela 15 - Tabela de recompensas da rede da Figura 19 69

Tabela 16 - Tabela de recompensas da rede da Figura 19 convertida para MDP

Tabela 17 - Tempos de processamento dos casos exemplos propostos. 75

Tabela $1 \mathrm{~A}$ - Estados e representação com as variáveis de estado do exemplo de tanques com sensores.

Tabela 2A - Estados e suas representações com as variáveis de estado do exemplo de tanques. iv

Tabela 3A - Função de transição de probabilidades para S1'=1 do exemplo de tanque. .. V

Tabela 4A - Função de transição de probabilidades para S1'=1 com intervalos de probabilidade do exemplo do tanque................................. viii

Tabela 1B - Tabela de probabilidades caso teste 1 ........................................

Tabela 2B - Tabela de recompensas caso teste 1 .........................................

Tabela 3B - Tabela de probabilidades caso teste 2 .......................................

Tabela 4B - Tabela de recompensas caso teste 2 .........................................xi

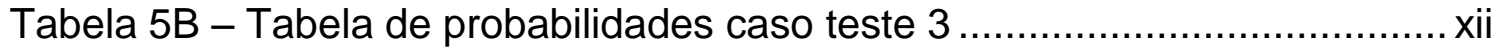

Tabela 6B - Tabela de recompensas caso teste 3 ...................................... xiii

Tabela 7B - Tabela de probabilidades caso teste 4 ..................................... xiv

Tabela 8B - Tabela de probabilidades caso teste 4 .................................... xiv

Tabela 9B - Tabela de recompensas caso teste 4 .........................................

Tabela 10B - Tabela de probabilidades caso teste 5 .................................... xvi

Tabela 11B - Tabela de probabilidades caso teste 6 .................................... xvi

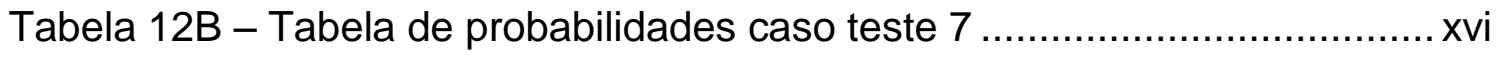


Tabela 13B - Tabela de probabilidades caso teste 8 .................................. xvii

Tabela 14B - Tabela de probabilidades caso teste 8 .................................... xvii

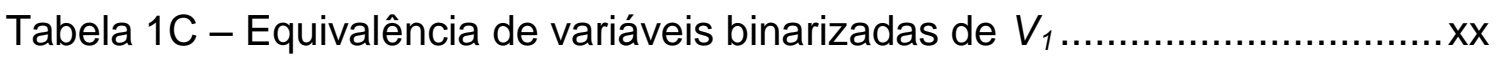

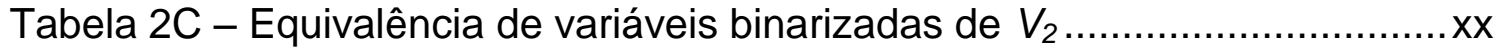

Tabela 3C - Tabela de binarização de A, B e vazio .......................................xxi

Tabela 4C - Tabela de binarização de A, B, C, E e vazio ...............................xxi

Tabela 5C - Tabela de dependência entre variáveis já binarizadas para exemplo da Figura 1C.................................................... xxiv

Tabela 6C - Tabela de probabilidades do segundo grupo de conflitos do exemplo da Figura 1C.................................................... Xxvi

Tabela 7C - Tabela de recompensas da rede da Figura $20 \ldots \ldots \ldots \ldots \ldots \ldots \ldots \ldots . . . . . x x v i i i$

Tabela $8 \mathrm{C}$ - Tabela de recompensas da rede da Figura 20 utilizando variáveis binarizadas do MDP ......................................................xxviii

Tabela 9C - Tabela de probabilidades do segundo grupo de conflitos do exemplo da Figura 1C....................................................... xxxi

Tabela 10C - Tabela de probabilidades do primeiro grupo de conflitos do exemplo da Figura 1C........................................................ Xxxii 


\section{LISTA DE ABREVIATURAS}

$\begin{array}{ll}\text { PN } & \text { Redes de Petri (Petri nets) } \\ \text { CPN } & \text { Redes de Petri coloridas (colored Petri nets) } \\ \text { FPN } & \text { Redes de Petri fatoradas (factored Petri nets) } \\ \text { FPNIP } & \text { FPN com probabilidades imprecisas (FPN with imprecise } \\ & \text { probabilities) } \\ \text { MDP } & \text { Processo de decisão markoviano (Markov Decision Process) } \\ \text { MDPIP } & \text { MDP com probab. imprecisas (MDP with Imprecise Probabilities) } \\ \text { FMDP } & \text { MDP Fatorado (Factored MDP) } \\ \text { FMDPIP } & \text { MDPIP Fatorado (Factored MDPIP) }\end{array}$




\section{LISTA DE SÍMBOLOS}

$\begin{array}{ll}K & \text { Capacidade do lugar } \\ L_{i} & \text { Lugar } i \text { da rede de Petri } \\ T_{i} & \text { Transição } i \text { da rede de Petri } \\ s & \text { Estado atual do MDP/MDPI } \\ s^{\prime} & \text { Estado do tempo seguinte do MDP/MDPI } \\ a & \text { Ação tomada no MDP/MDPIP } \\ F(s / a) & \text { Função que mapeia estados futuros dado estado } s \text { e ação a } \\ P\left(s^{\prime} / s, a\right) & \text { Probabilidade de } s^{\prime} \text { dada o estado } s \text { e ação a } \\ R(s) & \text { Recompensa do estado } s \\ P_{\text {inf }} & \text { Probabilidade inferior de um intervalo credal } \\ P_{\text {sup }} & \text { Probabilidade superior de um intervalo credal } \\ V_{i} & \text { Variável de estado } i \text { do MDP/MDPIP } \\ m_{i} & \text { Marca } i \text { da rede de Petri } \\ T_{f i} & \text { Transição fonte } i \text { da rede de Petri } \\ D & \text { Transição desabilitada }\end{array}$




\section{SUMÁRIO}

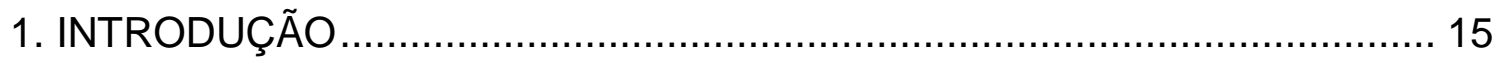

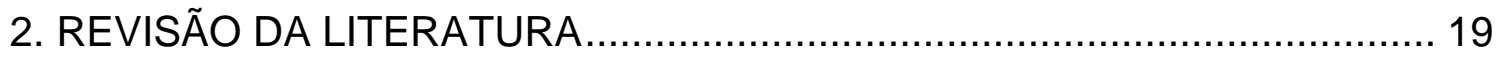

2.1Linhas de Manufatura Automobilística .....................................................19

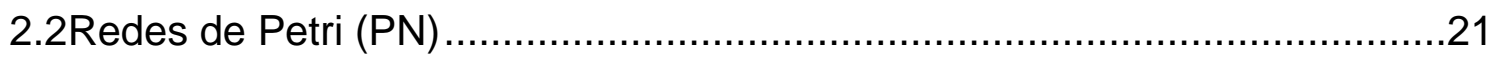

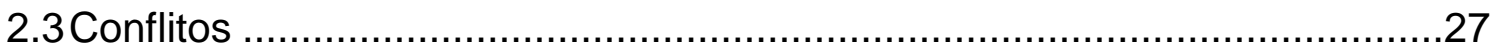

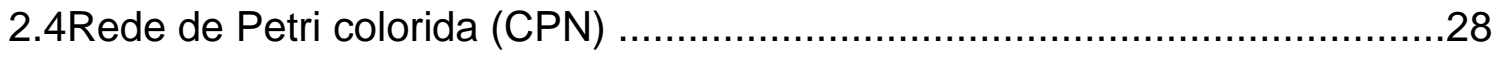

2.5 Processo de decisão markoviano (MDP) ………...................................32

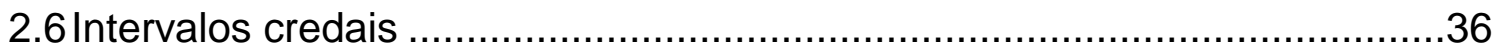

2.7Processo de decisão markoviano com probabilidades imprecisas (MDPIP) 37

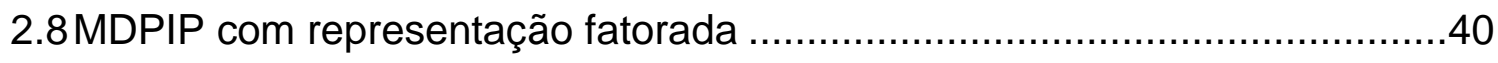

2.9 Resolução de processos de decisão markovianos.....................................45

3.MODELAGEM EM REDE DE PETRI .................................................. 46

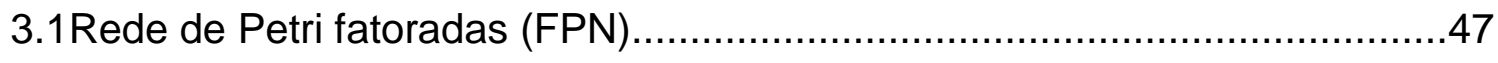

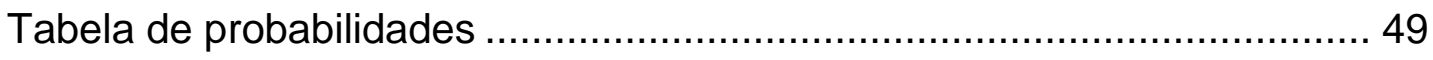

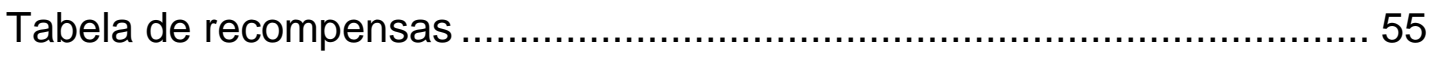

3.2 Rede de Petri fatorada com probabilidades imprecisas ..............................56

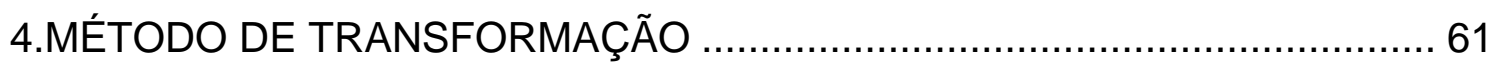

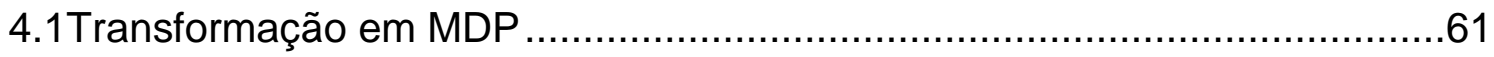

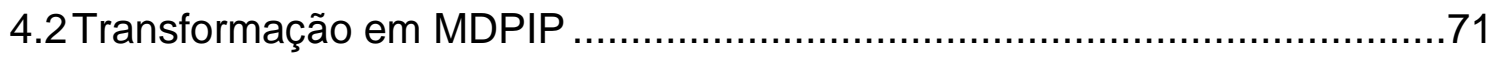

4.3 Resultados de simulação dos casos teste ……...........................................73

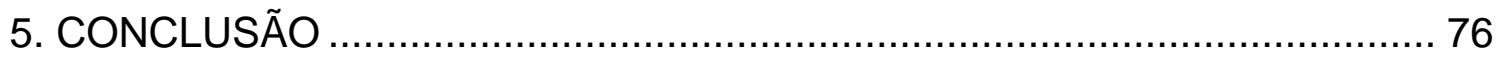

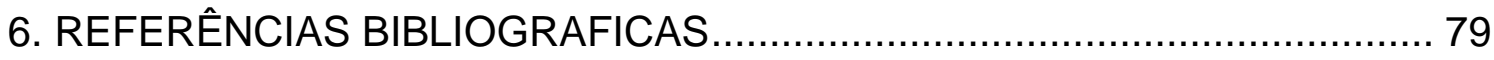

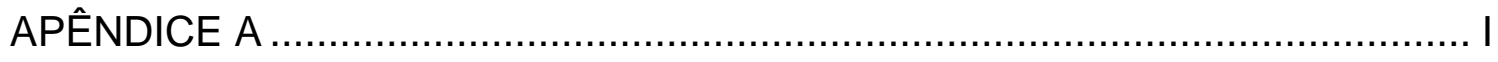

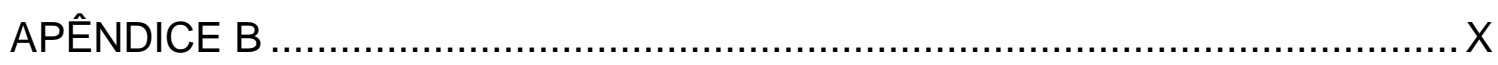

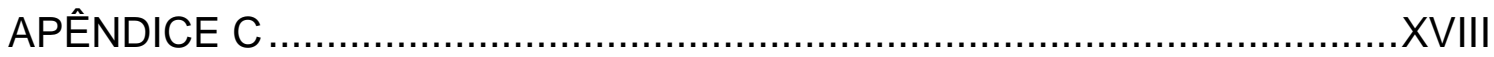

Transformação em MDP .................................................................xviii 
Transformação em MDPIP ................................................................ xxix

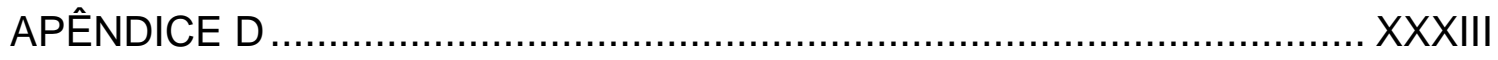




\section{INTRODUÇÃO}

A proposta deste trabalho é transformar uma rede de Petri colorida em processos de decisão markovianos com probabilidades imprecisas. Esta proposta nasceu do interesse em associar o poder de modelagem de rede de Petri ao poder de planejamento dos processos de decisão markovianos.

A motivação deste trabalho originou-se na observação de sistemas de manufatura. O estímulo foram linhas de manufatura nas quais é produzido mais de um tipo de produto e que necessitam de um planejamento de produção. Planejar a ordem de produção é decidir o que produzir e em que ordem produzir. Além disso, notou-se que apesar do avanço da automatização e controle dessas linhas, muitas ainda estão expostas a incertezas. A solução para esse tipo de problema depende da aplicação de um método de tomada de decisão capaz de tratar apropriadamente as incertezas presentes nessas linhas.

Decidiu-se investigar o uso de processos de decisão markovianos com probabilidades imprecisas, que são uma variação dos processos de decisão markovianos, modelo muito utilizado para resolução de problemas de

planejamento probabilístico. A escolha deve-se ao alto poder de planejamento deste modelo.

Entretanto, quando se inicia a análise de como modelar uma linha de produção usando processos de decisão markovianos, nota-se que para um sistema de manufatura ela não é trivial. Os estados associados à modelagem de linhas de produção em processos de decisão markovianos são numerosos e pouco intuitivos para quem o modela, inviabilizando o trabalho de modelagem. Além da dificuldade de modelagem dos estados, a especificação das probabilidades 
associadas à evolução destes estados se mostra complexa. Para viabilizar a aplicação do processo de decisão markoviano com probabilidades imprecisas, a utilização de outra linguagem para modelagem é necessária.

Procurou-se uma linguagem com três características: facilidade de modelagem de linhas de produção, capacidade de modelar os tipos de produtos e suas entradas, e possibilidade de transformação em processos de decisão markovianos com probabilidades imprecisas. Uma linguagem que atende esses requisitos é a rede de Petri colorida.

Rede de Petri colorida é bem difundida e possui uma gama enorme de possibilidades de modelagem. É um método bem difundido na indústria automobilística. Seu formalismo gráfico facilita seu aprendizado e assimilação, o que faz dela uma linguagem acessível. Ela fornece uma linguagem e ferramenta para modelagem, análise e simulação de sistemas dinâmicos movidos a eventos discretos. Em rede de Petri colorida é possível modelar a entrada e saída de recursos em fontes e sorvedouros. E por fim, analisando-se a rede de Petri, ela é susceptível à conversão em processos de decisão markovianos, pois em sua representação o princípio de Markov é seguido, ou seja, para o cálculo/definição do estado seguinte, usam-se apenas os dados do estado atual e da ação executada (já que o estado atual deriva de estados e ações executadas anteriormente).

Para que a rede de Petri possa modelar os problemas que motivaram este trabalho, é necessário que seja capaz de representar incertezas. As incertezas presentes em linhas de produção podem surgir desde causas simples como a concorrência de diferentes células de trabalho pelo mesmo recurso, a causas complexas e difíceis de serem levantadas, como o tempo de finalização de uma tarefa por um operador humano. Neste trabalho apenas são abordadas as incertezas relacionadas a concorrências entre células de trabalho. A rede de Petri colorida já possui ferramentas para a representação de concorrências, que 
são os conflitos. Porém, aos conflitos costuma ser associada apenas uma probabilidade precisa e que não se altera de acordo com o estado da rede. Para que a dinâmica de escolhas dentro do sistema possa ser representada e para que varie de acordo com o estado da rede, é criada uma variação da rede de Petri colorida, que é uma das contribuições deste trabalho.

Definido este cenário, delimita-se como segue o que aborda este trabalho. Ele consiste da modelagem de problemas em rede de Petri colorida e sua conversão em processos de tomada de decisão markovianos. $O$ foco é permitir esta conversão dadas as restrições aplicadas à rede de Petri colorida de modo a garantir as propriedades necessárias à sua conversão. Estas características garantem adequação às propriedades de um processo de decisão markoviano. As contribuições deste trabalho são as restrições que devem ser aplicadas à rede de Petri de modo a garantir que elas possam ser convertidas, e o método de conversão propriamente dito.

Para entender melhor as linguagens envolvidas nesta transformação, é feita uma revisão bibliográfica no Capítulo 2, onde são abordados a rede de Petri e os processos de tomada de decisão markovianos. Na seção 2.1 aborda-se o funcionamento de linhas de montagem automotivas. Nas Seções 2.2 e 2.3 é exposto o que é rede de Petri e a definição de conflito em rede de Petri, respectivamente. Na Seção 2.4 é explicado o que é rede de Petri colorida, que é a linguagem de modelagem de sistemas. Uma vez exposta a teoria referente à rede de Petri, inicia-se a revisão de processos de decisão markovianos na Seção 2.5. Consta na Seção 2.6 uma definição de intervalos credais, para que seja possível entender a explicação do que são processos de decisão markovianos com probabilidades imprecisas, presente na Seção 2.7. Utiliza-se neste problema uma representação especifica de processos de decisão markovianos com probabilidades imprecisas (MDPIP), que são os MDPIPs fatorados, explicados na Seção 2.8. Finaliza-se a revisão bibliográfica com uma breve descrição de métodos de solução de MDPs. 
No Capítulo 3 é definida uma versão interpretada de rede de Petri colorida, desenvolvida especialmente para a modelagem dos problemas em questão. No capítulo seguinte é explicado o método de transformação, inicialmente em processos de decisão markovianos (Seção 4.1) e finalizando em processos de decisão markovianos com probabilidades imprecisas (Seção 4.2). Encerra-se o trabalho com os Capítulos 5 e 6 onde são mostrados alguns resultados de simulação de exemplos e a conclusão do trabalho, respectivamente. 


\section{REVISÃO DA LITERATURA}

Neste capítulo são revisados itens necessários ao desenvolvimento e compreensão do trabalho. Primeiramente é dada uma visão geral de linhas de manufatura automobilísticas que foram a motivação. Em seguida há uma explanação de rede de Petri (PN), um detalhamento do que são conflitos em PN, seguido por rede de Petri colorida (CPN). Uma CPN é um tipo especial de $\mathrm{PN}$, e é a linguagem de modelagem do trabalho. Continua-se com a exposição de processos de decisão markovianos (MDPs). Em seguida, é apresentada uma breve explicação de intervalos credais, necessários para a compreensão dos itens seguintes, os MDP acrescidos de probabilidades imprecisas. Esse tipo especial de MDP é chamado processo de decisão markoviano com probabilidades imprecisas (MDPIP) e suas probabilidades imprecisas são representadas por intervalos credais. Há a descrição de um MDPIP com um tipo especifico de representação, o MDPIP fatorado (FMDPIP) que é a linguagem utilizada neste trabalho. Por fim, há a descrição de um MDPIP com um tipo especifico de representação, os MDPIPs fatorados (FMDPIP) que é a linguagem utilizada neste trabalho.

\subsection{Linhas de Manufatura Automobilística}

A organização das linhas de manufatura na indústria automobilística segue a organização por job-shops. São três shops principais [Miller \& Park (1998)]: o body shop (funilaria), paint shop (pintura) e assembly shop, também conhecido como general assembly (montagem final).

O body shop é o shop no qual a carroceria do veículo é montada, as peças são unidas principalmente por solda. O paint shop é onde a estrutura recebe 
tratamento químico e pintura. E por fim no assembly shop todo o conteúdo do veículo é montado (motor, bancos, rodas, painel, etc.).

O conteúdo dos veículos varia muito (tipo de bancos, motor, trio-elétrico, etc.) não é viável a existência de uma linha de montagem final para cada configuração. Devido a isso, diversos modelos são montados na mesma linha. Esta linha de montagem final que comporta diversos modelos é denominada mixed model [Miller \& Park (1998)]. O estimulo deste trabalho foram linhas de montagem final, devido à variedade de modelos e opcionais e também ao fato de grande parte dessas montagens ser realizado por operadores, fator que atribui muitas incertezas ao sistema.

Para ter-se um melhor entendimento do funcionamento de uma linha de montagem final, é necessário conhecer como funcionam as paradas de linha, que são momentos em que a linha para de trabalhar, trazendo prejuízo à empresa devido aos recursos ociosos. Também é necessário explicar como é utilizado o tempo do operador, que será o objeto de modelo.

Um método muito comum de parada de linhas é o sistema andom. Cada operador tem controle sobre o sistema andom através de painéis ou sistemas de cordas. O andom possui três estados, o primeiro que é o ideal é o "não acionado", que ocorre quando todas as tarefas estão ocorrendo no tempo estabelecido. Existe também o "estado de alerta", quando o operador sente que a tarefa não será cumprida no tempo disponível. Neste estado, coordenadores de times de trabalho são acionados de modo a ajudarem o operador em situação crítica a terminar o trabalho. E por fim há o "estado de parada de linha" devido ao operador não ter conseguido terminar a tarefa no tempo disponível. Neste último estado, toda a linha é parada e não apenas a estação de trabalho do operador em atraso.

Foram levantados métodos de planejamento da ordem de produção com profissionais da área, dado que por ser um assunto sigiloso, não costumam ser publicados artigos com seu conteúdo. Foram encontrados métodos cuja inteligência de planejamento, baseia-se no conhecimento de regras que evitem 
casos mais freqüentes de parada de linha, como por exemplo, "Não colocar três carros com ar condicionado em seguida na linha", ou então "não colocar dois carros com teto solar em seguida" e por assim se segue. O que se notou de diferente entre uma montadora e outras conversadas era a forma de obter 0 planejamento, desde um planejamento manual com checagem das regras, há algoritmos que encontravam a combinação do mix ideal quebrando nenhuma ou o menor número possível de regras. Foram encontrados métodos que dão pesos as regras, criando uma priorização entre as regras. Porém, mesmo determinado o peso, a probabilidade de parada não é conhecida, pois nenhum dos métodos encontrados baseava-se em medir o risco e trabalhar de forma a reduzi-lo. A proposta é mapear as probabilidades de modo a reduzir os riscos de parada e também conhecê-los.

\subsection{Redes de Petri (PN)}

Rede de Petri oferece uma representação gráfica e matemática para a modelagem de sistemas a eventos discretos [Marsan, Balbo, Conte, Donatelli \& Franceschinis (1995), Desrochers \& Al-Jaar (1995), Miyagi (1996), Zhou \& Venkatesh (1999)].

Uma rede de Petri possui quatro elementos que graficamente podem ser representados por: círculos, retângulos, setas e pontos. Na Figura 1 pode-se ver como é representado cada um destes elementos.

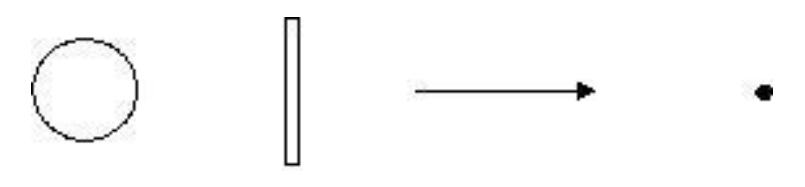

Figura 1 - Representação de elementos de redes de Petri: lugar, transição, arco e marca. 
Os círculos são os lugares, que são a representação de elementos passivos do sistema e que sofrem ações. Eles representam um recurso específico em um determinado estágio do processo.

Os retângulos são as transições, representações de elementos ativos do sistema. As transições representam alguma ação realizada nos itens indicados nos elementos passivos: pode ser uma movimentação de material, alteração ou montagem de peças.

As setas são arcos orientados que ligam lugares a transições e transições a lugares. Eles orientam o fluxo de itens do processo e as funções de como os itens interagem. Arcos orientados podem somente ligar transições a lugares e lugares a transições, nunca transições a transições ou lugares a lugares.

Os pontos são chamados de marcas ou tokens. Marcas aparecem na representação gráfica dentro dos lugares e cada uma delas representa uma unidade de determinado item ou recurso representado no lugar. Ou seja, a existência de uma marca em um lugar indica a existência do recurso representado pelo lugar. A distribuição de todas as marcas pelos lugares é chamada de estado da rede de Petri, isto é, marcação.

No exemplo de rede de Petri da Figura 2, há dois lugares representando os estados chapa de aço e peça pronta e uma transição representando a prensa, que é um elemento ativo que realiza a transformação de chapas de aço em peças prontas. Há uma marca dentro do lugar que representa chapa de aço e nenhuma no lugar que representa peça pronta, o que significa que há uma chapa de aço e nenhuma "peça pronta". 


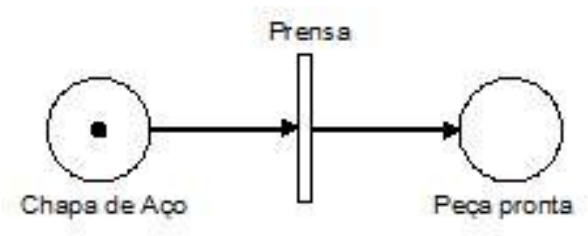

Figura 2 - Exemplo de representação com rede de Petri

A rede de Petri na qual só pode haver no máximo uma marca por lugar é chamada rede condição-evento. Existe também a rede na qual os lugares possuem uma capacidade maior que uma marca, chamada de rede lugartransição. Nesta rede, o número de determinado recurso disponível é o número de marcas que há em seu respectivo lugar. O número máximo de marcas em cada lugar é chamado da capacidade do lugar (k). Quando não indicado, assume-se 0 valor um. A distribuição de todas as marcas pelos lugares determinará o estado da rede de Petri. Neste tipo de rede, devem ser atribuídos valores aos arcos orientados, representando a quantidade de recursos consumidos (arcos de entrada) ou produzidos (arcos de saída) por uma transição. Estes valores devem ser indicados nos arcos.

O disparo da transição resulta na alteração do número de marcas dos lugares de entrada e dos lugares de saída da transição. A alteração do número de marcas pode ser ponderada pelos arcos (arcos ponderados). Esta ponderação determina quantas marcas são retiradas de lugares de entrada e quantas são adicionadas nos lugares de saída quando ocorre o disparo das transições. $O$ exemplo da Figura 3a apresenta dois lugares ( $L 1$ e L2) e uma transição (T1). $O$ lugar $L 1$ possui uma marca e o lugar L2 nenhuma. Depois de "disparada" a transição, a marca deixa $L 1$ e duas marcas são adicionadas em $L 2$, pois 0 arco de saída possui peso dois, como ilustrado na Figura 3b. 

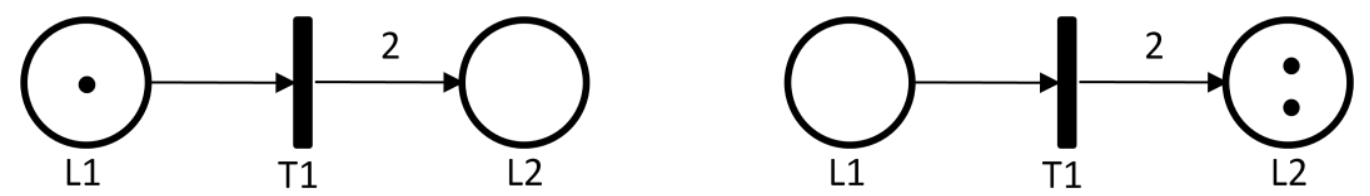

Figura 3 - Exemplo de elementos de rede de Petri a)Antes do disparo da transição b)Após o disparo da transição

Transições podem estar habilitadas ou desabilitadas. Para que possam ser disparadas, transições devem estar habilitadas, e para tal, suas pré-condições e pós-condições devem estar satisfeitas.

Pré-condições dizem respeito a todos os lugares cujos arcos são orientados para a transição. As pré-condições são consideradas satisfeitas quando esses lugares possuem, no mínimo, o número de marcas indicadas pelo arco ponderado. Seu significado no mundo físico é a existência de itens ou recursos suficientes para a realização da atividade. A Figura 4 ilustra exemplos de précondições insatisfeitas e satisfeitas, na Figura 4a não há nenhuma marca em uma das entradas, logo a transição está desabilitada por não cumprir as précondições. Na Figura $4 b$, pode-se notar que todos os lugares que são as entradas da transição possuem marcas, mas neste caso há apenas duas marcas em $L 2$ e seu arco orientado indica a necessidade de três, logo, a pré condição também não está satisfeita. Na Figura 4c por sua vez todas as précondições estão satisfeitas. 


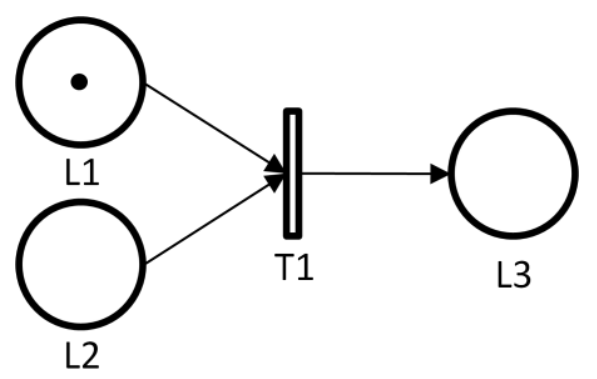

a)

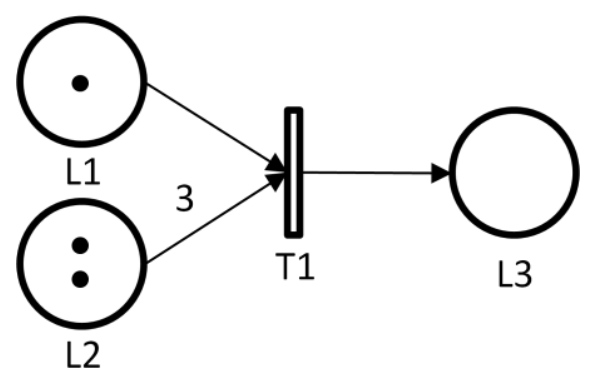

b)

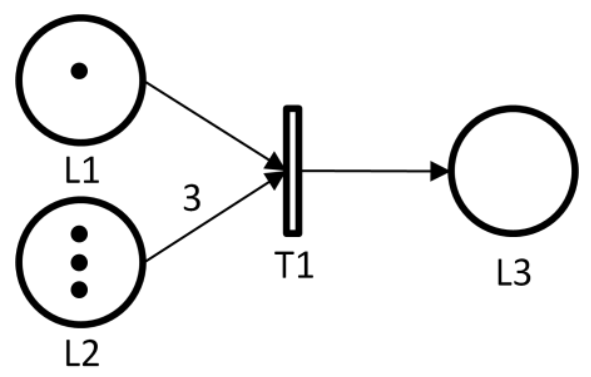

c)

Figura 4 - a)Transição desabilitada b)Transição desabilitada c)Transição habilitada

Pós-condições dizem respeito a todos os lugares que são apontados por arcos que saem da transição. Os lugares devem possuir capacidade para receber, no mínimo, o número de marcas indicadas pelo seu arco ponderado. Seu significado no mundo físico é a existência de espaço para receber itens ou recursos resultantes da atividade. A Figura 5 ilustra exemplos de pós-condições insatisfeitas e satisfeitas. Na Figura 5a, não há capacidade no lugar $L 3$ para 
receber mais marcas, logo, a transição está desabilitada por não cumprir as pós-condições. Na Figura 5b, há capacidade nos lugares para receber todas as marcas resultantes da operação, logo todas as pós-condições estão satisfeitas.

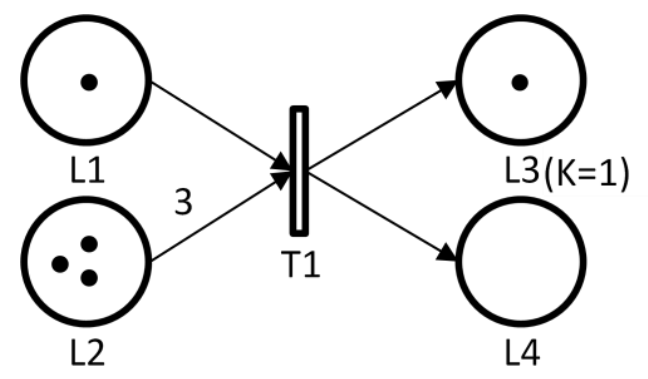

a)

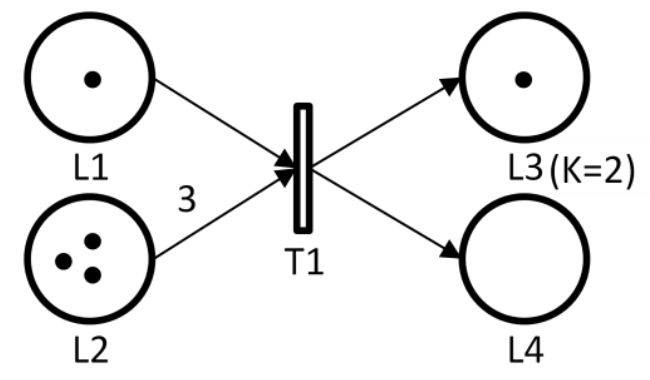

b)

Figura 5 - a) Transição desabilitada por pós condições b) Transição habilitada

Como dito anteriormente, pré e pós-condições devem ser satisfeitas para que haja a habilitação da transição. Na Figura $6 \mathrm{a}$ e $6 \mathrm{~b}$, a transição não está habilitada devido a não satisfação das pré-condições e pós-condições respectivamente. Na Figura 6c por sua vez, a transição está habilitada, pois as pré e pós condições foram atendidas. 


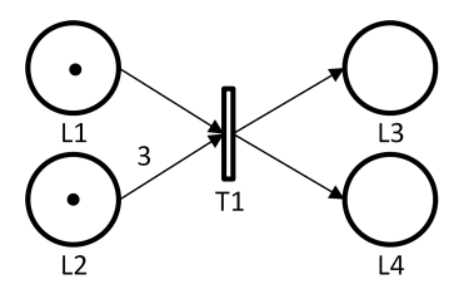

a)

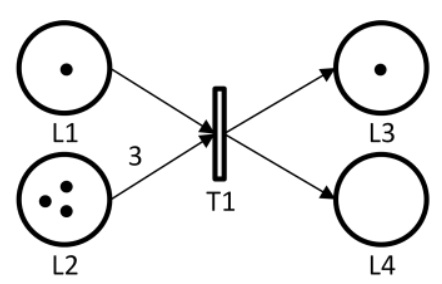

b)

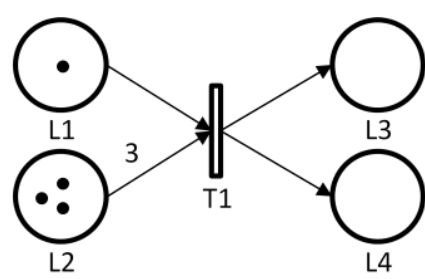

c)

Figura 6 - a)Transição desabilitada por pré-condições b)Transição desabilitada por póscondições c)Transição habilitada

\subsection{Conflitos}

Conforme exposto no item anterior, para que a transição possa disparar, a mesma precisa estar habilitada. Porém, apenas a habilitação das transições não garante seus disparos, pois pode haver conflitos entre transições, trazendo para a rede de Petri um comportamento não determinístico. Dois eventos de uma rede estão em conflito entre si quando ambos estão ativados e a ocorrência de um resulta na desativação do outro. A Figura 7 ilustra dois exemplos de conflitos. No primeiro caso duas transições, $T 1$ e $T 2$, concorrem pela marca do lugar $L 1$, logo, apenas uma é disparada. No segundo caso, uma vez disparada uma das transições, o lugar que é pós-condição (L3) fica ocupado, desabilitando a outra transição.

Uma maneira de tratar conflitos, adotada neste trabalho, é a definição de um mecanismo de arbitragem chamado random switch, no qual é atribuída a cada transição uma probabilidade de disparo. Por exemplo, na Figura 8, foi associada a $T 1$ a probabilidade $0.6(60 \%)$ e a $T 2$ foi associada $0.4(40 \%)$, significando que a probabilidade de disparo de $T 1$ é $60 \%$ e de $T 2$ é $40 \%$. Os 
random switches associados a conflitos são responsáveis por trazer a informação probabilística da evolução dos sistemas.
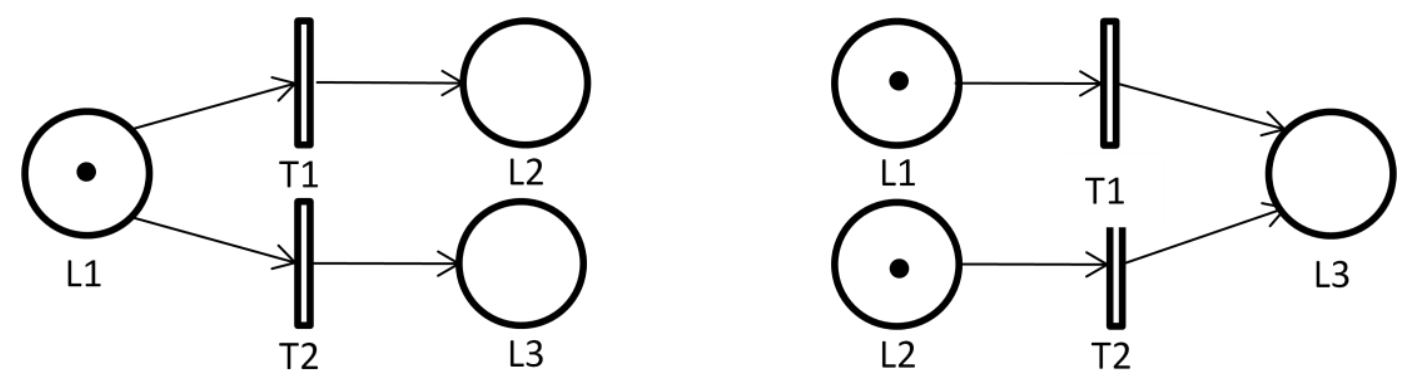

Figura 7 - Exemplos de conflito por recursos e por lugares

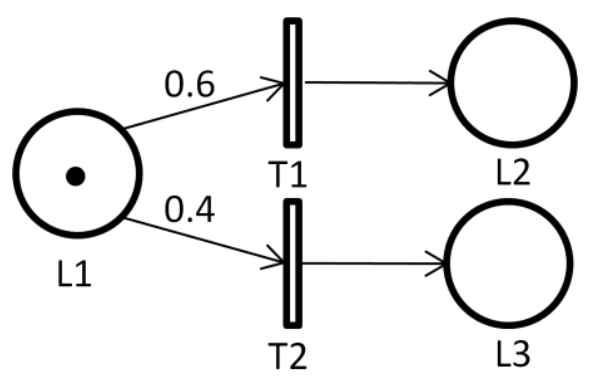

Figura 8 - Exemplo de conflito resolvido com random switch

\subsection{Rede de Petri colorida (CPN)}

Nesta seção é explicado o que é rede de Petri com marcas individuais (rede colorida) [Jensen (1994), Miyagi (1996), Jensen (1998), Jensen, Kirstensen \& Cristensen (1998)], base para a transformação em MDPs e MDPIPs. Em todas as representações vistas até o momento, os itens são representados por 
marcas indistintas. A rede de Petri colorida possibilita a distinção entre as marcas, facilitando a modelagem e permitindo reduzir o número de lugares de uma rede sem perder poder de representação. Há dois tipos de rede com marcas individuais, a rede com arcos com inscrições fixas e a rede com arcos com inscrições variáveis.

Segundo Miyagi (1996), uma rede de Petri com marcas individuais e arcos com inscrições fixas é constituída por:

- Lugares, transições e arcos orientados como em uma rede lugartransição;

- Itens individuais e distintos, que podem fluir pela rede como marcas;

- Uma marcação inicial que define o conteúdo de cada lugar no momento inicial;

- Uma inscrição em cada arco orientado indicando um item individual;

- As pré-condições e pós-condições de transições são definidas de modo análogo à rede lugar-transição.

A forma como a rede evolui numa rede de Petri com marcas individuais também se altera, dando-se da seguinte forma, segundo Miyagi (1996):

- Uma transição $T$ está ativada se todo o lugar $L$ das suas pré-condições contém o item designado pela inscrição do arco de $L$ para $T$.

- Uma transição ativada $T$ ocorre de modo que:

- Para cada lugar $L$ das pré-condições de $T$, o item indicado de $L$ para $T$ é removido;

- Para todo o lugar L' das pós-condições de $T$ recebe 0 item indicado pelo arco correspondente de $T$ a $L$ '.

Na Figura 9 há um exemplo a rede de Petri lugar-transição que representa a montagem de carros com teto solar e com teto padrão. O sistema é representado por uma rede condição-evento na qual as marcas são indistintas. 
Nota-se que na Figura 10 há uma rede na qual a indicação dos diferentes tipos de marcas (rede colorida), $C$ representando carro, TS representando teto solar e TP representando teto padrão. O sistema possui a mesma representatividade que o anterior, porém há dois lugares a menos, simplificando a representação do sistema.

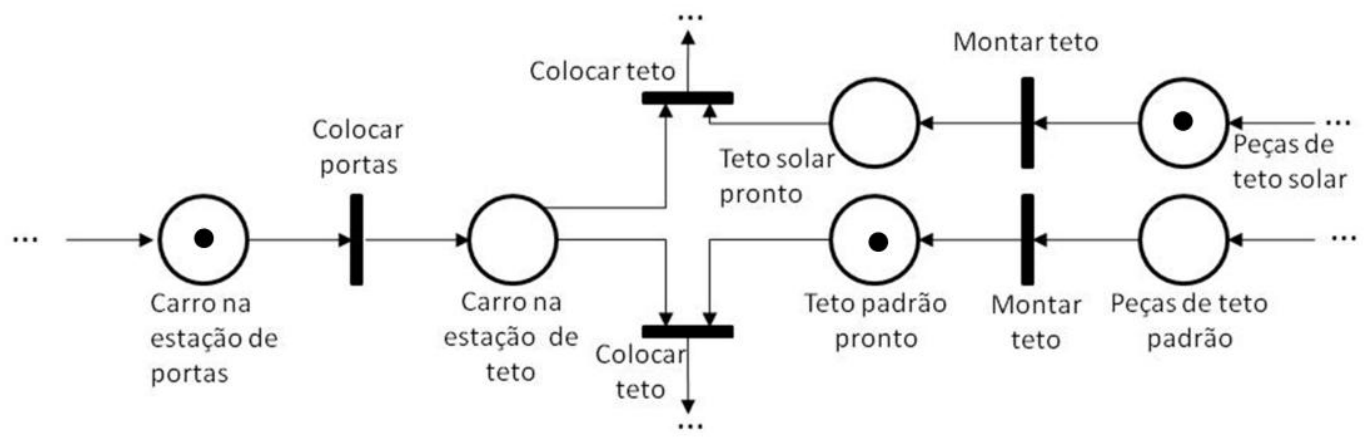

Figura 9 - Exemplo de rede lugar-transição com marcas indistintas

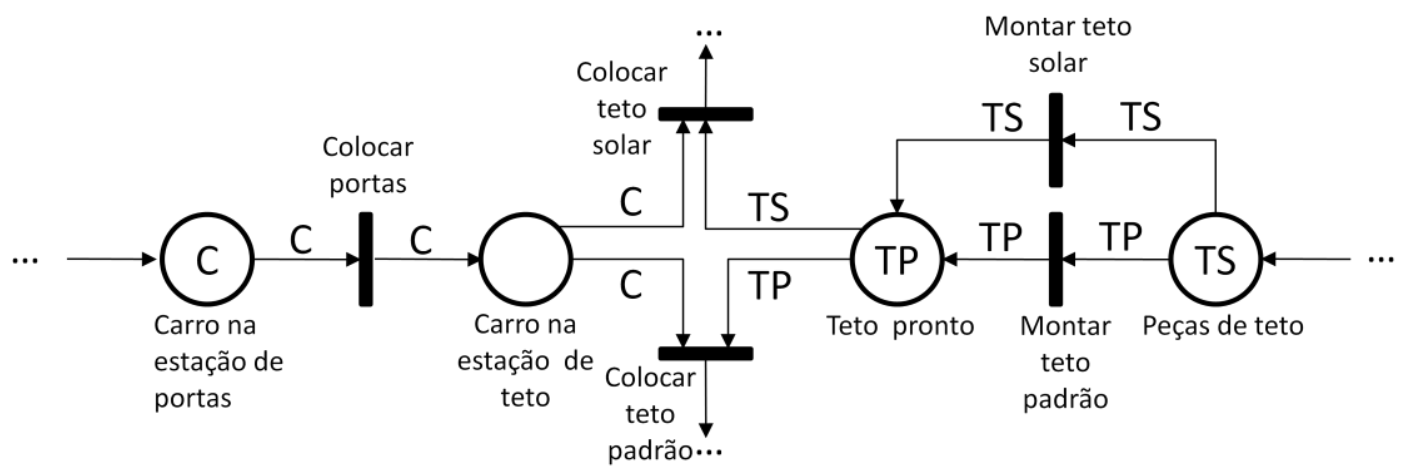

Figura 10 - Exemplo de rede de Petri colorida com arcos indicando marcas.

Além da rede com marcas individuais com arcos com inscrições fixas, há também a rede com marcas individuais com arcos com inscrições variáveis. Sua constituição é dada por [Miyagi (1996)]: 
- Lugares, transições, arcos orientados e uma configuração inicial constituída de itens individuais como na rede com arcos com inscrição fixa;

- Uma variável $(x, y, z, \ldots)$ como uma inscrição para cada um dos arcos;

- As pré-condições e pós condições de transições são definidas de modo análogo à rede com inscrições fixas.

Segundo Miyagi (1996), a evolução deste tipo de rede dá-se da seguinte forma:

- Uma substituição dos valores das variáveis indicadas nos arcos para a transição $T$ consiste em substituir todas as variáveis dos arcos que partem ou terminam em $T$ por um item individual;

- Variáveis de arcos orientados que ocorrem mais de uma vez são substituídas em todos os lugares pelo mesmo item;

- Uma transição $T$ está ativada em relação à substituição se todo o lugar $L$ das pré-condições de $T$ contém o item que substituirá a variável dos arcos de $L$ a $T$;

- Uma transição $T$ que está ativada em relação à substituição ocorrerá de forma que:

- O item é removido de todo o lugar $L$ dos lugares das précondições de $t$ como indicado na substituição de variáveis do arco de $L$ para $T$;

- Todo lugar $L$ dos lugares das pós-condições de $T$ recebe 0 item que substituiu a variável do arco de $T$ para $L$.

Sua dinâmica pode ser vista em comparação ao exemplo anterior. Considerando a rede lugar-transição representada na Figura 9, se variáveis no arco são utilizadas, pode-se reduzir a apresentação do exemplo da Figura 10 pelo exibido na Figura 11. A representação da Figura 11 é mais concisa e sem perder nenhum detalhe da representação. Na Figura 11 há três variáveis, var1, var2, var3 e var4. A partir do momento que a transição é disparada, o valor que 
var3 recebeu deve ser aplicado para as variáveis de todos os arcos que possuam var3. O mesmo vale para as variáveis var1, var2 e var4.

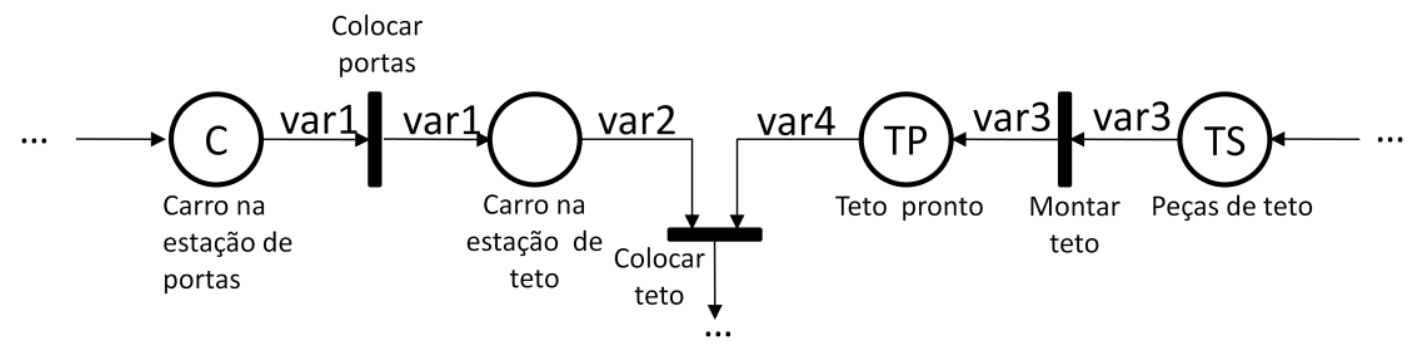

Figura 11 - Exemplo de rede de Petri colorida com variáveis nos arcos orientados.

\subsection{Processo de decisão markoviano (MDP)}

Nesta seção, é feita uma revisão do conceito de processos de decisão markovianos (MDPs), que são a base para o entendimento de um tipo específico de MDP, o MDPIP (processo de decisão markoviano com probabilidades imprecisas). Os MDPs [Bertsekas \& Tsitsiklis (1991), Puterman (1994)] foram desenvolvidos para modelar situações nas quais as saídas dependem parcialmente de ações do agente e são parcialmente aleatórias, ou seja, mesmo conhecendo-se o estado atual e a ação, não há certeza de qual será seu próximo estado. Seu uso tem sido vasto em problemas de otimização e planejamento nos quais os estados seguintes dependem apenas do estado atual e da ação executada [Russel \& Norvig (2004)].

Um MDP é descrito por estados nos quais o tomador de decisão pode aplicar ações. Para cada estado atingido é atribuída uma recompensa. É a otimização da recompensa esperada que estimula a tomada de decisão [Boutilier, Dean \& Hanks (1999)]. Um problema descrito em MDP é em geral resolvido buscandose maximizar a função acumulada de recompensas esperadas, ou seja, a soma 
das recompensas esperadas acumuladas em cada estado atingido. Para cada estado $s$ e ação a é atribuída uma função que determina as probabilidades de evolução para o próximo estado. Um MDP segue a propriedade de Markov, na qual a evolução para um novo estado $s$ ' depende apenas do estado atual $s$, ou seja, independe dos demais estados anteriores.

Estado é a descrição do sistema em questão em um determinado momento. A descrição deste sistema deve contemplar todas as informações necessárias para o agente de tomada de decisão, logo varia de aplicação para aplicação. Em MDPs, o espaço dos estados é o conjunto de todos os estados que podem ser atingidos pelo sistema. Na definição do sistema do problema, deve-se, além de conhecer o espaço dos estados, saber qual é o conjunto de estados iniciais não vazio.

Ações são as intervenções que o agente pode realizar no sistema. Deve-se saber que ações podem ser tomadas a cada estado. Descrevendo a iteração entre o estado atual e a ação, há uma função $F(s, a)$ que mapeia todos os estados seguintes possíveis dado que o estado atual é s e a ação tomada foi $a$.

O MDP também considera uma distribuição de probabilidades. Esta distribuição $P\left(s^{\prime} \mid s, a\right)$ mensura a probabilidade de, dado o estado atual $s$ e a ação tomada $a$, atingir-se o estado $s$, para todos os estados seguintes mapeados pela função $F(s, a)$.

A formalização do MDP é dada por [Bertsekas \& Tsitsiklis (1991), Puterman (1994)]:

1. Um espaço dos estados $S$, que é finito;

2. Um conjunto de ações $A(s) \subseteq A$ representando as ações aplicáveis em cada estado $s$; 
3. Uma função de transição de estado $F(s, a) \subseteq S$ que mapeia o estado $s$ e a ação $a \in A(s)$ para um conjunto não-vazio de estados $|F(s, a)| \geq 1$;

4. Uma recompensa positiva $R(s)$ para cada estado $s$ atingido;

5. Uma distribuição probabilística $P\left(s^{\prime} \mid s, a\right)$ em $F(s, a)$ para todo $s \in S$ e todo $a \in A(s)$.

Pode-se compreender 0 a representação através de um exemplo de reabastecimento de um carro de fórmula 1 durante uma competição. O nível do tanque de combustível é uma informação necessária ao agente de tomada de decisão, logo ele reflete nos estados do problema, que podem ser três: alto, baixo e zero (sem combustível), ou seja, $S=\{a l t o$, baixo, zero\}.

Neste exemplo, há duas ações do piloto possíveis: abastecer ou continuar na corrida. As ações para cada estado podem ser as seguintes:

$$
\begin{aligned}
& A(\text { alto })=\{\text { continua }\} \\
& A(\text { baixo })=\{\text { continua }, \text { abastece }\} \\
& A(\text { zero })=\{\}
\end{aligned}
$$

Continuar $70 \%$

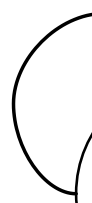

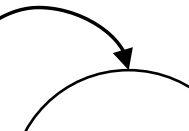

Alto

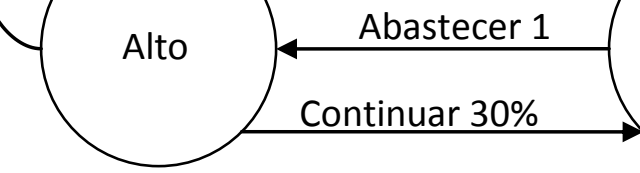

Continuar 30\%

Figura 12 - Representação gráfica da evolução dos estados do exemplo de fórmula um 
O mapeamento das funções e probabilidades deste exemplo de abastecimento de carro de F1 pode ser visto na Tabela 1, na qual $s$ representa o estado atual, $s^{\prime}$ o estado seguinte, a a ação tomada, $P_{\text {ss' }}^{a}$ a probabilidade de ir-se do estado $s$ para s' dada a ação $a$, e $R_{s^{\prime}}$ a recompensa por atingir o estado $s^{\prime}$.

Conforme ilustrado na tabela, caso o nível do tanque de combustível esteja alto, o carro pode completar mais uma volta sem correr o risco de ficar sem combustível (nível zero), podendo estar no estado seguinte ainda com nível alto ou com nível baixo. Mas se o carro estiver com nível baixo de combustível é possível que não consiga terminar a corrida por falta do mesmo, ou seja, atingir nível zero. A cada volta dada a recompensa é de 1 , ou seja, a cada estado diferente de zero recebe-se 1 de recompensa. Caso o carro pare por falta de combustível (nível zero), ele perde a corrida, o que é representado pela recompensa de -71 , que é a recompensa por atingir o nível zero.

Tabela 1 - Tabela de probabilidades e recompensas do exemplo de fórmula um.

\begin{tabular}{ccccc}
$\boldsymbol{s}_{\mathbf{n}} \boldsymbol{s}_{\boldsymbol{t}}$ & $\boldsymbol{s}^{\prime}=\boldsymbol{s}_{\boldsymbol{t}+\mathbf{1}}$ & $\boldsymbol{a}_{\mathbf{a}} \boldsymbol{a}_{\boldsymbol{t}}$ & $\boldsymbol{P}_{\mathbf{s s}^{\prime}}$ & $\boldsymbol{R}_{\boldsymbol{s}^{\prime}}$ \\
\hline \hline Alto & Alto & Continua & $70 \%$ & 1 \\
Alto & Baixo & Continua & $30 \%$ & 1 \\
Alto & Zero & Continua & 0 & -71 \\
Baixo & Alto & Continua & 0 & 1 \\
Baixo & Baixo & Continua & $40 \%$ & 1 \\
Baixo & Zero & Continua & $60 \%$ & -71 \\
Baixo & Alto & Abastece & $100 \%$ & 1 \\
Baixo & Baixo & Abastece & 0 & 1 \\
Baixo & Zero & Abastece & 0 & -71 \\
\hline \hline
\end{tabular}

Se o nível de combustível é alto, a probabilidade do nível de combustível continuar alto após uma volta é $70 \%$, enquanto a probabilidade de ir para o 
nível baixo é de $30 \%$. Se o nível de combustível é baixo, a probabilidade do nível de combustível que estava no nível baixo permanecer baixo após a ação continuar é de $40 \%$, e em contrapartida, a probabilidade do carro ficar sem combustível (nível zero) é de $60 \%$. Sempre que o veículo for abastecido seu tanque ficará com nível alto, logo sua probabilidade de continuar alto após 1 volta é de $100 \%$. A representação gráfica das interações está na Figura 12. Por fim, do nível zero, nenhuma ação pode ser tomada e o estado não de altera mais.

\subsection{Intervalos credais}

Antes de definir-se o que é um MDP com probabilidades imprecisas (MDPIP), é necessário compreender o que é um intervalo credal. Intervalo credal é um intervalo de probabilidades, permitindo assim que sejam representadas probabilidades incertas, para casos em que um valor pontual não é facilmente atribuído.

Intervalos credais são indicados por seus limites superiores e inferiores denominados probabilidade superior e probabilidade inferior respectivamente. A probabilidade inferior corresponde ao valor mínimo da probabilidade e a superior ao valor máximo que a probabilidade pode atingir. Isso significa que a probabilidade de determinado evento está entre o seu valor inferior e superior.

Enquanto um valor de probabilidade é pontual, por exemplo, a chance de chuva é cinqüenta e cinco por cento, ou seja, determina um valor específico de probabilidade, o intervalo credal permite uma maior maleabilidade nesta especificação. Se a probabilidade de chuva for expressa por um intervalo credal, pode-se, por exemplo, dizer que ela fica entre trinta e nove e sessenta e 
um por cento, representando a incerteza que em geral existe em relação à probabilidade de chuva. Neste caso, indica-se a probabilidade inferior por $P_{\text {inf }}($ chuva $)=0.39$ e a probabilidade superior por $P_{\text {sup }}($ chuva $)=0.61$.

\subsection{Processo de decisão markoviano com probabilidades imprecisas (MDPIP)}

Nesta seção é definida uma generalização do MDP, o MDPIP, que é uma das ferramentas de tomada de decisão escolhidas para a solução dos sistemas modelados inicialmente em PN. O MDPIP escolhido é um MDP no qual o efeito das ações é modelado por um intervalo credal $K$ sobre o espaço de estado, ou seja, a distribuição de probabilidades $P\left(s^{\prime} \mid s, a\right)$ nos estados sucessores em $S$ é representada por um intervalo credal não vazio $K_{S}(a)$ para todo $s \in S$ e $s^{\prime} \in S$.

Um MDPIP consiste em [Bertsekas \& Tsitsiklis (1991), Puterman (1994)]:

1. Um espaço dos estados $S$, que é finito e discreto;

2. Um conjunto de ações $A(s) \subseteq A$ representando as ações aplicáveis em cada estado $s$;

3. Uma recompensa positiva $\mathrm{R}(\mathrm{s})$ para cada estado $s$ atingido;

4. Um intervalo credal não vazio $K_{S}(a)$ para todos $s \in S$ e $a \in A(s)$, representando a distribuição de probabilidades $P\left(s^{\prime} \mid s, a\right)$ em relação aos estados sucessores em $S$.

Aplicando a descrição de MDPIP ao exemplo 2 do carro de fórmula 1 , a modelagem do sistema mantém-se completamente a mesma, exceto pelos valores de $P\left(s^{\prime} / s, a\right)$, que deixam de ser um valor fixo e passam a ser 
representados por um intervalo credal. Neste caso, o conteúdo da coluna $P_{s s^{\prime}}^{a}$ da Tabela 1 deixa de ser representado por um valor exato de probabilidades e passa a ser representado por um intervalo, como exposto na Tabela 2.

Tabela 2 - Probabilidades e recompensas do exemplo de fórmula um com intervalos de probabilidades.

\begin{tabular}{|c|c|c|c|c|}
\hline$s=s_{t}$ & $S^{\prime}=s_{t+1}$ & $a=a_{t}$ & $P_{s s}^{a}$ & $R_{s s^{\prime}}^{a}$ \\
\hline Alto & Alto & Continua & $60 \%<P_{s s^{\prime}}^{a}<80 \%$ & $\overline{1}$ \\
\hline Alto & Baixo & Continua & $20 \%<P_{s s^{\prime}}^{a}<40 \%$ & 1 \\
\hline Alto & Zero & Continua & 0 & -71 \\
\hline Baixo & Alto & Continua & 0 & 1 \\
\hline Baixo & Baixo & Continua & $20 \%<P_{s s}^{a}<40 \%$ & 1 \\
\hline Baixo & Zero & Continua & $60 \%<P_{s s^{\prime}}^{a}<80 \%$ & -71 \\
\hline Baixo & Alto & Abastece & $100 \%$ & 1 \\
\hline Baixo & Baixo & Abastece & 0 & 1 \\
\hline Baixo & Zero & Abastece & 0 & -71 \\
\hline
\end{tabular}

Podem-se aplicar estes conceitos a um exemplo de linhas de manufatura de veículos. Considere o caso de um sistema onde se tem a passagem de três carros, C1, C2 e C3, por uma estação de trabalho W1. Deseja-se obter a ordem ótima de fabricação dos carros, de forma que o processamento do carro que está na estação excede o tempo padrão pré-determinado para aquela estação de trabalho. A ordem dos carros afeta o desempenho da estação de trabalho.

Neste exemplo, os estados devem incluir a informação de como está o funcionamento da estação, ou seja, se ela excedeu ou não o tempo no processamento do primeiro carro (em t1 segundos), do segundo (em t2 segundos) e do terceiro (em t3 segundos). Representa-se por um quando o tempo padrão é cumprido e zero quando ele é excedido. Utilizando esta representação, obtêm-se oito estados diferentes, representados na Tabela 3. 
Por exemplo, no estado $s 1, t 1, t 2$ e $t 3$ recebem valor um, ou seja, os três carros passaram pela estação $W 1$ obedecendo ao tempo padrão da linha.

Tabela 3 - Exemplo de definição dos estados dos sistemas e suas recompensas.

\begin{tabular}{|c|c|c|c|c|}
\hline Estado & $t 1$ & $t 2$ & t3 & $\boldsymbol{R}$ \\
\hline s1 & 1 & 1 & 1 & $\overline{3}$ \\
\hline s2 & 1 & 1 & 0 & 2 \\
\hline s3 & 1 & 0 & 1 & 2 \\
\hline s4 & 1 & 0 & 0 & 1 \\
\hline s5 & 0 & 1 & 1 & 2 \\
\hline$s 6$ & 0 & 1 & 0 & 1 \\
\hline s7 & 0 & 0 & 1 & 1 \\
\hline s8 & 0 & 0 & 0 & 0 \\
\hline
\end{tabular}

As ações possíveis neste sistema são:

- Colocar primeiro na linha o carro C1 (1C1)

- Colocar primeiro na linha o carro C2 (1C2)

- Colocar primeiro na linha o carro C3 (1C3)

- Colocar segundo na linha o carro C1 (2C1)

- Colocar segundo na linha o carro C2 (2C2)

- Colocar segundo na linha o carro C3 (2C3)

- Colocar terceiro na linha o carro C1 (3C1)

- Colocar terceiro na linha o carro C2 (3C2)

- Colocar terceiro na linha o carro C3 (3C3)

As ações possíveis de serem tomadas em cada estado são mapeadas. Por exemplo, as ações que podem ser tomadas são $1 C 1,1 C 2$ e $1 C 3$, logo, $A\left(S_{0}\right)=$ $\{1 C 1,1 C 2,1 C 3\}$. 
A especificação de probabilidades fica, por exemplo, $20 \%<P\left(s_{1} / s_{0}, 1 C 1\right)<$ $40 \%$, onde se lê que a probabilidade de se atingir o estado um a partir do estado zero, dado que foi realizada a ação 1C1, está entre $20 \%$ e $40 \%$.

\subsection{MDPIP com representação fatorada}

Neste trabalho é utilizada uma representação específica de MDPIP na qual os estados recebem uma codificação de forma fatorada. Esta representação foi selecionada por ser mais compatível para a conversão dos problemas em questão.

MDPIP que se apresenta de forma fatorada possuem a vantagem de sua modelagem ser mais concisa. Ao invés de listar todos os estados possíveis do MDPIP, a representação fatorada lista variáveis cuja combinação dos valores compõe os estados equivalentes aos do MDPIPs. Pode-se dizer que este método simplifica a modelagem, pois ao invés de modelar todos os estados do sistema individualmente, têm-se apenas algumas variáveis de estado cujos valores combinados resultam nos estados do sistema.

Definindo formalmente, os estados do sistema $\vec{v}$ são representados pelo conjunto de variáveis de estado $\Lambda=\left\{V_{1}, V_{2}, \ldots, V_{n}\right\}$. O estado $\vec{v} \in S$ é representado pela tupla $\left\{v_{1}, v_{2}, \ldots, v_{n}\right\}$ na qual $v_{i}$ é um valor da variável $V_{i}$.

O entendimento do conceito de fatoração é mais simples através de um exemplo. O exemplo na Figura 13 consiste de dois tanques que possuem sensores de nível. Considera-se que caso o sensor não esteja ativado o nível do tanque é baixo, e caso esteja ativado o nível é alto. Este sistema possui quatro estados: ambos os tanques com nível baixo, o tanque 1 com nível alto e 
o tanque 2 com nível baixo, o tanque $1 \mathrm{com}$ nível baixo e o tanque $2 \mathrm{com}$ nível alto, ambos os tanques com níveis altos. As ações do agente neste exemplo podem ser abrir a torneira e fechar a torneira. Na representação deste exemplo através de um MDPIP de forma padrão, estes quatro estados são representados explicitamente, e a evolução entre eles se dá de acordo com a representação na Figura 14. Nesta figura é visto que todos os estados podem ser atingidos a partir dos outros.

Este exemplo também pode ser modelado de forma fatorada, considerando apenas os valores dos sensores/tanque ( $S 1$ e S2) ao invés do estado que eles representam. A combinação dos valores destas variáveis informa qual o estado do sistema. Na Figura 15, é mostrada a dependência entre as variáveis, ou seja, Tanque1' depende apenas do valor de Tanque1, e Tanque2' depende apenas do valor de Tanque2. Pode-se notar que a representação dos estados e sua evolução ficou mais concisa e simples.
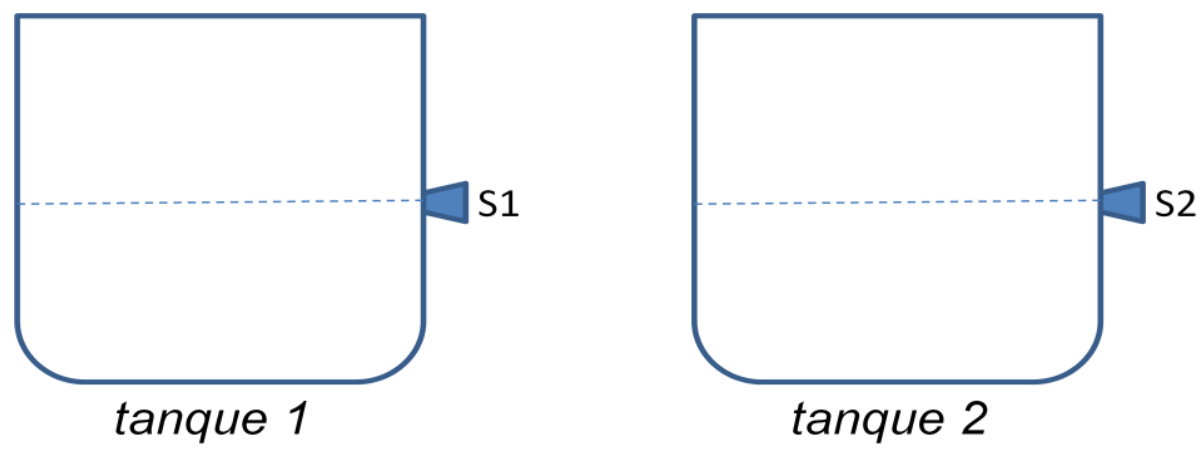

Figura 13 - Ilustração do exemplo de dois tanques 


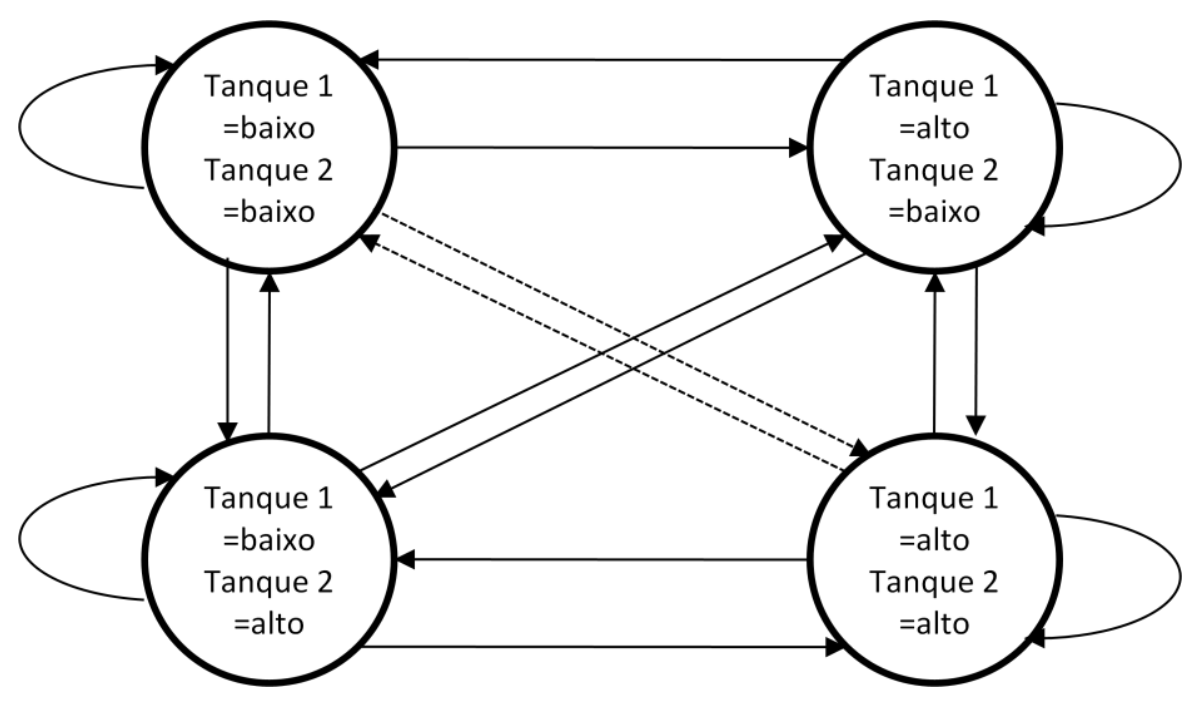

Figura 14 - Representação dos estados do MDPIP e evoluções no modo tradicional do exemplo dos dois tanques.

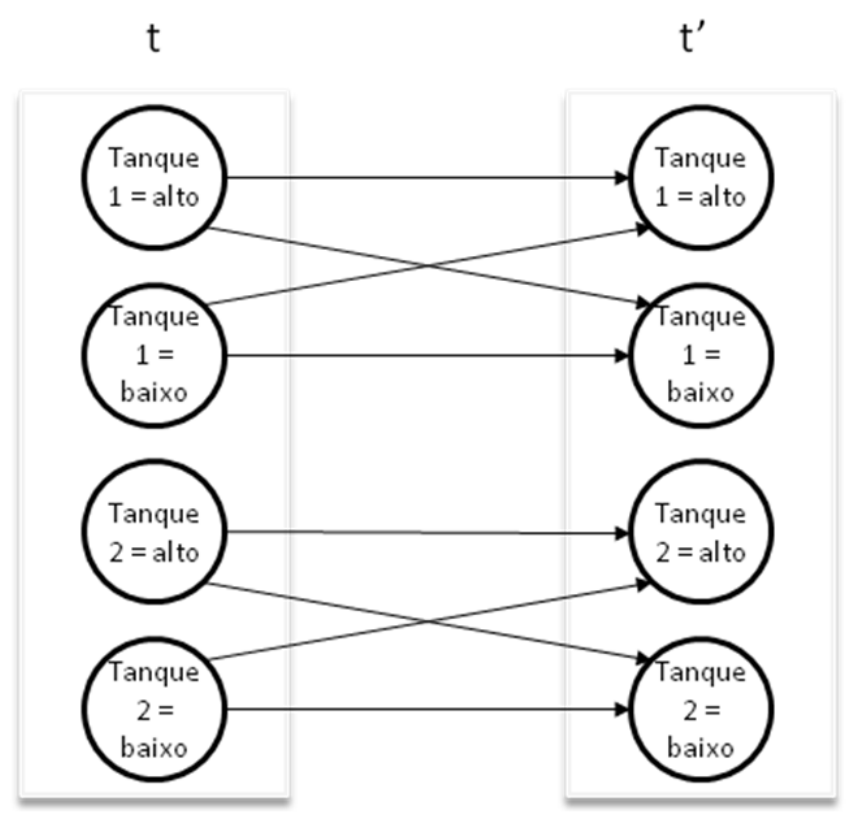

Figura 15 - Representação da evolução das variáveis de estado do MDPIP no modo fatorado do exemplo de dois tanques. 
Ao efetuar esta conversão, deve sempre atentar-se para como os estados atuais das variáveis alteram seus valores futuros, ou seja, qual a dependência entre as variáveis. No caso exemplo, tanque 1 (S1) e tanque 2 (S2) são independentes, mas deve-se sempre tomar cuidado e observar como estas variáveis alteram o valor futuro umas das outras.

Outro beneficio na representação diz respeito a tabela com as probabilidades de transição de estados do sistema. Enquanto no primeiro caso poderíamos ter a Tabela 4 para representar as probabilidades, na representação fatorada esta tabela é substituída por duas tabelas mais concisas: Tabelas 5 e 6.

Tabela 4 - Tabela de probabilidades do exemplo de MDP de tanques não fatorado.

\begin{tabular}{|c|c|c|c|}
\hline$s=s_{t}$ & $s^{\prime}=s_{t+1}$ & $a=a_{t}$ & $P_{s s^{\prime}}^{a}$ \\
\hline Baixo/Baixo & Baixo/Baixo & Abrir torneira & $24 \%$ \\
\hline Baixo/Baixo & Alto/Baixo & Abrir torneira & $36 \%$ \\
\hline Baixo/Baixo & Baixo/Alto & Abrir torneira & $16 \%$ \\
\hline Baixo/Baixo & Alto/Alto & Abrir torneira & $24 \%$ \\
\hline Baixo/Baixo & Baixo/Baixo & Fechar torneira & $100 \%$ \\
\hline Baixo/Alto & Baixo/Alto & Abrir torneira & $40 \%$ \\
\hline Baixo/Alto & Alto/Alto & Abrir torneira & $60 \%$ \\
\hline Baixo/Alto & Baixo/Baixo & Fechar torneira & $60 \%$ \\
\hline Baixo/Alto & Baixo// & Fechar torn & $40 \%$ \\
\hline Alto/Baixo & Alto/Baixo & Abrir torneira & $60 \%$ \\
\hline Alto/Baixo & Alto/Alto & Abrir torneira & $40 \%$ \\
\hline Alto/Baixo & Baixo/Baixo & Fechar torneira & $40 \%$ \\
\hline Alto/Baixo & Alto/Baixo & Fechar torneira & $60 \%$ \\
\hline Alto/Alto & Alto/Alto & Abrir torneira & $100 \%$ \\
\hline Alto/Alto & Baixo/Baixo & Fecha & $24 \%$ \\
\hline Alto/Alto & Alto/Baixo & Fechar torneira & $36 \%$ \\
\hline Alto/Alto & Baixo/Alto & Fechar torneira & $16 \%$ \\
\hline Alto/Alto & Alto/Alto & Fechar torneira & $24 \%$ \\
\hline
\end{tabular}


Tabela 5 - Tabela de probabilidades do tanque 1 do exemplo de MDP de tanques fatorado.

\begin{tabular}{cccc} 
Tanque1 & Tanque 1, & $\boldsymbol{a}_{\mathbf{a}} \mathrm{a}_{\boldsymbol{t}}$ & $\boldsymbol{P}^{\mathrm{a}}{ }_{\mathrm{ss}}{ }^{\prime}$ \\
\hline \hline Baixo & Baixo & Abrir torneira & $40 \%$ \\
Baixo & Alto & Abrir torneira & $60 \%$ \\
Baixo & Baixo & Fechar torneira & $100 \%$ \\
Alto & Alto & Abrir torneira & $100 \%$ \\
Alto & Baixo & Fechar torneira & $40 \%$ \\
Alto & Alto & Fechar torneira & $60 \%$ \\
\hline \hline
\end{tabular}

Tabela 6 - Tabela de probabilidades do tanque 2 do exemplo de MDP de tanques fatorado.

\begin{tabular}{|c|c|c|c|}
\hline Tanque2 & Tanque 2' & $a=a_{t}$ & $P_{s s^{\prime}}^{a}$ \\
\hline Baixo & Baixo & Abrir torneira & $60 \%$ \\
\hline Baixo & Alto & Abrir torneira & $40 \%$ \\
\hline Baixo & Baixo & Fechar torneira & $100 \%$ \\
\hline Alto & Alto & Abrir torneira & $100 \%$ \\
\hline Alto & Baixo & Fechar torneira & $60 \%$ \\
\hline Alto & Alto & Fechar torneira & $40 \%$ \\
\hline
\end{tabular}

Esta fatoração auxilia muito em problemas de grande porte que possuem um número relativamente grande de estados. Imagine por exemplo uma rede de Petri colorida com dez lugares nos quais cada um pode receber os recursos $A$, $B, C$ ou ficar vazio. A representação em MDPIP possuiria $4^{10}$ estados, ou seja, acima de um milhão de estados. Por outro lado, utilizando a versão fatorada, tem-se apenas dez variáveis de estado, uma para cada lugar. A utilização deste tipo de MDPIP é assim considerada adequada aos problemas que são abordados neste trabalho por serem problemas com número relativamente adequado de estados. 


\subsection{Resolução de processos de decisão markovianos}

O problema motivação deste trabalho tem como fim encontrar uma política ideal. Ou seja, uma vez realizada a transformação da rede de Petri em processo de decisão markoviano, resolvê-lo e encontrar esta política: que ações tomar em que momento/estado. Há diversas formas de procura de política, aqui serão apresentados os princípios de apenas uma forma que é no caso de um agende de aprendizagem passivo. Deve-se atentar que uma vez possuído o problema modelado em MDP pode-se aplicar outras formas de decisão.

No caso de um agente de aprendizagem passivo, deve-se determinar uma política $\pi$ para um estado $s$. Ou seja, sempre que atingido o estado $s$ será tomada a ação $\pi(s)$. Dado isso, a função do agente é descobrir o quão boa é a política $\pi(s)$ através do aprendizado de sua função de utilidade $U^{\pi}(s)$.

Uma forma tradicional de busca do do valor da utilidade é a estimativa de utilidade direta [Russel \& Novig (2004)]. A utilidade de um estado é a recompensa total esperada deste estado e seus sucessores. Dada esta definição, as utilidades dos estados não são independentes. A utilidade dos estados é sua própria recompensa adicionada à utilidade esperada de seus estados sucessores. Seus valores de utilidade obedecem à equação de Bellman para política física.

$U^{\pi}(s)=R(s)+\gamma \cdot \sum_{s^{\prime}} T\left(s, \pi(s), s^{\prime}\right) \cdot U^{\pi}\left(s^{\prime}\right)$

(Equação de Bellman)

Obtendo-se o valor das utilidades através da equação de Bellman, pode-se avaliar se a política definida é ótima (ação) para cada estado do sistema (dado este conceito de utilidade). 


\section{MODELAGEM EM REDE DE PETRI}

Para a modelagem dos casos utilizados neste trabalho, devem ser utilizadas duas versões de rede de Petri colorida interpretadas para o problema em questão. Estas versões, definidas neste capítulo, são aqui chamadas de rede de Petri fatorada (FPN) e a rede de Petri fatorada com probabilidades imprecisas (FPNIP).

Cogitou-se utilizar um tipo amplamente utilizado de rede de Petri para representar incertezas, que é a rede de Petri estocástica. Rede de Petri estocástica é um tipo especial de rede de Petri com transição temporizada [Desrochers \& Al-Jaar (1995)](TTPN - timed transition Petri nets). Nela, a temporização do disparo da transição não é determinística [Marsan, Balbo, Conte, Donatelli \& Franceschinis (1995), Zhou \& Venkatesh (1999), Desrochers \& Al-Jaar (1995), Hass (2004)]. Esta característica aumenta seu poder de representação, permitindo a modelagem de sistemas afetados por fatores não determinísticos como atrasos, quebra de equipamentos, entre outros. O tempo de disparo de suas transições costuma ser descrito com uma distribuição probabilística. Ele equivale ao tempo necessário para desempenhar a atividade associada a tal transição.

Apesar deste tipo de rede de Petri fornecer uma ampla modelagem para diversas incertezas aos quais os sistemas são expostos, sua modelagem estocástica refere-se ao tempo da transição e não aos conflitos, não atendendo a necessidade deste trabalho que é a modelagem de probabilidades de conflitos. Devido a isso foi definida rede de Petri fatorada. 


\subsection{Rede de Petri fatoradas (FPN)}

A FPN é uma rede de Petri colorida na qual são aplicadas determinadas restrições. Em FPNs todos os lugares devem possuir capacidade $k=1$ independente do tipo de marca; deve haver no mínimo uma transição fonte (transição sem pré-condições) com número finito de tipos de marcas que podem ser entradas; e os arcos orientados devem possuir valores fixos de marcas ou indicação de alguma variável. Além disso, as probabilidades das transições em conflito e as recompensas por estado devem ser especificadas. A definição formal de FPN é apresentada a seguir.

- Um conjunto não vazio de lugares $L=\left\{I_{1}, I_{2}, \ldots, I_{N}\right\}$;

- Um conjunto não vazio de marcas possíveis para os lugares $M=$ $\left\{m_{1}, m_{2}, \ldots, m_{z}\right\}$;

- Um conjunto não vazio de transições $T=\left\{t_{1}, t_{2}, \ldots, t_{M}\right\}$;

- Um subconjunto não vazio de $T, T_{f}=\left\{t_{f 1}, t_{t 2}, \ldots, t_{f y}\right\}$, que contém as transições fonte ;

- Um conjunto não vazio de marcas $M\left(T_{f i}\right)=\left\{m_{f i 1}, . ., m_{\text {tij. }}\right\}$, que podem ser entradas pelas transições fontes ;

- Um conjunto não vazio de arcos orientados $A=\left\{a_{1}, a_{2}, \ldots, a_{w}\right\}$, que conectam uma transição $t_{i}$ a um lugar $l_{j}$ ou um lugar $l_{j}$ a uma transição $t_{i}$ e cuja inscrição pode ser um valor de marca ou uma variável;

- Um conjunto de probabilidades de disparo das transições $P\left(T_{i} / E_{j}\right)$ dado o conteúdo dos lugares da rede (Estado da rede $E_{j}=\left\{l_{1 j}, I_{2 j}\right.$, ..., $\left.I_{q j}\right\}$;

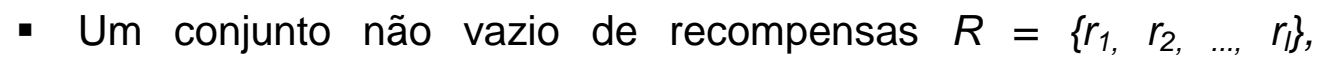
associadas ao conteúdo dos lugares da rede. 
É importante notar que esta descrição de rede de Petri segue as regras de evolução de estados de uma rede de Petri colorida, ou seja, o estado futuro depende apenas do estado atual de marcações. Dada esta característica, para saber-se qual o estado futuro de cada lugar necessita-se apenas conhecer o estado atual da rede de Petri. Portanto, as probabilidades de disparo devem variar de valor dependendo apenas da configuração atual da rede.

Para facilitar a compreensão desta formalização, utiliza-se o exemplo da rede de Petri ilustrada na Figura 15. Nela possuímos o conjunto de lugares $L=\{L 1$, $L 2, L 3, L 4\}$, o conjunto de marcas $M=\{A, B, C, E\}$, o conjunto de transições $T$ $=\{$ Fonte, T1, T2, T3, T4, T5 $\}$, o conjunto de transições fonte $T_{f}=\{$ Fonte $\}, 0$ conjunto de arcos orientados $A=\left\{a_{1}, a_{2}, a_{3}, a_{4}, a_{5}, a_{6}, a_{7}, a_{8}\right\}$ e o conjunto de entradas que podem haver em cada transição fonte $M\left(T_{F}\right)=\{A, B\}$.

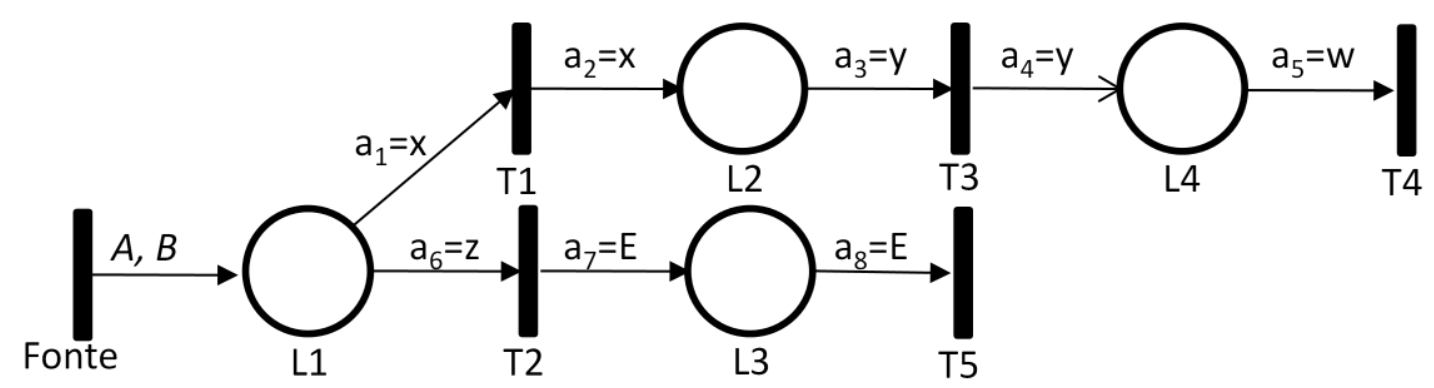

Figura 15 - Exemplo de representação gráfica de rede de Petri fatorada

As probabilidades das transições em conflito e as recompensas são apresentadas em forma de tabelas, uma vez que estas informações não estão compreendidas na representação tradicional de redes de Petri. 


\section{Tabela de probabilidades}

A forma de representação da tabela de probabilidades é uma das contribuições deste trabalho. A partir dela consegue-se representar todas as probabilidades presentes nos sistemas modelados. Seu desenvolvimento foi importante, pois além de possuir a representação de todas as probabilidades, ela é relativamente simples de ser montada e concisa. Apenas listar exaustivamente todos os estados de redes de Petri e suas probabilidades atingiria o objetivo inicial, que era fornecer os valores de probabilidade, porém seria muito trabalhoso para quem modela. Propôs-se então uma modelagem mais simples e não exaustiva.

A tabela de probabilidade deve expressar a probabilidade da transição ser disparada dada a atual configuração do sistema. Por definição, a probabilidade de disparo de uma transição depende de:

- Lugares que são pré e pós-condições da transição.

- Lugares que são pré e pós-condições de todas as transições pertencentes ao mesmo grupo de conflito.

Define-se grupo de conflito de uma transição o conjunto de transições cujo dispsro afeta a probabilidade de disparo da transição. Grupos de conflitos por definição são compostos por todas as transições cuja habilitação afeta sua probabilidade de disparo.

Considerando o exemplo da Figura 15, pode-se verificar que as transições $T 1 \mathrm{e}$ T2 estão em conflito, e suas pré-condições e pós-condições são $L 1, L 2$ e $L 3$. A Tabela 7 apresenta todas as combinações possíveis entre estes lugares. Porém, nem todas as combinações necessitam ser apresentadas na tabela de probabilidades. As combinações em que uma ou as duas transições estão desabilitadas são desnecessárias, pois estas combinações não apresentam 
conflito. O conteúdo dos lugares $L 2$ e $L 3$ também não precisam ser exibidos, dado que por definição os conteúdos destes lugares não afetam os valores de probabilidades. O conteúdo destes lugares apenas determina a habilitação das transições, informação que já é indicada por " $\boldsymbol{D}$ ", que significa que a transição em questão encontra-se desabilitada. Por definição, os únicos lugares que necessitam constar nas tabelas de probabilidades são os lugares que são précondições. Portando, a Tabela 7 pode ser simplificada, resultando na Tabela 8.

É importante observar que cada rede pode possuir mais de uma tabela de probabilidades, sendo cada uma associada a um grupo independente de conflitos. A suposição aqui adotada é que cada transição do grupo de conflito tem probabilidades de disparo independentes das demais transições da FPN. Esta independência que auxilia na definição dos grupos de disparo.

Pode-se considerar o conteúdo de cada lugar uma variável independente e associar a cada transição uma variável independente binária (dispara ou não dispara). Sendo os grupos de conflito independentes estatisticamente por definição, pode-se dizer que o grupo de variáveis aleatórias associadas aos disparos das transições de um determinado grupo de conflito são estatisticamente independentes às variáveis aleatórias associadas a transições de outro grupo de conflito.

Um exemplo de grupo de conflito pode ser visto na Figura 16. Neste caso, há quatro conflitos. A transição $T 1$ pode estar em conflito com $T 2$ pelo recurso ou item no lugar $L 1$, e as transições T2, T3, T4 e T5 podem estar em conflito entre si pelo recurso/item em L2. Pode-se considerar estes dois conflitos como um grupo de conflito, pois um interfere com o outro por possuírem uma transição em comum (T2). Tem-se então para este grupo de conflito a tabela de probabilidades exibida na Tabela 9. Nota-se nesta tabela a existência de mais de uma linha com o mesmo conteúdo de $L 1$ e $L 2$. Isto ocorre porque o que torna a linha única é a combinação entre o conteúdo dos lugares que nela 
aparecem (que são os lugares que são pré-condições) e que transições encontram-se habilitadas e desabilitadas. Isso ocorre pois esta habilitação ou desabilitação de transições traz informações sobre os estados dos lugares não listados na tabela que são pós-condições destas transições.

O mesmo vale para os outros dois conflitos da rede. A transição $T 6$ pode estar em conflito com $T 7$ pelo recurso/item no lugar $L 8$, e as transições $T 7$ e $T 8$ podem estar em conflito entre si pelo recurso/item em L4. Como ambos possuem a transição $T 7$, comum, estes dois conflitos formam um outro grupo de conflito. Suas probabilidades são determinadas pela configuração de $L 3, L 4, L 5$, L8 e L9. Tem-se então para este grupo de conflito a tabela de probabilidades exibida na Tabela 10, onde apenas as entradas $\angle 3$ e $\angle 4$ são indicadas porque o conteúdo de $L 5, L 8$ e $L 9$ está implícito na indicação de desabilitação das transições " $\boldsymbol{D}$ ". 
Tabela 7 - Tabela de probabilidades de transições em conflito de uma rede de Petri fatorada.

\begin{tabular}{|c|c|c|c|c|}
\hline L1 & $L 2$ & L3 & $T 1$ & $T 2$ \\
\hline Vazio & Vazio & Vazio & $\overline{D D}$ & $\bar{D}$ \\
\hline Vazio & Vazio & $A$ & $D$ & $D$ \\
\hline Vazio & Vazio & $B$ & $D$ & $D$ \\
\hline Vazio & $A$ & Vazio & $D$ & $D$ \\
\hline Vazio & $A$ & $A$ & $D$ & $D$ \\
\hline Vazio & $A$ & $B$ & $D$ & $D$ \\
\hline Vazio & $B$ & Vazio & $D$ & $D$ \\
\hline Vazio & $B$ & $A$ & $D$ & $D$ \\
\hline Vazio & $B$ & $B$ & $D$ & $D$ \\
\hline$A$ & Vazio & Vazio & 0.6 & 0.4 \\
\hline$A$ & Vazio & $A$ & 1 & $D$ \\
\hline$A$ & Vazio & $B$ & 1 & $D$ \\
\hline$A$ & $A$ & Vazio & $D$ & 1 \\
\hline$A$ & $A$ & $A$ & $D$ & $D$ \\
\hline$A$ & $A$ & $B$ & $D$ & $D$ \\
\hline$A$ & $B$ & Vazio & $D$ & 1 \\
\hline$A$ & $B$ & $A$ & $D$ & $D$ \\
\hline$A$ & $B$ & $B$ & $D$ & $D$ \\
\hline$B$ & Vazio & Vazio & 0.7 & 0.3 \\
\hline$B$ & Vazio & $A$ & 1 & $D$ \\
\hline$B$ & Vazio & $B$ & 1 & $D$ \\
\hline$B$ & $A$ & Vazio & $D$ & 1 \\
\hline$B$ & $A$ & $A$ & $D$ & $D$ \\
\hline$B$ & $A$ & $B$ & $D$ & $D$ \\
\hline$B$ & $B$ & Vazio & $D$ & 1 \\
\hline$B$ & $B$ & $A$ & $D$ & $D$ \\
\hline$B$ & $B$ & $B$ & $D$ & $D$ \\
\hline
\end{tabular}


Tabela 8 - Tabela reduzida de probabilidades de transições em conflito de redes de Petri fatoradas.

\begin{tabular}{ccc} 
L1 & T1 & T2 \\
\hline \hline$A$ & 0.6 & 0.4 \\
$B$ & 0.7 & 0.3 \\
\hline \hline
\end{tabular}

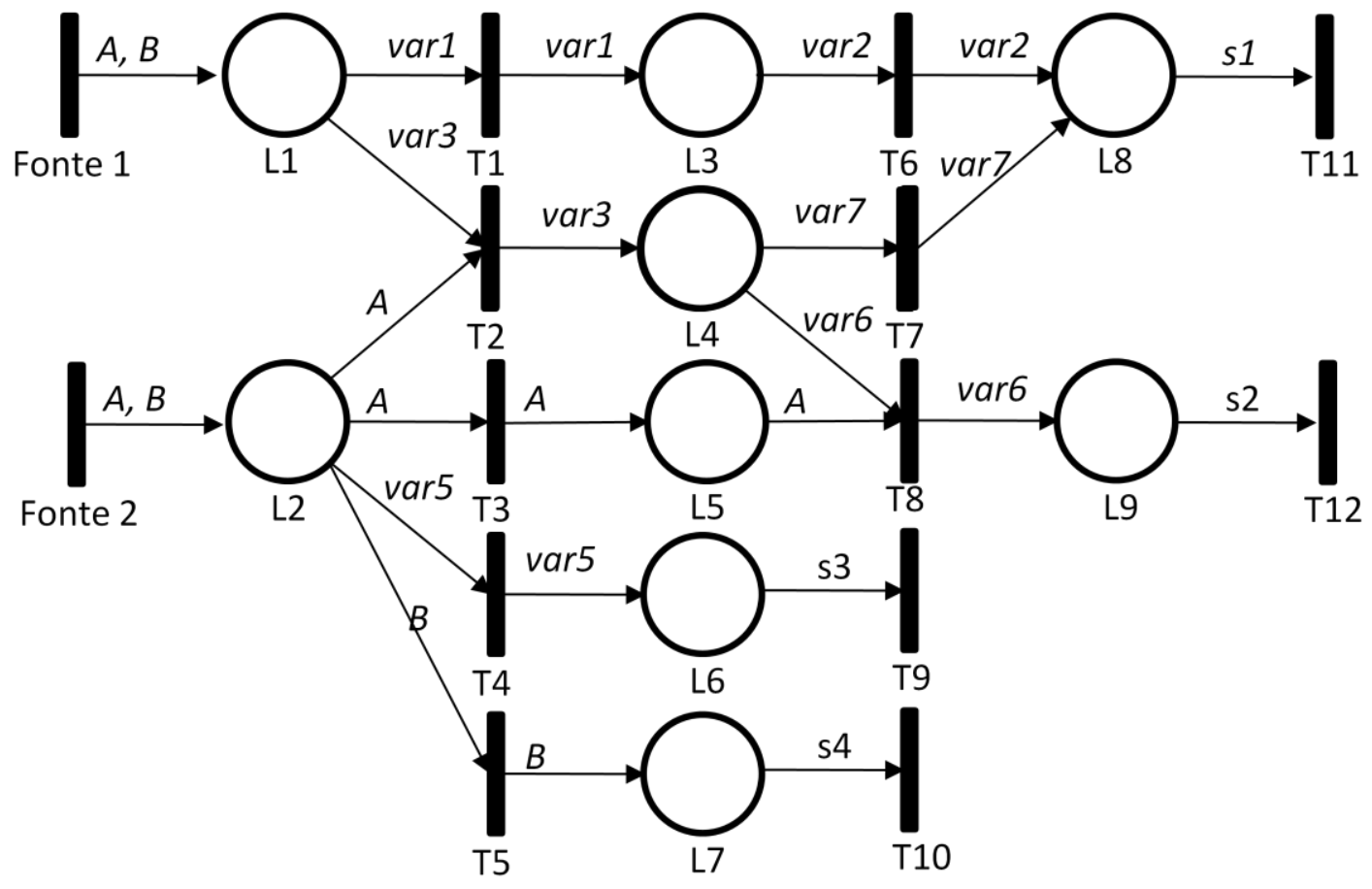

Figura 16 - Segundo exemplo de representação gráfica de rede de Petri seguindo restrições. 
Tabela 9 - Tabela de probabilidades do primeiro grupo de conflito do exemplo de rede de Petri fatorada da Figura 16.

\begin{tabular}{|c|c|c|c|c|c|c|}
\hline L1 & L2 & $\mathrm{P}(\mathrm{T} 1)$ & $\mathrm{P}(\mathrm{T} 2)$ & $\mathrm{P}(\mathrm{T} 3)$ & $\mathrm{P}(\mathrm{T} 4)$ & $\mathrm{P}(\mathrm{T} 5)$ \\
\hline Vazio & $A$ & $D$ & $D$ & $60 \%$ & $40 \%$ & $D$ \\
\hline 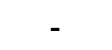 & B & $D$ & $D$ & $D$ & $50 \%$ & $50 \%$ \\
\hline A & A & $60 \%$ & $40 \%$ & $25 \%$ & $35 \%$ & $D$ \\
\hline$A$ & $A$ & $45 \%$ & $55 \%$ & $45 \%$ & $D$ & $D$ \\
\hline A & $A$ & $38 \%$ & $62 \%$ & $D$ & $38 \%$ & $D$ \\
\hline$A$ & $A$ & $38 \%$ & $62 \%$ & $D$ & $D$ & $D$ \\
\hline$A$ & $A$ & $100 \%$ & $D$ & $42 \%$ & $58 \%$ & $D$ \\
\hline$A$ & $A$ & $D$ & $40 \%$ & $25 \%$ & $35 \%$ & $D$ \\
\hline A & $A$ & $D$ & $55 \%$ & $45 \%$ & $D$ & $D$ \\
\hline A & $A$ & $D$ & $65 \%$ & $D$ & $35 \%$ & $D$ \\
\hline A & A & $D$ & $D$ & $42 \%$ & $58 \%$ & $D$ \\
\hline B & A & $60 \%$ & $40 \%$ & $25 \%$ & $35 \%$ & $D$ \\
\hline B & $A$ & $45 \%$ & $55 \%$ & $45 \%$ & D & $D$ \\
\hline B & $A$ & $38 \%$ & $62 \%$ & D & $38 \%$ & $D$ \\
\hline B & $A$ & $38 \%$ & $62 \%$ & D & $\mathrm{D}$ & $D$ \\
\hline$B$ & $A$ & $100 \%$ & $D$ & $42 \%$ & $58 \%$ & $D$ \\
\hline$B$ & $A$ & $D$ & $40 \%$ & $25 \%$ & $35 \%$ & $D$ \\
\hline B & $A$ & $D$ & $55 \%$ & $45 \%$ & $D$ & $D$ \\
\hline B & $A$ & $D$ & $65 \%$ & $D$ & $35 \%$ & $D$ \\
\hline $\mathrm{B}$ & $\mathrm{A}$ & $D$ & $D$ & $42 \%$ & $58 \%$ & $D$ \\
\hline
\end{tabular}

É importante ressaltar que a tabela de probabilidades representa as probabilidades das transições dispararem considerando todos os lugares da rede que as afetam. Exatamente pelo significado destas probabilidades é que se deve representá-las na mesma tabela do grupo de conflito.

Considerando como evento, a combinação de disparos dentro de um grupo de conflito, a combinação de eventos de grupos de conflito diferentes pode ser obtida a partir da multiplicação das probabilidades de disparo das transições de cada grupo de conflito. Deve-se notar que a multiplicação pode ser realizada apenas entre grupos de conflito diferentes. Dois eventos pertencentes ao mesmo grupo de conflito não podem ser multiplicados para obter-se a 
probabilidade conjunta. Esta propriedade é válida apenas para os grupos de conflito distintos, pois eles são, por suposição, eventos independentes.

Tabela 10 - Tabela de probabilidades do segundo grupo de conflito para exemplo de rede de Petri fatorada da Figura 16.

\begin{tabular}{cc|ccc} 
L3 & L4 & $\mathrm{P}(\mathrm{T} 6)$ & $\mathrm{P}(\mathrm{T} 7)$ & $\mathrm{P}(\mathrm{T} 8)$ \\
\hline \hline Vazio & $\mathrm{A}$ & $\boldsymbol{D}$ & $60 \%$ & $40 \%$ \\
\hdashline Vazio & $\mathrm{B}$ & $\boldsymbol{D}$ & $30 \%$ & $70 \%$ \\
\hdashline $\mathrm{A}$ & $\mathrm{A}$ & $40 \%$ & $60 \%$ & $40 \%$ \\
$\mathrm{~A}$ & $\mathrm{~A}$ & $45 \%$ & $65 \%$ & $\boldsymbol{D}$ \\
$\mathrm{A}$ & $\mathrm{A}$ & $\boldsymbol{D}$ & $60 \%$ & $40 \%$ \\
\hline $\mathrm{A}$ & $\mathrm{B}$ & $70 \%$ & $30 \%$ & $70 \%$ \\
$\mathrm{~A}$ & $\mathrm{~B}$ & $45 \%$ & $65 \%$ & $\boldsymbol{D}$ \\
$\mathrm{A}$ & $\mathrm{B}$ & $\boldsymbol{D}$ & $30 \%$ & $70 \%$ \\
\hdashline $\mathrm{B}$ & $\mathrm{A}$ & $45 \%$ & $55 \%$ & $45 \%$ \\
$\mathrm{~B}$ & $\mathrm{~A}$ & $45 \%$ & $55 \%$ & $\boldsymbol{D}$ \\
$\mathrm{B}$ & $\mathrm{A}$ & $\boldsymbol{D}$ & $60 \%$ & $40 \%$ \\
\hdashline $\mathrm{B}$ & $\mathrm{B}$ & $70 \%$ & $30 \%$ & $70 \%$ \\
$\mathrm{~B}$ & $\mathrm{~B}$ & $45 \%$ & $55 \%$ & $\boldsymbol{D}$ \\
$\mathrm{B}$ & $\mathrm{B}$ & $\boldsymbol{D}$ & $30 \%$ & $70 \%$ \\
\hline \hline
\end{tabular}

\section{Tabela de recompensas}

$\mathrm{Na}$ tabela de recompensas devem constar os estados que devem receber uma recompensa. Estes estados são caracterizados pelo conteúdo dos lugares. Da mesma forma que a tabela de probabilidades, não é necessário listar todos os lugares, apenas aqueles que caracterizam estados que recebem recompensas.

Para a rede da Figura 15, a tabela de recompensas correspondente é exibida na Tabela 11. No caso deste exemplo definiu-se que a recompensa depende apenas da marcação final produzida, portanto, os conteúdos de $L 1$ e $L 2$ são desconsiderados. Esta tabela significa que, por exemplo, caso seja atingido um 
estado onde L3 apresenta a marca C e $L 4$ a marca B, deve-se receber " 3 " de recompensa.

Tabela 11 - Exemplo de tabela de recompensas do exemplo de rede de Petri fatorada da Figura 15.

\begin{tabular}{ccc} 
L3 & L4 & Recompensa \\
\hline \hline$C$ & Vazio & 1 \\
$C$ & $A$ & 2 \\
$C$ & $B$ & 3 \\
$C$ & $C$ & 2 \\
Vazio & $A$ & 1 \\
Vazio & $B$ & 2 \\
Vazio & $C$ & 1 \\
Vazio & Vazio & 0 \\
\hline \hline
\end{tabular}

\subsection{Rede de Petri fatorada com probabilidades imprecisas}

A redes de Petri fatorada com probabilidades imprecisas (FPNIP) é uma variação da FPN. Suas representações são as mesmas exceto pela representação de probabilidades pelas tabelas de probabilidades. Ao invés de associar um valor de probabilidade exato para o disparo de cada transição, atribui-se um intervalo de probabilidades, delimitado inferiormente por $P\left(T_{i}\right)_{\text {inf }} \mathrm{e}$ superiormente por $P\left(T_{i}\right)_{\text {sup. A }}$ A representação destas probabilidades para o exemplo da Figura 15, agora considerando que ele é um FPNIP, esta na Tabela 12. É importante notar que a tabela de recompensas mantém-se inalterada. 
Tabela 12 - Tabela de probabilidades imprecisas do conflito de uma rede de Petri fatorada com probabilidades imprecisas para o exemplo da Figura 15.

\begin{tabular}{ccccc}
$L 1$ & $P(T 1)_{\text {inf }}$ & $P(\mathbf{T 1})_{\text {sup }}$ & $\boldsymbol{P}(\mathbf{T} 2)_{\text {inf }}$ & $\boldsymbol{P}(\mathbf{T} 2)_{\text {sup }}$ \\
\hline \hline$A$ & 0.55 & 0.65 & 0.3 & 0.5 \\
$B$ & 0.29 & 0.68 & 0.31 & 0.72 \\
\hline \hline
\end{tabular}

Considerando a modelagem FPNIP também para o exemplo da Figura 16, temse como exemplo a tabela de probabilidades do primeiro grupo de conflito exibida na Tabela 13, e a do segundo grupo exibida na Tabela 14.

Há uma restrição que deve ser considerada na definição dos intervalos de probabilidades. Esta restrição possui origem matemática, e não possui nenhuma equivalência no mundo real. $O$ valor da probabilidade superior de qualquer transição do grupo de conflito deve ser maior do que o necessário para completar probabilidade igual a cem por cento quando acrescido de todas as probabilidades inferiores dos arcos em conflito com o arco em questão.

Assim, dado um conjunto de transições em conflito $T=\left\{t_{1}, t_{2}, \ldots, t_{n}\right\}$, deve-se garantir que para qualquer $i$ entre 1 e $n$, o valor mínimo de $P_{\text {sup }}\left(t_{i}\right)$ siga a regra:

$$
P_{\text {sup }}\left(t_{i}\right) \geq 1-\sum P_{\text {inf }}\left(t_{j}\right)+P_{\text {inf }}\left(t_{i}\right)
$$


Tabela 13 - Tabela de probabilidades do primeiro grupo de conflitos para o exemplo de rede de Petri fatorada com probabilidades imprecisas da Figura 16.

\begin{tabular}{|c|c|c|c|c|c|c|c|c|c|c|c|}
\hline \multirow[b]{2}{*}{ L1 } & \multirow[b]{2}{*}{ L2 } & \multicolumn{2}{|c|}{$\mathrm{P}(\mathrm{T} 1)$} & \multicolumn{2}{|c|}{$\mathrm{P}(\mathrm{T} 2)$} & \multicolumn{2}{|c|}{$\mathrm{P}(\mathrm{T} 3)$} & \multicolumn{2}{|c|}{$\mathrm{P}(\mathrm{T} 4)$} & \multicolumn{2}{|c|}{$\mathrm{P}(\mathrm{T} 5)$} \\
\hline & & inf & Sup & $\operatorname{lnf}$ & Sup & Inf & sup & Inf & sup & Inf & Sup \\
\hline Vazio & A & $D$ & $D$ & $D$ & $D$ & $55 \%$ & $65 \%$ & $30 \%$ & $50 \%$ & $D$ & $D$ \\
\hline- & B & $D$ & $D$ & $D$ & $D$ & $D$ & $D$ & $40 \%$ & $60 \%$ & $48 \%$ & $52 \%$ \\
\hline A & A & $57 \%$ & $63 \%$ & $25 \%$ & $55 \%$ & $20 \%$ & $30 \%$ & $25 \%$ & $45 \%$ & $D$ & $D$ \\
\hline A & A & $42 \%$ & $48 \%$ & $40 \%$ & $70 \%$ & $40 \%$ & $50 \%$ & $D$ & $D$ & $D$ & $D$ \\
\hline A & $A$ & $35 \%$ & $41 \%$ & $47 \%$ & $77 \%$ & $D$ & $D$ & $28 \%$ & $48 \%$ & $D$ & $D$ \\
\hline A & A & $35 \%$ & $41 \%$ & $47 \%$ & $77 \%$ & $D$ & $D$ & $D$ & $D$ & $D$ & $D$ \\
\hline A & A & $100 \%$ & $100 \%$ & $D$ & $D$ & $37 \%$ & $47 \%$ & $48 \%$ & $68 \%$ & $D$ & $D$ \\
\hline A & A & $D$ & $D$ & $25 \%$ & $55 \%$ & $20 \%$ & $30 \%$ & $25 \%$ & $45 \%$ & $D$ & $D$ \\
\hline A & A & $D$ & $D$ & $40 \%$ & $70 \%$ & $40 \%$ & $50 \%$ & $D$ & $D$ & $D$ & $D$ \\
\hline A & A & $D$ & $D$ & $50 \%$ & $80 \%$ & $D$ & $D$ & $25 \%$ & $45 \%$ & $D$ & $D$ \\
\hline A & $A$ & $D$ & $D$ & $D$ & $D$ & $37 \%$ & $47 \%$ & $48 \%$ & $68 \%$ & $D$ & $D$ \\
\hline B & $A$ & $57 \%$ & $63 \%$ & $25 \%$ & $55 \%$ & $20 \%$ & $30 \%$ & $25 \%$ & $45 \%$ & D & $D$ \\
\hline B & $A$ & $42 \%$ & $48 \%$ & $40 \%$ & $70 \%$ & $40 \%$ & $50 \%$ & $D$ & $D$ & $D$ & $D$ \\
\hline B & A & $35 \%$ & $41 \%$ & $47 \%$ & $77 \%$ & $D$ & $D$ & $28 \%$ & $48 \%$ & $D$ & $D$ \\
\hline B & A & $35 \%$ & $41 \%$ & $47 \%$ & $77 \%$ & $D$ & $D$ & $D$ & $D$ & $D$ & $D$ \\
\hline B & $A$ & $100 \%$ & $100 \%$ & $D$ & $D$ & $37 \%$ & $47 \%$ & $48 \%$ & $68 \%$ & $D$ & $D$ \\
\hline B & $A$ & $D$ & $D$ & $25 \%$ & $55 \%$ & $20 \%$ & $30 \%$ & $25 \%$ & $45 \%$ & $D$ & $D$ \\
\hline B & A & $D$ & $D$ & $40 \%$ & $70 \%$ & $40 \%$ & $50 \%$ & $D$ & $D$ & $D$ & $D$ \\
\hline B & A & $D$ & $D$ & $50 \%$ & $80 \%$ & $D$ & $D$ & $25 \%$ & $45 \%$ & $D$ & $D$ \\
\hline$B$ & A & $D$ & $D$ & $D$ & $D$ & $37 \%$ & $47 \%$ & $48 \%$ & $68 \%$ & $D$ & $D$ \\
\hline
\end{tabular}


Tabela 14 - Tabela de probabilidades do segundo grupo de conflitos para o exemplo de rede de Petri fatorada com probabilidades imprecisas da Figura 16

\begin{tabular}{|c|c|c|c|c|c|c|c|}
\hline \multirow[b]{2}{*}{ L3 } & \multirow[b]{2}{*}{ L4 } & \multicolumn{2}{|c|}{$\mathrm{P}(\mathrm{T} 6)$} & \multicolumn{2}{|c|}{$\mathrm{P}(\mathrm{T} 7)$} & \multicolumn{2}{|c|}{$\mathrm{P}(\mathrm{T} 8)$} \\
\hline & & Inf & Sup & Inf & Sup & Inf & Sup \\
\hline Vazio & A & $D$ & $D$ & $55 \%$ & $65 \%$ & $36 \%$ & $44 \%$ \\
\hline Vazio & $B$ & $D$ & $D$ & $25 \%$ & $35 \%$ & $63 \%$ & $77 \%$ \\
\hline A & A & $30 \%$ & $50 \%$ & $55 \%$ & $65 \%$ & $36 \%$ & $44 \%$ \\
\hline A & $A$ & $35 \%$ & $55 \%$ & $60 \%$ & $70 \%$ & $D$ & $D$ \\
\hline A & A & $D$ & $D$ & $55 \%$ & $65 \%$ & $36 \%$ & $44 \%$ \\
\hline $\bar{A}$ & $B$ & $60 \%$ & $80 \%$ & $25 \%$ & $35 \%$ & $63 \%$ & $77 \%$ \\
\hline A & $B$ & $35 \%$ & $55 \%$ & $60 \%$ & $70 \%$ & $D$ & $D$ \\
\hline A & $B$ & $D$ & $D$ & $25 \%$ & $35 \%$ & $63 \%$ & $77 \%$ \\
\hline B & $A$ & $35 \%$ & $55 \%$ & $50 \%$ & $60 \%$ & $41 \%$ & $49 \%$ \\
\hline B & $A$ & $35 \%$ & $55 \%$ & $50 \%$ & $60 \%$ & $D$ & $D$ \\
\hline$B$ & A & $D$ & $D$ & $55 \%$ & $65 \%$ & $36 \%$ & $44 \%$ \\
\hline $\mathrm{B}$ & $\mathrm{B}$ & $60 \%$ & $80 \%$ & $25 \%$ & $35 \%$ & $63 \%$ & $77 \%$ \\
\hline B & $B$ & $35 \%$ & $55 \%$ & $50 \%$ & $60 \%$ & $D$ & $D$ \\
\hline$B$ & $\mathrm{~B}$ & $D$ & $D$ & $25 \%$ & $35 \%$ & $63 \%$ & $77 \%$ \\
\hline
\end{tabular}

Um exemplo pode ser ilustrado pela Figura 17. Supondo os seguintes valores de $p 1, p 2$ e $p 3:$

- $0,15<p 1<0,30$

- $0,40<p 2<0,60$

- $0,25<p 3<0,45$

Para este caso, a probabilidade do lugar $L 3$ receber o recurso $A$ é dada por:

$$
P_{\text {inf }}(L 3=A)=P_{\text {inf }}(\text { T2 disparar })+P_{\text {inf }}(\text { T3 disparar })=0,40+0,25=0,65
$$

Porém observa-se que a soma de $P_{\text {inf }}(L 3=A)$ acrescida da probabilidade superior de $P_{\text {sup }}(L 2=A)$ é 0,9 , enquanto deveria ser no mínimo um (100\%). Obedecendo a restrição proposta, esta distorção não ocorreria, dado que por ela, saberíamos que o valor mínimo de probabilidade de $P_{\text {sup }}\left(t_{1}\right)$ é dado por:

$$
P_{\text {sup }}\left(t_{1}\right) \geq 1-\sum P_{\text {inf }}\left(t_{j}\right)+P_{\text {inf }}\left(t_{1}\right)=1-(0,15+0,40+0,25)-0,15=0,35
$$




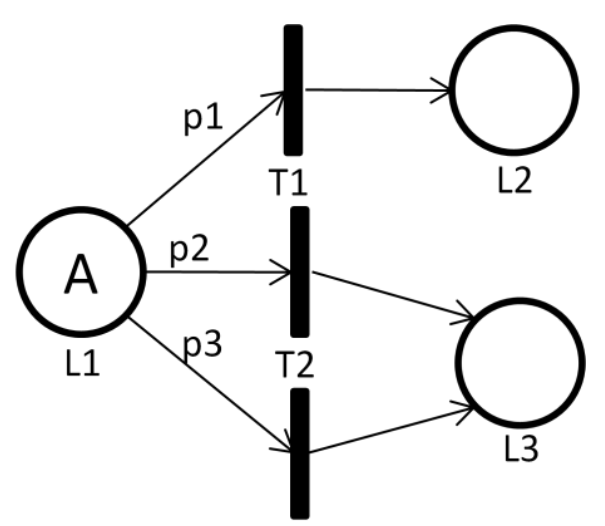

T3

Figura 17 - Exemplo de restrição de probabilidades superiores mínimas.

Sabe-se que as probabilidades dentro de seu próprio grupo de conflito não são independentes entre si. Esta restrição fez-se necessária pois caso contrario haveria necessidade de um algoritmo robusto para o cálculo das probabilidades de transição entre estados da PN. 


\section{MÉTODO DE TRANSFORMAÇÃO}

Nesta seção são expostas e detalhadas as etapas previstas para o método de transformação de FPN em MDP e em seguida de FPNIP em MDPIP, que é a principal contribuição deste trabalho.

\subsection{Transformação em MDP}

Nesta seção as etapas de transformação são detalhadas, com o auxílio de alguns exemplos. FPN são convertidas em MDP seguindo as seguintes etapas:

1. Criação das variáveis de estado

2. Associação das variáveis de estado aos seus possíveis valores

3. Definição das ações possíveis

4. Definição da dependência entre as variáveis

5. Associação e cálculo das probabilidades para cada variável em cada estado

6. Definição das recompensas por estado do MDP

A primeira etapa consiste em criar as variáveis de estado que compõem o estado do MDP. Esta conversão é direta, sendo criada uma variável de estado do MDP para cada lugar da rede de Petri. Estas variáveis combinadas compõem o estado do sistema modelado. Por exemplo, na FPN exibida na Figura 18, são necessárias três variáveis de estado para descrever os estados possíveis do sistema, que são $V 1$ representando o conteúdo de $L 1$, V2 para $L 2$ e por fim, $V 3$ representando o conteúdo de $L 3$. 


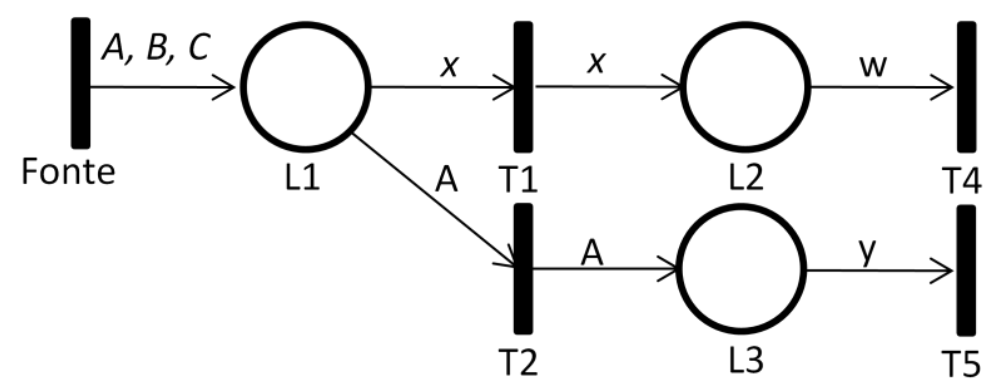

Figura 18 - Rede de Petri para exemplo de listagem de variáveis em MDP.

Finalizada a primeira etapa, é necessário compreender que valores estas variáveis podem ter. Esta fase se faz necessária pois nem todos os tipos de marcas existentes na rede podem ocupar todos os lugares. Na rede da Figura 18 pode-se notar que $L 1$ pode receber marcas tipo $A, B$ e $C$, portanto os valores possíveis de $V 1$ podem ser vazio, $A, B$ e $C$. Os mesmos valores são possíveis para $V 2$, pois pela estrutura do grafo $L 2$ ele pode receber as mesmas marcas de $V 1$ (indicado pela variável $x$ ). A variável $V 3$ por sua vez, pode ter apenas os valores zero ou $A$, pois o arco orientado apontado para o lugar $L 3$ indica que apenas marcas tipo $A$ podem ser passadas.

A etapa seguinte consiste em definir que ações podem ser tomadas no MDP. As ações consistem na decisão de que recursos entram na rede de Petri através do disparo das transições fonte. A ação é composta pela combinação de cada marca adicionada à rede pelo disparo de cada transição fonte. No exemplo da Figura 18, pode-se notar que há apenas uma fonte, então as quatro ações possíveis são:

- Inserir uma marca A na rede através do disparo da Fonte

- Inserir uma marca B na rede através do disparo da Fonte

- Inserir uma marca $C$ na rede através do disparo da Fonte

- Não inserir nenhuma marca através do não disparo da Fonte 
Para compreender melhor o conceito de combinação de marcas, utiliza-se o exemplo exibido na Figura 19, onde há duas transições fontes. As ações possíveis são a combinação do que deve ser adicionado ao sistema através dessas transições fonte. Para a Fonte 1 há as opções: não colocar nenhum recurso em $L 1$; colocar $A$ em $L 1$; ou colocar $B$ em $L 1$, e para a Fonte 2 há as opções: não colocar nenhum recurso em L2; colocar $B$ em $L 2$; ou colocar $C$ em L2. Combinando estas opções são obtidas as seguintes ações para o MDP:

- Nenhuma - não entrar com nenhuma marca no sistema

- _ B - não colocar nada em $L 1$ e colocar $B$ em $L 2$

- _C- não colocar nada em $L 1$ e colocar $C$ em $L 2$

- $A_{\text {_ }}$ - colocar $A$ em $L 1$ e não colocar nada em $L 2$

- $A B$ - colocar $A$ em $L 1$ e colocar B em L2

- AC-colocar A em L1 e colocar C em L2

- $B_{\text {_ }}$ - colocar B em $L 1$ e não colocar nada em $L 2$

- BB - colocar B em $L 1$ e em $L 2$

- BC-colocar B em $L 1$ e colocar C em $L 2$

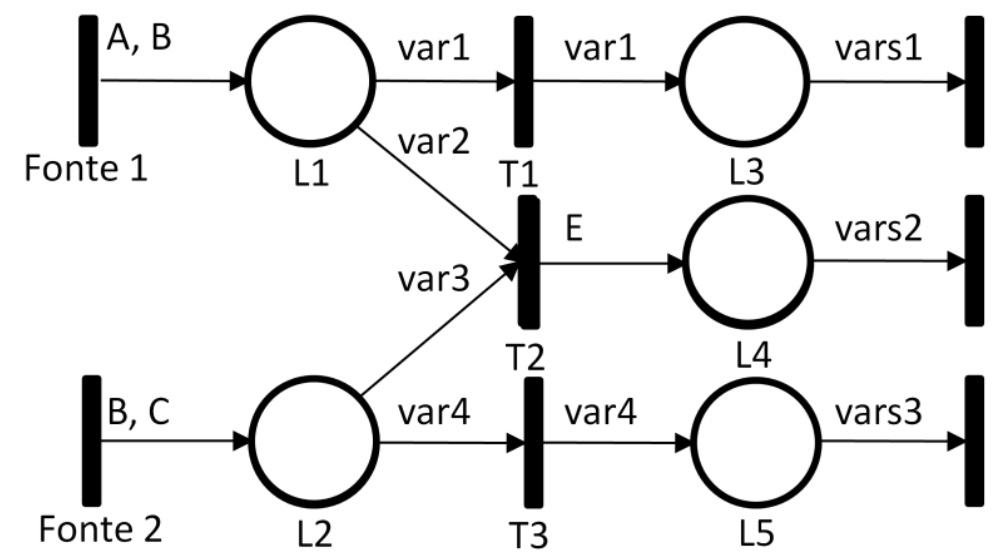

Figura 19 - Rede de Petri para exemplo de listagem de ações em MDP. 
A quarta etapa consiste em determinar a dependência entre as variáveis do MDP. Em rede de Petri, o estado seguinte depende apenas do estado atual e da ação tomada. Isto é, a marcação futura de cada lugar depende apenas de seu valor atual, das transições de onde este lugar é entrada ou saída ou das ações associadas a esta transição que pode estar num grupo de conflito. A marcação futura de um lugar apenas depende das ações caso tenha como pré condição uma transição fonte.

Por exemplo, na rede exibida na Figura 20, há dois grupos de conflito. 0 primeiro grupo de conflito é composto por T1 e T2 e o segundo por T4 e T5. Ao analisar cada variável deve-se considerar todos os grupos aos quais ela pertence e todas as transições que são entradas ou saídas para o lugar em questão. $L 1$ ( $V_{1}$ no MDP) pertence apenas ao primeiro grupo de conflito, portanto, depende de todas as pré e pós condições deste grupo, ou seja, seu estado futuro depende de $L 1, L 2$ e $L 3\left(V_{1}, V_{2}\right.$ e $\left.V_{3}\right)$ e também da ação tomada, dado que a transição Fonte é sua pré-condição. O lugar $L 2$ (variável $V_{2}$ no $M D P)$, também pertence a este grupo e depende do estado dos mesmos lugares $L 1, L 2$ e $L 3(V 1, V 2$ e $V 3)$ e também do estado de $L 4$ ( $V_{4}$ no MDP) que é pós-condição da transição T3 de onde ele é entrada. Já $L 3$ ( $V_{3}$ no MDP), pertence a dois grupos de conflito e deve possuir as pré e pós condições de ambos. Tem-se então que o estado futuro de $L 3$ depende dos estados atuais de $L 1, L 2, L 3, L 5$ e $L 6\left(V_{1}, V_{2}, V_{3}, V_{5}\right.$ e $\left.V_{6}\right)$. Analogamente, $L 5$ e $L 6\left(V_{5}\right.$ e $\left.V_{6}\right)$ que pertencem ao mesmo grupo de conflito dependem do estado atual de $L 3, L 5 \mathrm{e}$ $L 6\left(V_{3}, V_{5}\right.$ e $\left.V_{6}\right)$. Por fim, há o caso de $L 4\left(V_{4}\right)$, que não pertence a nenhum grupo de conflito. Seu estado depende apenas das pré e pós condições de todas as transições de onde este lugar é entrada ou saída, neste caso há apenas a pré condição $\mathrm{L} 2\left(\mathrm{~V}_{2}\right)$. 


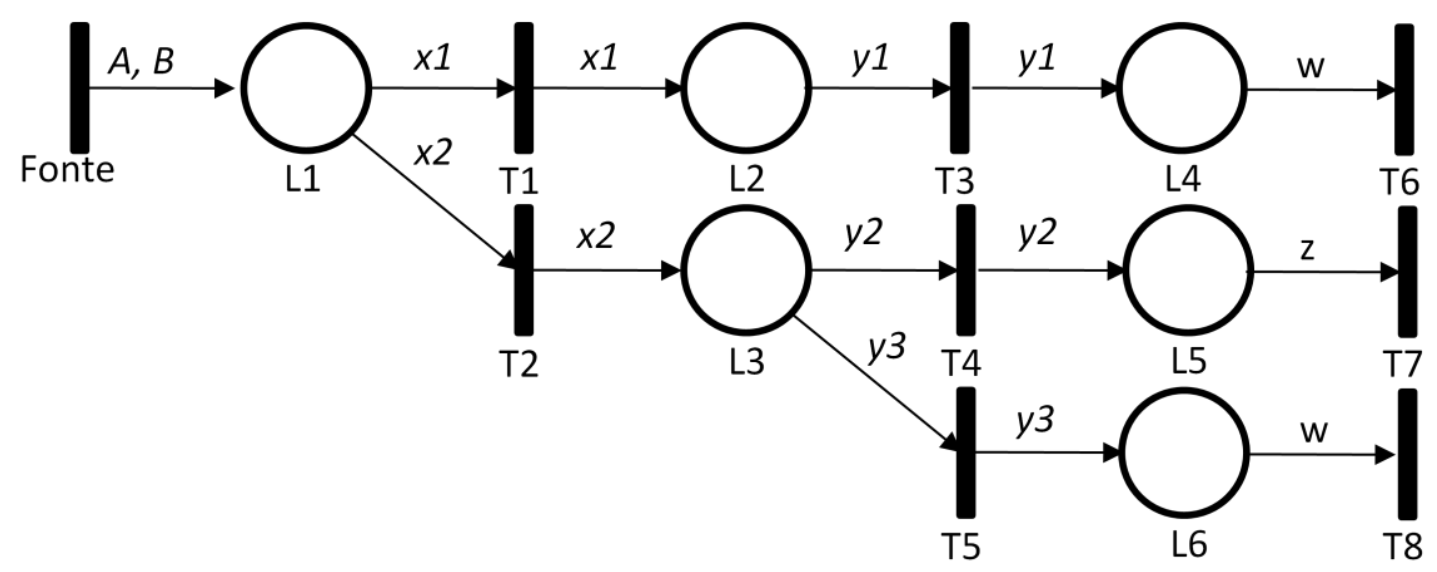

Figura 20 - Rede de Petri para exemplo de dependência entre variáveis.

Como as variáveis no MDP são diretamente equivalentes aos lugares da FPN, têm-se as seguintes dependências para $V_{i}^{\prime}$ (estado futuro da variável $V_{i}$ ):

- $\quad V_{1}^{\prime}$ depende de $V 1, V 2$ e V3 e da ação tomada

- $\quad V_{2}^{\prime}$ depende de $V 1, V 2, V 3$ e $V 4$

- $V_{3}$ ' depende de $V 1, V 2, V 3, V 5$ e V6

- $V_{4}$ ' depende de V2 e V4

- $V_{5}^{\prime}$ depende de $\mathrm{V} 3, \mathrm{~V} 5$ e $V 6$

- $V_{6}^{\prime}$ depende de $V 3, V 5$ e $V 6$

Compreendida a dependência entre as variáveis, a quinta etapa trata de entender como $V_{i}^{\prime}$ é afetada pelo estado das variáveis das quais ela depende. Isto é, determinar com que configuração de variáveis e com que probabilidade atinge-se um determinado estado futuro. É importante notar que estas probabilidades são alteradas pelo estado da rede, que é uma conseqüência das ações tomadas anteriormente (ou seja, recursos imputados na rede), mas que esta relação não é direta. Uma ação tomada num determinado momento, pode alterar uma probabilidade daqui há algumas iterações (quando a marca entrada pela ação esteja em um lugar que afeta a probabilidade de algum conflito). 
Compreendida a dependência entre as variáveis, a quinta etapa trata de entender como $V_{i}$ 'é afetada pelo estado das variáveis das quais ela depende. Isto é, determinar com que configuração de variáveis e com que probabilidade atinge-se um determinado estado futuro. Suponha uma variável $V_{1}$ que pode possuir os valores $v_{11}, v_{12}$ e vazio. Para calcular a probabilidade de $V_{1}$ ' igual a $\mathrm{V}_{11}$, devem-se considerar as seguintes regras:

1. Se $V_{1}=V_{12}$, a probabilidade $P\left(V_{1}^{\prime}=v_{11}\right)=0$;

2. Se $V_{1}=v_{11}$, a probabilidade $P\left(V_{1}{ }^{\prime}=v_{11}\right)=1-\sum P\left(T_{E 11}\right)$, onde $P\left(T_{E 1 j}\right)$ são as probabilidades de disparo de cada transição de saída de $L_{1}$;

3. Se $V_{1}=$ vazio, a probabilidade $P\left(V_{1}{ }^{\prime}=v_{11}\right)=\sum P\left(T_{S 1 j}\right)$, onde $P\left(T_{S 1 j}\right)$ são as probabilidades de disparo de cada transição de entrada de $L_{1} \mathrm{e}$ receberá $v_{1}$ caso ela seja disparada.

O primeiro caso é simples de ser compreendido considerando a FPN, pois se o lugar já está ocupado por uma variável, seu estado seguinte poderá ser vazio ou com mesmo valor, não podendo receber nenhum outro valor. Note que $v_{12}$ representa qualquer valor de variável diferente do desejado e diferente de vazio.

No segundo caso, a variável desejada já se encontra no lugar, portanto a variável apenas é mantida se as transições de saída de $L_{1}$ não dispararem. Por isso o cálculo é um (100\%) menos a probabilidade de uma dessas transições dispararem.

No terceiro caso, é calculada a probabilidade do lugar estar vazio e receber a marca desejada no estado seguinte através do disparo de alguma de suas transições de entrada de $L_{1}$. Para isso as probabilidades de disparo de todas as transições cujo disparo resulte na marca $v_{11}$ em $L_{1}$ devem ser somadas.

Entendendo cada um desses casos, para cada configuração de marcas devemse buscar as probabilidades nas tabelas de probabilidades, mostradas na 
Seção 3. Porém, estas tabelas não apresentam todos os dados, e as informações faltantes devem ser obtidas a partir da observação do estado da rede.

Primeiro deve-se entender que a configuração de marcas nos lugares determina o " $D$ " de uma determinada transição, ou seja, a situação para que esta transição esteja desabilitada. Como mostrado na seção de revisão bibliográfica, uma transição estará desabilitada caso suas pré-condições e/ou pós-condições não sejam atendidas.

Além das transições de grupos de conflito, devem ser conhecidas as probabilidades de disparo das transições que não estão em conflito. Elas não constam nas tabelas de probabilidades, pois por definição, o que não apresenta conflito não precisa ser informado. As transições não estão nas tabelas são aquelas que estão habilitadas e não estão em conflito (probabilidade de disparo igual a um) ou desabilitadas (probabilidade de disparo igual a zero). Ou seja, para uma configuração que habilite uma determinada transição não envolvida em conflito, a probabilidade de disparo é igual a um, e caso a transição não esteja habilitada, sua probabilidade de disparo é igual a zero.

No exemplo da rede da Figura 21 há três transições que têm como lugar de saída $L 4$. Porém, caso se deseje saber a probabilidade do lugar $L 4$ receber a marca $A$, a probabilidade de disparo da transição T2 não deverá ser considerada porque não gera uma marca $A$, apenas a marca $E$. 


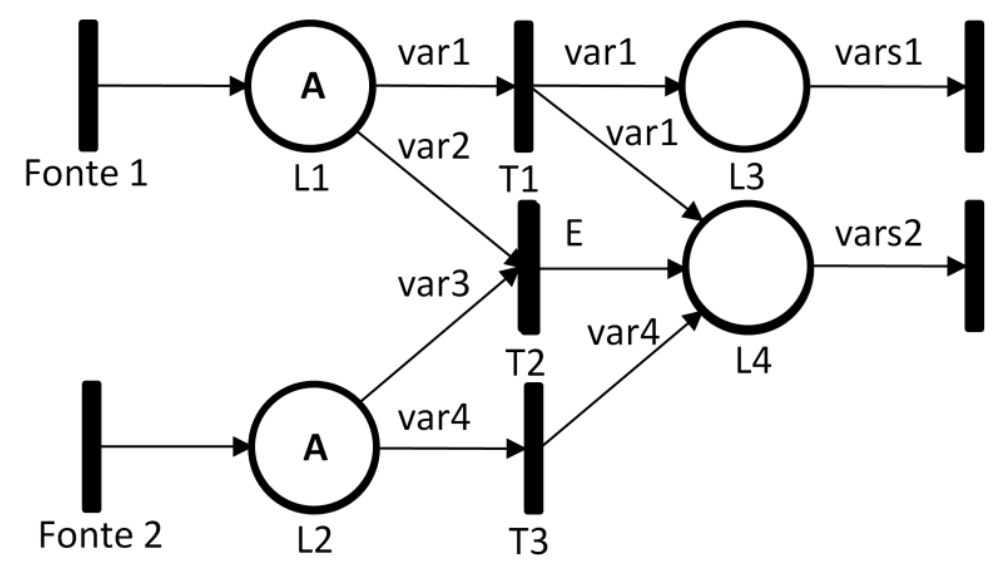

Figura 21 - Rede de Petri para exemplo do que é transições de saída para cálculo de probabilidades de estado futuro.

Entendido como funciona a associação e o cálculo das probabilidades para cada variável em cada estado, a etapa seguinte (etapa 6) consiste na definição da recompensa. Por definição, a recompensa é determinada por uma tabela que é criada junto com a modelagem em FPN, portanto, deve-se adequar esta tabela às variáveis do MDP. Supondo a Tabela 15 como sendo a tabela de recompensas da rede da Figura 19, sua conversão resulta na Tabela 16, igual à anterior, mas utilizando as variáveis do MDP.

Ao representar as recompensas em MDP, também se deve levar em consideração apenas estas variáveis, não necessitando listar as que não afetam o valor da recompensa. Os estados que não foram listados receberão valor zero, como por exemplo, o estado que combina $V_{3}, V_{4}$ e $V_{5}$ iguais a $E$. 
Tabela 15 - Tabela de recompensas da rede da Figura 19

\begin{tabular}{cccc} 
L3 & L4 & L5 & Recompensa \\
\hline \hline Vazio & E & Vazio & 5 \\
Vazio & Vazio & $B$ & 1 \\
Vazio & Vazio & $C$ & 3 \\
$A$ & Vazio & Vazio & 2 \\
A & Vazio & $B$ & 3 \\
$A$ & Vazio & $C$ & 5 \\
$B$ & Vazio & Vazio & 1 \\
$B$ & Vazio & $B$ & 2 \\
$B$ & Vazio & $C$ & 4 \\
\hline \hline
\end{tabular}

Tabela 16 - Tabela de recompensas da rede da Figura 19 convertida para MDP

\begin{tabular}{cccc}
$\boldsymbol{V}_{\mathbf{3}}$ & $\boldsymbol{V}_{\mathbf{4}}$ & $\boldsymbol{V}_{\mathbf{5}}$ & Recompensa \\
\hline \hline Vazio & $E$ & Vazio & 5 \\
Vazio & Vazio & $B$ & 1 \\
Vazio & Vazio & $C$ & 3 \\
$A$ & Vazio & Vazio & 2 \\
$A$ & Vazio & $B$ & 3 \\
$A$ & Vazio & $C$ & 5 \\
$B$ & Vazio & Vazio & 1 \\
$B$ & Vazio & $B$ & 2 \\
$B$ & Vazio & $C$ & 4 \\
\hline \hline
\end{tabular}

\section{Algoritmo}

O algoritmo para esta transformação é composto por seis etapas:

Entrada: FPN/FPNIP

Saída: MDP/MDPIP 
01. Converter todos os lugares da rede de Petri em variáveis do MDP.

02. Mapear a dependência de cada variável em relação às demais.

03. Converter a tabela de probabilidades, substituindo lugares e transições pelas variáveis do MDP.

04. Completar a tabela de probabilidades com os casos em que a probabilidade de disparo das transições é 1 ou 0 .

05. Atribuir a probabilidade associada a cada combinação $V^{\prime}$ de $V$ dado 0 estado $E$ definido pelas variáveis das quais $V$ depende da ação tomada $a$.

06. Converter a tabela de recompensas, substituindo lugares da FPN por variáveis do MDP.

Teorema:

Toda FPN pode ser convertida em um MDP/MDPIP fatorado.

Prova: Dado um estado $E$ em FPN, constrói-se um único estado $V$ de MDP/MDPIP

1. Para toda marcação $m_{i}$ do lugar $L_{i}$, constrói-se uma variável $v_{i}$.

2. Para todo o estado da FPN, a variável $v_{i}$ esta associada ao tipo de marcação $m_{i}$, portanto tem-se um estado único $\left[v_{1}, v_{2}, \ldots, v_{n}\right]$.

Dado o conjunto de transições fonte $T_{f}$ e o conjunto de marcas que são saídas destas fontes $M\left(T_{\text {fii }}\right)$ da FPN, constrói-se o conjunto de ações $F$ de MDP/MDPIP

1. Para cada combinação de marcas geradas pelas transições fonte $\left[m_{f i 1}\right.$, $m_{f i 2}, \ldots m_{f i j}$, onde $j$ é o número de transições fonte, obtém-se uma ação $f_{i}$ pertencente ao conjunto de ações do MDP/MDPIP.

2. O conjunto de todas as ações $f_{i}$ compõe o conjunto de todas as ações $F$ do MDP/MDPIP. 
Dado o conjunto de probabilidades de disparo das transições dependente do estado da rede de Petri, obtém-se o conjunto de probabilidades de evolução de estados da variável $V_{i}: P\left(V_{i} / V\right)$

1. Para cada variável que representa a probabilidade $p_{j}$ de evolução do estado $E_{i}$, constrói-se uma variável $p_{v j}$ representando a probabilidade de evolução de um estado $V i$ para um estado $V_{i}^{\prime}$ dado o disparo da transição $j$ no modelo em FPN.

2. A partir da composição de probabilidades de disparo de cada transição da FPN, obtém-se a probabilidade de evolução de um estado $V$ para um estado V': $P\left(V^{\prime} / V\right)$.

3. Para cada estado $V^{\prime}$ há apenas uma configuração de $v_{i}^{\prime}$. A soma das probabilidades de todos os estados que resultam em $v_{i}^{\prime}$ é a probabilidade e $v_{i}^{\prime}$ dado $V$ atual: $P\left(v_{i}^{\prime} / V\right)$.

Dado um conjunto de recompensas $R$ no estado $E$ em FPN, constrói-se um conjunto de recompensas $R_{v}$ de MDP/MDPIP

1. Para toda recompensa $r$ do estado $e_{i}$, constrói-se uma recompensa $r_{v}$ do estado $v_{i}$.

2. Para todo o estado da FPN, a variável $r_{v}$ possui o valor de $r$, portanto tem-se um conjunto único de recompensas $R_{v}=\left[\begin{array}{llll}r_{v 1}, & r_{v 2}, & \ldots, & N_{n}\end{array}\right]$ equivalente a $R$.

\subsection{Transformação em MDPIP}

Todas as etapas de transformação de FPN em MDP e FPNPI em MDPIPs são iguais, exceto a quarta etapa, no qual há a associação das probabilidades. 
Neste caso, como os valores não são pontuais, as tabelas de probabilidades contem seus limites inferiores e superiores, conforme visto na descrição de FPNPI.

Nesta etapa, as regras de cálculo de probabilidade de transições são alteradas. Suponha um sistema como o da Figura 20, e uma variável $V_{1}$ que pode possuir os valores $v_{11}, v_{12}$ e vazio. Para analisar a probabilidade de $V_{1}$ igual a $v_{11}$, devem-se considerar as seguintes regras:

1. Se $V_{1}=V_{12}$, a probabilidade de $V_{1}{ }^{\prime}=v_{11}$ é igual a zero;

2. Se $V_{1}=V_{11}$, o intervalo de probabilidades de $V_{1}^{\prime}=V_{11}$ é definido superiormente por $1-\sum P_{\text {inf }}\left(T_{E 1 j}\right)$, e inferiormente por $1-\sum P_{\text {sup }}\left(T_{E 1 j}\right)$. Caso $1-\sum P_{\text {sup }}\left(T_{E 1 j}\right)$ seja menor do que zero, considera-se seu limite inferior 0 valor zero;

3. Se $V_{1}=$ vazio, o intervalo probabilidade de $V_{1}^{\prime}=v_{11}$ é definido inferiormente por $\sum P_{\text {inf }}\left(T_{S 1 j(v 1)}\right)$, e superiormente por $\sum P_{\text {sup }}\left(T_{S 1 j(v 1))}\right)$, onde $P_{\text {inf }}\left(T_{E 1 j}\right)$ e $P_{\text {sup }}\left(T_{E 1 j}\right)$ são as probabilidades inferiores e superiores, respectivamente, de disparo de cada transição de saída de $L_{1}, P_{\text {inf }}\left(T_{S 1 j}\right)$ e $P_{\text {sup }}\left(T_{S 1 j}\right)$ são as probabilidades inferiores e superiores, respectivamente, de disparo de cada transição de entrada de $L_{1}$ que receberá $v_{1}$. Caso $\sum P_{\text {sup }}\left(T_{S 1 j(v 1)}\right)$ seja maior do que um (100\%), considera-se que o limite superior é um (100\%).

As três regras possuem a mesma justificativa que as regras para cálculo de probabilidades de MDPs, apenas foram adaptadas para lidar com intervalos de probabilidade. Porém, conforme explicado na seção de transformação em MDPs, neste caso também há probabilidades iguais a zero e iguais a um, que não são definidas por intervalos. Para que se adaptem ao cálculo dos intervalos de probabilidade, quando a probabilidade for zero, considera-se zero tanto para probabilidade inferior como para o superior e quando for igual a um definem-se sua probabilidade inferior e superior ambos iguais a um. 
O entendimento de que configuração de marcas nos lugares determina o " $D$ " de uma determinada transição é o mesmo explicado na Seção 4.1.

\subsection{Resultados de simulação dos casos teste}

Como a proposta deste trabalho nasceu da idéia de realizar planejamento de sistemas de manufatura expostos a incertezas, deve-se tentar resolver alguns problemas de modo a verificar se a solução de problemas convertidos é viável em relação ao tempo de resolução. Para tal utilizou-se o método de solução de MDPs e MDPIPs fatorados desenvolvido por Karina Valdivia [Delgado, Barros, Cozman\& Shirota (2009)]. A linguagem para modelagem de MDPs para a resolução por este método é o SPUDD-IP. Consideraram-se oito exemplos, os primeiros quatro expostos a probabilidades pontuais e os seguintes mantendo os mesmos modelos em rede de Petri porém com intervalos de probabilidades. Os casos teste um, dois, três e quatro constam nas Figuras 22, 23, 24 e 25 respectivamente. Os casos teste cinco, seis, sete e oito possuem os mesmos modelos em rede de Petri que casos teste um, dois, três e quatro, respectivamente. Suas tabelas de probabilidades e recompensas constam no Apêndice B.

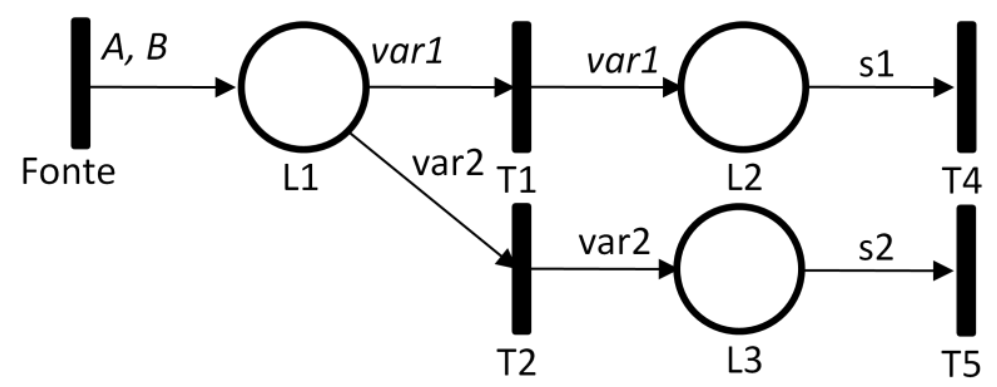

Figura 22 - Caso teste 1. 


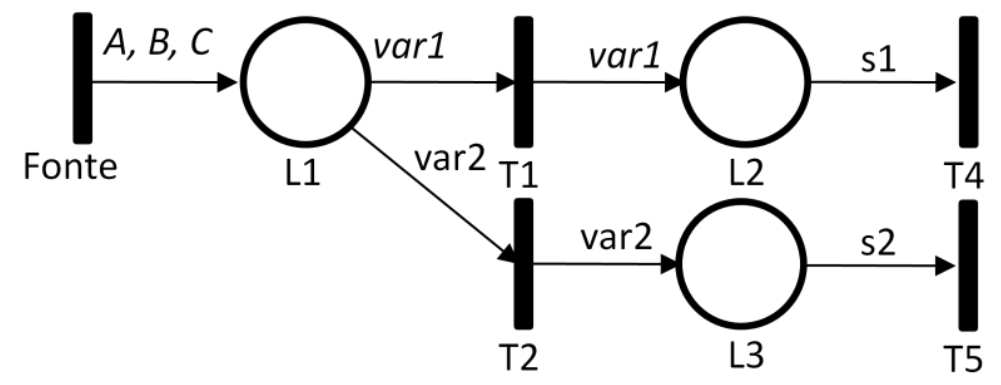

Figura 23 - Caso teste 2.

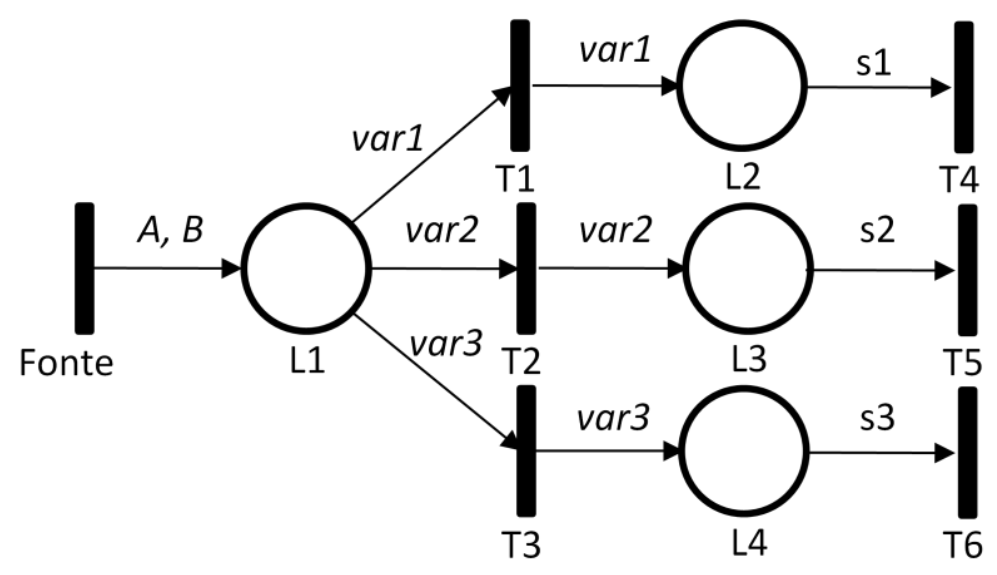

Figura 24 - Caso teste 3. 


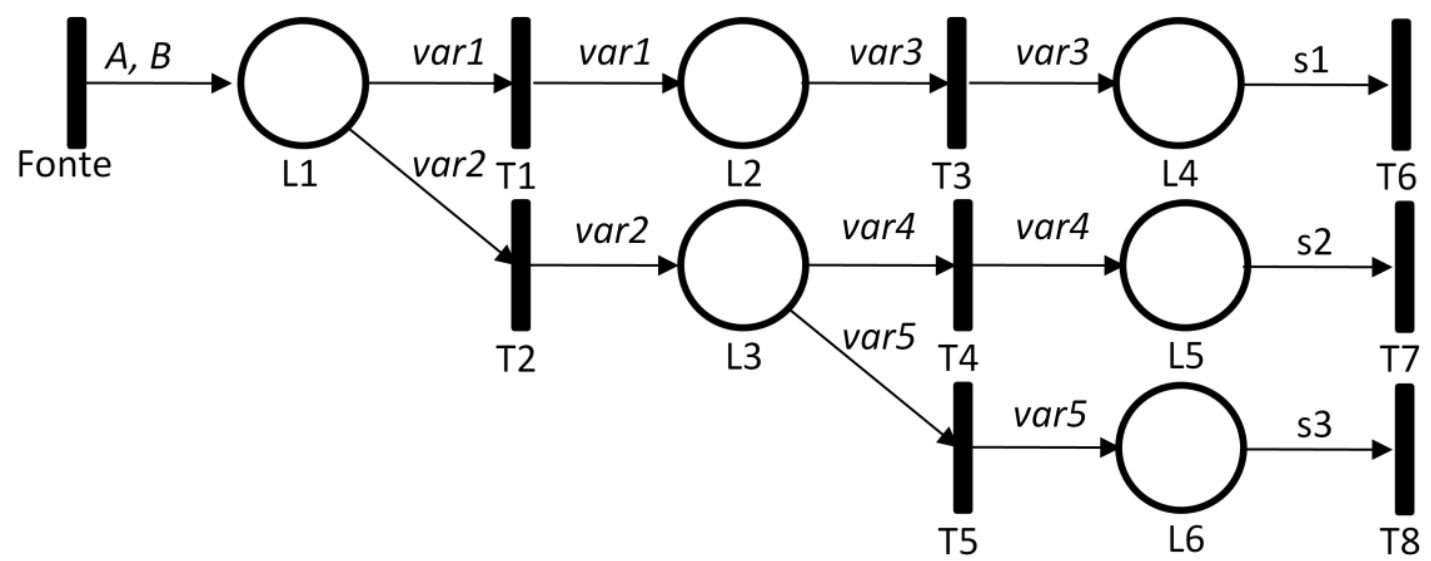

Figura 25 - Caso teste 4.

A simulação destes casos teste durou apenas alguns segundos. O que mostra que o método é viável para a solução das FPN convertidas. A Tabela 17 mostra os tempos de processamento.

Tabela 17 - Tempos de processamento dos casos exemplos propostos.

\begin{tabular}{cc} 
Exemplo & Tempo (s) \\
\hline \hline Exemplo 1 MDP & $<1$ \\
Exemplo 2 MDP & $<1$ \\
Exemplo 3 MDP & 3 \\
Exemplo 4 MDP & 13 \\
Exemplo 1 MDPIP & $<1$ \\
Exemplo 2 MDPIP & $<1$ \\
Exemplo 3 MDPIP & 6 \\
Exemplo 4 MDPIP & 13 \\
\hline \hline
\end{tabular}




\section{CONCLUSÃO}

Este trabalho atingiu seu objetivo que foi obter a transformação de rede de Petri colorida em processo de decisão markoviano com probabilidades imprecisas. Esta conversão faz com que se torne possível o planejamento de sistemas modelados em redes de Petri utilizando métodos de tomada de decisão em sistemas com comportamento estocástico.

Este trabalho atingiu seu objetivo, que era aliar as vantagens de rede de Petri às vantagens de MDP. A representação em FPN manteve-se simples e compacta, apesar da quantidade de informação embutida. Sua conversão em MDP foi possível e este se mostrou viável para a realização do planejamento da produção. Esta viabilidade foi comprovada através dos testes que comprovaram uma resolução relativamente rápida. Os testes demonstraram que mesmo para casos com imprecisão probabilística o tempo de processamento é adequado, viabilizando a utilização do método. Estabelecido que o horizonte máximo de dispêndio em uma indústria para planejamento seja de no máximo quatro horas (da determinação do mix do dia seguinte a liberação do planejamento para planta e fornecedores). E extrapolando os tempos de testes para linhas maiores, suponto um crescimento linear, este método atenderia mais de duzentas estações sem extrapolar o tempo limite disponível para planejamento.

No decorrer do desenvolvimento, foram geradas duas contribuições adicionais. A primeira é a criação da interpretação de redes de Petri, que foi nomeada redes de Petri fatorada. Esta interpretação foi vital para permitir que a conversão em MDPs fosse possível porque ela garantiu a adequação desta modelagem.

A segunda contribuição é a introdução de tabelas de probabilidades, que apresentam uma forma concisa de representar as probabilidades das diversas 
configurações dos conflitos na rede de Petri. O principal ganho associado a esta tabela é a simplicidade de representação. As probabilidades podem ser associadas à rede de Petri de modo conciso e de simples compreensão.

Apesar dos resultados obtidos, ainda há pontos para investigação futura. $O$ primeiro deles seria considerar lugares na FPN com capacidade maior que 1. Esta evolução do método aparenta ser simples, porém não é trivial pelo cuidado que se deve ter em relação ao aumento exponencial do mínimo de estados possíveis. Ao que tudo indica, o método de conversão seria o mesmo, porém talvez seja necessário algum tipo de desenvolvimento. Este desenvolvimento deve garantir que a representação dos estados se dê utilizando o menor número possível de estados.

Um passo seguinte seria retirar a restrição associada às probabilidades imprecisas. A restrição indicada no Capítulo 3 é matemática, por impossibilidade de o método tratar alguns casos. Para que haja a liberdade na modelagem dessas probabilidades com maior fidelidade ao sistema modelado, deve-se retirar esta restrição. Retirar esta restrição não é trivial porque requer o desenvolvimento de métodos para lidar com esta imprecisão irrestrita.

Um terceiro desenvolvimento seria associar aos arcos orientados da FPN relações tipo fórmulas e não apenas variáveis e valores fixos. Este desenvolvimento necessita o mesmo cuidado em relação a capacidade dos lugares da rede de Petri, pois pode resultar em aumento de estados. Além disso, deve-se entender todo o tipo de marca processada pelas transições associadas aos arcos e como tratar cada um destes tipos.

Um quarto ponto seria associar a representação de tempo às transições da FPN. Este é um ponto importante, e que aumenta o poder de modelagem. Não é trivial e pode-se dizer que envolve a concepção de uma nova classe de rede. Deve-se compreender como representar este tempo que afeta as evoluções de estado no MDP. Para que tal associação seja possível, também é necessário 
que seja proposta um novo tipo de redes de Petri, que atenda todos os requisitos de modelagem para conversão.

Além disso, resta ainda aplicar o que foi desenvolvido a um sistema real. Isto é, no presente trabalho o foco foi na verificação e validação de um método que gera o modelo a ser usado no planejamento da produção de um sistema de manufatura, e os testes e simulações foram realizados apenas para confirmar a viabilidade conceitual da proposta. Seria necessário agora realizar testes para comprovar se realmente a modelagem em rede de Petri proposta é viável e simples, e se o MDP realmente é capaz de realizar o planejamento de produção de um sistema de manufatura real. 


\section{REFERÊNCIAS BIBLIOGRAFICAS}

ANDERSON D. M. Build-to-otder and Mass Customization. CIM Press, 2004.

BERTSEKAS D. P.; TSITSIKLIS J. N. An analysis of stochastic shortest path problems. Math. Oper. Res., 16(3):580\{595, 1991

BOUTILIER C.; DEAN T.; HANKS S. Decision-theoretic planning: structural assumptions and computational leverage. Journal of Artificial Intelligence Research, 1999, pg 1-94.

DELGADO K. V.; BARROS L. N.; COZMAN F. G.; SHIROTA R. Representing and solving factored Markov decision processes with imprecise probabilities. Durham, United Kingdom: 6th International Symposium on Imprecise Probability: Theories and Applications, 2009, pg 169-178.

DELGADO K. V.; SANNER S.; BARROS L. N.; COZMAN F. G.Efficient solutions to factored MDPs with imprecise transition probabilities. Thessaloniki, Greece: In Proceedings of the Nineteenth International Conference on Automated Planning and Scheduling (ICAPS-09), 2009.

DESROCHERS A. A.; AL-JAAR R. Y. Applications of Petri Nets in Manufacturing Systems. IEEE Press, 1995

HASS P. J. Stochastic Petri nets for modeling and simulation. Washington: Winter Simulation Conference, 2004, pg 101-112

HAYES R.H.; PISANO G. P. Manufacturing Strategy: at the intersection of two paradigm shifts. Production and Operations Management, 1996, pg 25-41.

JENSEN K. An introduction to the practical use of colored Petri nets. Berlim, Heideberg, Nova lorque: Springer Verlag, 1998, pg.237-292. 
JENSEN K. An introduction to the theoretical aspects of colored Petri Nets. Lecture Notes in Computer Science vol. 803, Springer Verlag, 1994, pg.230272.

JENSEN K.; KRISTENSEN L. M.; CRISTENSEN S. The practioner's guide to coloured Petri nets. Berlim, Heideberg, Nova lorque: Springer Verlag, 1998, pg.98-132.

MARSAN M. A.; BALBO G.; CONTE G.; DONATELLI S.; FRANCESCHINIS G. Modeling with Generalized Stochastic Petri Nets. John Wiley and Sons, 1995.

MILLER D. M.; PARK Y. Simulation and analysis of an automotive assembly operation. SAE, 1998, pg 338-444.

MIYAGI P. E. Controle Programavel. Editora Edgard Blücher, 1996

PUTERMAN, M. L. Markov Decision Processes. Wiley series in probability and mathematical statistics. New York: John Wiley and Sons, 1994

RUSSEL S.; NORVIG P. Inteligência Artificial. Editora Campus, 2004.

TREVIZAN F. W.; BARROS L. N.; COZMAN F. G. Unifying nondeterministic and probabilistic planning through imprecise Markov decision processes. Ribeirão Preto: Brazilian Symposium on Artificial Intelligence, 2006, p. 502-511.

TREVIZAN F. W.; COZMAN F. G.; BARROS L. N. Nondeterministic mixed probabilistic and factored planning through Markov decision processes with set-valued transitions. Australia: Workshop: A Reality Check for Planning and Scheduling under Uncertainty at ICAPS 2008.

TREVISAN F. W.; COZMAN F. G.; BARROS L. N. Planning under risk and knightian uncertainty. Hyderabad: International Joint Conference on Artificial Intelligence, 2007, pg. 2023-2028.

ZHOU M.; VENKATESH K. Modeling, Simulation and Control of flexible manufacturing systems - A Petri Net approach. World Scientific, 1999. 


\section{APÊNDICE A}

A representação original dos FMDPIPs no formato SPUDD-IP [Delgado, Sanner, Barros \& Cozman (2009)] se dá com a definição de sete elementos, porém, para o caso em questão apenas cinco são necessários:

1. Lista das variáveis de estado

2. Função de transição de probabilidades para cada ação e variável de estado

3. Função de recompensas

4. Fator de desconto

5. Tolerância

O primeiro elemento consiste na listagem das variáveis cuja combinação de valores configura o estado do sistema. Uma exigência para esta modelagem é que todas as variáveis sejam binárias. No exemplo ilustrado na Figura $1 \mathrm{~A}$ há um tanque com três sensores (Sensor S1, Sensor S2 e Sensor S3), cujos sinais indicam o nível do tanque. Pode-se considerar que o sinal de cada sensor é uma variável de estado (S1, S2 e S3). Este sinal é binário, indica se o nível de água atingiu o sensor ou não. A descrição das variáveis no SPUDD-IP seria:

variables (S1 S2 S3) 


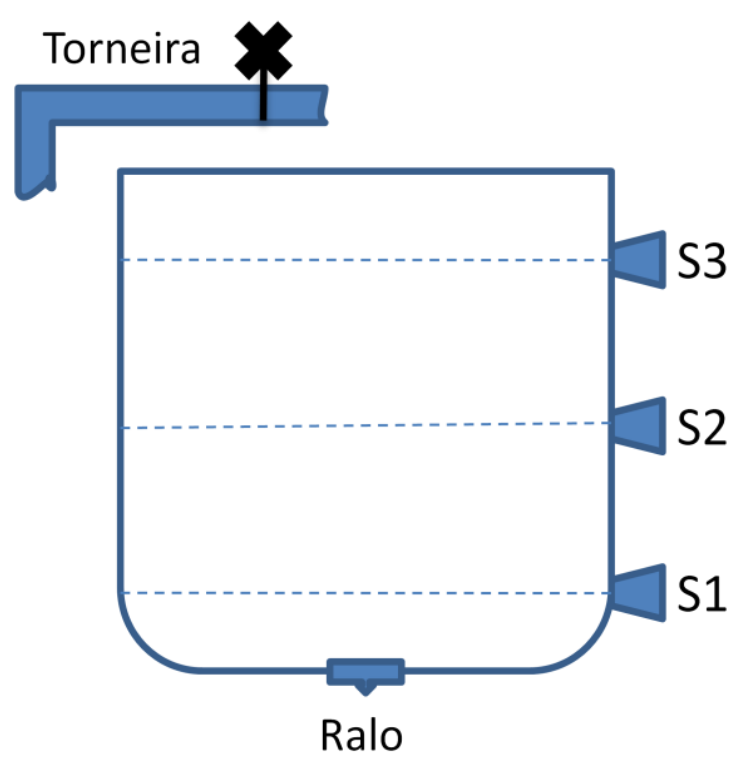

Figura 1A - llustração do exemplo do tanque com sensores

A combinação destas variáveis representa os estados da forma representada na Tabela $1 \mathrm{~A}$. Note que há alguns estados impossíveis se serem alcançados. A forma como tratá-los é mostrada mais a frente nesta seção.

Tabela 1A - Estados e representação com as variáveis de estado do exemplo de tanques com sensores.

\begin{tabular}{llll} 
Estado & S1 & S2 & S3 \\
\hline \hline Vazio & 0 & 0 & 0 \\
Nível Baixo & 1 & 0 & 0 \\
Nível Médio & 1 & 1 & 0 \\
Nível Alto & 1 & 1 & 1 \\
Estado impossível & 0 & 1 & 0 \\
Estado impossível & 0 & 0 & 1 \\
Estado impossível & 0 & 1 & 1 \\
Estado impossível & 1 & 0 & 1 \\
\hline \hline
\end{tabular}


O segundo elemento, função de transição de probabilidades, consiste em descrever as probabilidades da evolução de cada variável dada uma ação e o estado do sistema. Utilizando o exemplo da Figura 1A, supondo que para as três variáveis de estado que existem (S1, S2 e S3) podem ser aplicadas duas ações: Abrir a torneira e abrir o ralo, $A 1$ e $A 2$ respectivamente. Todas as variáveis dependem das ações e das demais variáveis, do modo descrito na Tabela 2A. Nesta tabela Nível $t$ representa o nível do tanque atual e Nível t'o nível no instante seguinte. 
Tabela 2A - Estados e suas representações com as variáveis de estado do exemplo de tanques.

\begin{tabular}{|c|c|c|c|}
\hline Nível $t^{\prime}$ & Nível $t$ & Ação & Probabilidade \\
\hline Vazio & Vazio & Abrir ralo & $100 \%$ \\
\hline Vazio & Baixo & Abrir ralo & $65 \%$ \\
\hline Vazio & Médio & Abrir ralo & $10 \%$ \\
\hline Vazio & Alto & Abrir ralo & $1 \%$ \\
\hline Baixo & Vazio & Abrir ralo & $0 \%$ \\
\hline Baixo & Baixo & Abrir ralo & $35 \%$ \\
\hline Baixo & Médio & Abrir ralo & $60 \%$ \\
\hline Baixo & Alto & Abrir ralo & $20 \%$ \\
\hline Médio & Vazio & Abrir ralo & $0 \%$ \\
\hline Médio & Baixo & Abrir ralo & $0 \%$ \\
\hline Médio & Médio & Abrir ralo & $25 \%$ \\
\hline Médio & Alto & Abrir ralo & $75 \%$ \\
\hline Alto & Vazio & Abrir ralo & $0 \%$ \\
\hline Alto & Baixo & Abrir ralo & $0 \%$ \\
\hline Alto & Médio & Abrir ralo & $0 \%$ \\
\hline Alto & Alto & Abrir ralo & $4 \%$ \\
\hline Vazio & Vazio & Abrir torneira & $10 \%$ \\
\hline Vazio & Baixo & Abrir torneira & $0 \%$ \\
\hline Vazio & Médio & Abrir torneira & $0 \%$ \\
\hline Vazio & Alto & Abrir torneira & $0 \%$ \\
\hline Baixo & Vazio & Abrir torneira & $80 \%$ \\
\hline Baixo & Baixo & Abrir torneira & $25 \%$ \\
\hline Baixo & Médio & Abrir torneira & $0 \%$ \\
\hline Baixo & Alto & Abrir torneira & $0 \%$ \\
\hline Médio & Vazio & Abrir torneira & $7 \%$ \\
\hline Médio & Baixo & Abrir torneira & $55 \%$ \\
\hline Médio & Médio & Abrir torneira & $50 \%$ \\
\hline Médio & Alto & Abrir torneira & $0 \%$ \\
\hline Alto & Vazio & Abrir torneira & $3 \%$ \\
\hline Alto & Baixo & Abrir torneira & $20 \%$ \\
\hline Alto & Médio & Abrir torneira & $50 \%$ \\
\hline Alto & Alto & Abrir torneira & $100 \%$ \\
\hline
\end{tabular}


A partir desta tabela obtém-se a função de transição de probabilidades para cada variável. Por exemplo, para $S 1^{\prime}=1$ seria a exibida na Tabela $3 A$.

Tabela 3A - Função de transição de probabilidades para $S 1$ '=1 do exemplo de tanque.

\begin{tabular}{ccccc} 
S1 & S2 & S3 & Ação & Probabilidade \\
\hline \hline 0 & 0 & 0 & Abrir o ralo & $0 \%$ \\
1 & 0 & 0 & Abrir o ralo & $35 \%$ \\
1 & 1 & 0 & Abrir o ralo & $90 \%$ \\
1 & 1 & 1 & Abrir o ralo & $99 \%$ \\
0 & 0 & 0 & Abrir a torneira & $90 \%$ \\
1 & 0 & 0 & Abrir a torneira & $100 \%$ \\
1 & 1 & 0 & Abrir a torneira & $100 \%$ \\
1 & 1 & 1 & Abrir a torneira & $100 \%$ \\
\hline \hline
\end{tabular}

Esta função transição de probabilidades é traduzida na linguagem do SPUDDIP da seguinte forma:

action AbrirRalo

S1

(S1

(S2

$(S 3([1])([1]))$

$(S 3([0])([1])))$

(S2

(S3 ([0]) ([0]))

(S3 ([0]) ([0.9]))))

Endaction

action AbrirTorneira

S1

(S1

(S2

(S3 ([.99]) ([.9] ))

(S3 ([0]) ([.35])))

(S2

(S3 ([0]) ([0]))

(S3 ([O]) ([0] ))))

Endaction 
Para entender o layout de input de dados de variáveis, a Figura 2A ilustra que trechos pertencem a que valores de variáveis. No quadro a esquerda, mostra que o primeiro grupo de probabilidades que segue $S 1$, é de "S1 é igual a um" e o seguinte "S1 é igual a zero". No quadro do centro pode-se ver que o mesmo padrão é seguido, assim que $S 2$ é declarado, o primeiro grupo de probabilidades é "S2 é igual a um" e o seguinte "S2 é igual a zero", só que neste caso, este padrão aparece duas vezes, pois $S 2$ é declarado duas vezes. A variável S2 foi declarada duas vezes, pois seguia apenas uma variável (S1). Por fim, no quadro à direita, a primeira probabilidade de S3 é "S3 é igual a um", seguida de "S3 igual a zero", e neste caso o padrão se repete quatro vezes porque há duas variáveis anteriores $\left(2^{2}\right)$. Este padrão é seguido independente do número de variáveis, o primeiro grupo de probabilidades seguido da declaração da variável é sempre dela igual a um, e o seguinte zero.

S1

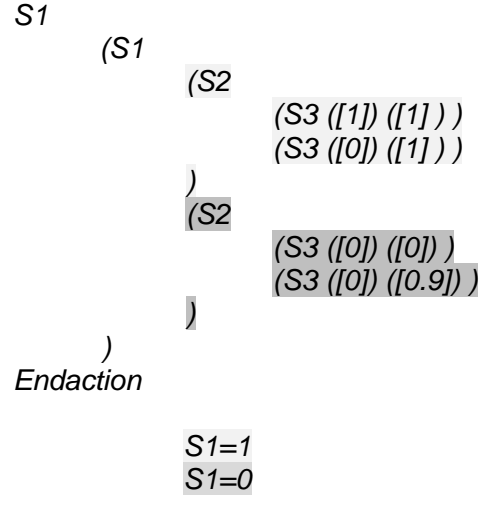

S1

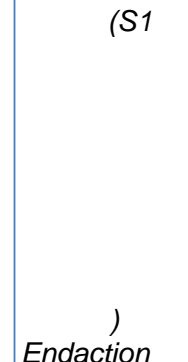

(S2

)

(S2

)

Endaction
$(S 3([1])([1]))$

(S3 ([0]) ([1]))

(S3 ([0]) ([0]))

$(S 3([0])([0.9]))$
S1

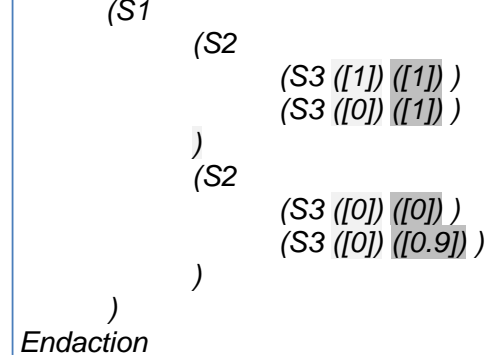

$S 3=1$

$\mathrm{S} 3=0$

Figura 2A - Layout de input do valor das probabilidades

Entendido como é o layout das probabilidades, é importante notar que foram marcados com " $O$ " os estados impossíveis, por exemplo o caso em que $S 1$ é igual a zero, S2 é igual a um e S3 é igual a um. 
No exemplo, os valores de probabilidades são fixos, mas poderiam ser substituídos por intervalos de probabilidade. Para representar estes intervalos de probabilidade, inicialmente se substituem estas probabilidades que não são fixas por polinômios que representem esta probabilidade. Por exemplo, ao invés de [.99] pode-se colocar [ [ $\left.{ }^{*} p 1\right]$. Substituindo as probabilidades pelos intervalos de probabilidades na Tabela 4A, obtém-se o seguinte exemplo de representação no SPUDD-IP:

action AbrirRalo

S1 (S1

(S2

(S3 ([1]) ([1]))

$(S 3([0])([1])))$

(S2

(S3 ([0]) ([0] ) )

(S3 ([0]) ([1*p1]))))

Endaction

action AbrirTorneira

S1

(S1

(S2

(S3 ([1 $\left.\left.\left.{ }^{*} p 2\right]\right)\left(\left[1^{*} p 1\right]\right)\right)$

(S3 ([0]) ([1* $\left.\left.\left.\left.{ }^{*} 3\right]\right)\right)\right)$

(S2

(S3 ([0]) ([0] ))

(S3 ([0]) ([0] ))))

Endaction 
Tabela 4A - Função de transição de probabilidades para $S 1$ '=1 com intervalos de probabilidade do exemplo do tanque.

\begin{tabular}{ccccc} 
S1 & S2 & S3 & Ação & Probabilidade \\
\hline \hline 0 & 0 & 0 & Abrir o ralo & $0 \%$ \\
1 & 0 & 0 & Abrir o ralo & $30 \%-40 \%$ \\
1 & 1 & 0 & Abrir o ralo & $80 \%-100 \%$ \\
1 & 1 & 1 & Abrir o ralo & $98 \%-100 \%$ \\
0 & 0 & 0 & Abrir a torneira & $80 \%-100 \%$ \\
1 & 0 & 0 & Abrir a torneira & $100 \%$ \\
1 & 1 & 0 & Abrir a torneira & $100 \%$ \\
1 & 1 & 1 & Abrir a torneira & $100 \%$ \\
\hline \hline
\end{tabular}

Após lista as funções de transições de probabilidades, deve-se definir as variáveis probabilísticas utilizadas nesta descrição. Por exemplo, para o pequeno trecho da Tabela 4A fica:

$$
\begin{aligned}
& \text { constraints } \\
& \text { ( } \\
& (p 1>=0.8) \\
& \text { (p1<=1) } \\
& \text { (p2 > } 0.98 \text { ) } \\
& \text { (p2 }<=1 \text { ) } \\
& \text { (p3 }>=0.3 \text { ) } \\
& \text { ) } \\
& \text { (p3 }<=0.4 \text { ) }
\end{aligned}
$$

Apesar das constraints completarem a descrição das funções de transições de probabilidades, elas são listadas apenas após a listagem das recompensas. Recompensas com valor positivo são recompensas propriamente ditas e em caso de valor negativo, representam custos. A listagem das recompensas ocorre seguindo a mesma lógica para as funções de transição de probabilidades. Supondo que a recompensa seja de 3 (três) para cada estado 
"cheio" atingido e 1 (um) para cada estado "Médio" atingido, têm-se a seguinte função de recompensas para este exemplo:

reward

(S1

$(S 2$

(S3 (3) (1))

$(S 3(0)(0)))$

(S2

$(S 3(0)(0))$

$(S 3(0)(0))))$

Isto representa as seguintes recompensas para os estados:

- $S 1=1, S 2=1$ e $S 3=1$ a recompensa é 3

- $S 1=1, S 2=1$ e $S 3=0$ a recompensa é 1

- $S 1=1, S 2=0$ e $S 3=1$ a recompensa é 0

- $S 1=1, S 2=0$ e $S 3=0$ a recompensa é 0

- $S 1=0, S 2=1$ e $S 3=1$ a recompensa é 0

- $S 1=0, S 2=1$ e $S 3=0$ a recompensa é 0

- $S 1=0, S 2=0$ e $S 3=1$ a recompensa é 0

- $S 1=0, S 2=0$ e $S 3=0$ a recompensa é 0

Para que o planejamento possua infinitas interações e nunca encontre a politica, define-se um fator de desconto, quanto maior, mais se valoriza os primeiros estados em relação aos seguintes.

discount 0.025

E por último é determinada a tolerância, que representa a tolerância a ser considerada nos cálculos.

tolerance 0.01 


\section{APÊNDICE B}

As Tabelas 1B e 2B, de probabilidades e recompensas respectivamente, foram utilizadas para o primeiro caso teste.

Tabela 1B - Tabela de probabilidades caso teste 1

\begin{tabular}{ccc}
$\mathbf{L 1}$ & $\boldsymbol{P}(\boldsymbol{T} 1)$ & $\boldsymbol{P}(\mathbf{T} \mathbf{2})$ \\
\hline \hline $\boldsymbol{A}$ & 0.61 & .39 \\
$\boldsymbol{B}$ & 0.58 & 0.42 \\
\hline \hline
\end{tabular}

Tabela 2B - Tabela de recompensas caso teste 1

\begin{tabular}{ccc} 
L2 & L3 & Recompensa \\
\hline \hline- & $\boldsymbol{A}$ & 1 \\
- & $\boldsymbol{B}$ & 1 \\
$\boldsymbol{A}$ & - & 1 \\
$\boldsymbol{A}$ & $\boldsymbol{A}$ & 2 \\
$\boldsymbol{A}$ & $\boldsymbol{B}$ & 2 \\
$\boldsymbol{B}$ & - & 1 \\
$\boldsymbol{B}$ & $\boldsymbol{A}$ & 2 \\
$\boldsymbol{B}$ & $\boldsymbol{B}$ & 2 \\
\hline \hline
\end{tabular}

As Tabelas 3B e 4B, de probabilidades e recompensas respectivamente, foram utilizadas para o segundo caso teste. 
Tabela 3B - Tabela de probabilidades caso teste 2

\begin{tabular}{ccc}
$L 1$ & $P(T 1)$ & $P(T 2)$ \\
\hline \hline$A$ & 0.61 & .39 \\
$B$ & 0.58 & 0.42 \\
$C$ & 0.6 & 0.4 \\
\hline \hline
\end{tabular}

Tabela 4B - Tabela de recompensas caso teste 2

\begin{tabular}{ccc} 
L2 & L3 & Recompensa \\
\hline \hline- & $\boldsymbol{A}$ & 1 \\
- & $\boldsymbol{B}$ & 1 \\
- & $\boldsymbol{C}$ & 1 \\
$\boldsymbol{A}$ & - & 1 \\
$\boldsymbol{A}$ & $\boldsymbol{A}$ & 2 \\
$\boldsymbol{A}$ & $\boldsymbol{B}$ & 2 \\
$\boldsymbol{A}$ & $\boldsymbol{C}$ & 2 \\
$\boldsymbol{B}$ & - & 1 \\
$\boldsymbol{B}$ & $\boldsymbol{A}$ & 2 \\
$\boldsymbol{B}$ & $\boldsymbol{B}$ & 2 \\
$\boldsymbol{B}$ & $\boldsymbol{C}$ & 2 \\
$\boldsymbol{C}$ & - & 1 \\
$\boldsymbol{C}$ & $\boldsymbol{A}$ & 2 \\
$\boldsymbol{C}$ & $\boldsymbol{B}$ & 2 \\
$\boldsymbol{C}$ & $\boldsymbol{C}$ & 2 \\
\hline \hline
\end{tabular}

As Tabelas 5B e 6B, de probabilidades e recompensas respectivamente, foram utilizadas para o terceiro caso teste. 
Tabela 5B - Tabela de probabilidades caso teste 3

\begin{tabular}{cccc}
$L 1$ & $P(T 1)$ & $P(T 2)$ & $P(T 3)$ \\
\hline \hline $\boldsymbol{A}$ & 0.683 & 0.317 & $\boldsymbol{D}$ \\
$\boldsymbol{A}$ & 0.775 & $\boldsymbol{D}$ & 0.225 \\
$\boldsymbol{A}$ & $\boldsymbol{D}$ & 0.61 & 0.39 \\
$\boldsymbol{A}$ & 0.626 & 0.297 & 0.077 \\
$\boldsymbol{B}$ & 0.633 & 0.367 & $\boldsymbol{D}$ \\
$\boldsymbol{B}$ & 0.3 & $\boldsymbol{D}$ & 0.7 \\
$\boldsymbol{B}$ & $\boldsymbol{D}$ & 0.58 & 0.42 \\
$\boldsymbol{B}$ & 0.546 & 0.147 & 0.306 \\
\hline \hline
\end{tabular}


Tabela 6B - Tabela de recompensas caso teste 3

\begin{tabular}{cccc} 
L2 & L3 & L4 & Recompensa \\
\hline \hline- & - & $A$ & 1 \\
- & - & $B$ & 2 \\
- & $A$ & - & 1 \\
- & $A$ & $A$ & 2 \\
- & $A$ & $B$ & 3 \\
- & $B$ & - & 2 \\
- & $B$ & $A$ & 3 \\
- & $B$ & $B$ & 4 \\
$A$ & - & - & 1 \\
$A$ & - & $A$ & 2 \\
$A$ & - & $B$ & 3 \\
$A$ & $A$ & - & 2 \\
$A$ & $A$ & $A$ & 3 \\
$A$ & $A$ & $B$ & 4 \\
$A$ & $B$ & - & 3 \\
$A$ & $B$ & $A$ & 4 \\
$A$ & $B$ & $B$ & 5 \\
$B$ & - & - & 2 \\
$B$ & - & $A$ & 3 \\
$B$ & - & $B$ & 4 \\
$B$ & $A$ & - & 3 \\
$B$ & $A$ & $A$ & 4 \\
$B$ & $A$ & $B$ & 5 \\
$B$ & $B$ & - & 4 \\
$B$ & $B$ & $A$ & 5 \\
$B$ & $B$ & $B$ & 6 \\
\hline \hline
\end{tabular}

As Tabelas 7B, 8B e 9B, as suas primeiras de probabilidades e a terceira de recompensas, foram utilizadas para o quarto caso teste. 
Tabela 7B - Tabela de probabilidades caso teste 4

\begin{tabular}{ccc} 
L1 & $P($ T1 $)$ & $P($ T2 $)$ \\
\hline \hline$A$ & 0.61 & .39 \\
$B$ & 0.58 & 0.42 \\
\hline \hline
\end{tabular}

Tabela 8B - Tabela de probabilidades caso teste 4

\begin{tabular}{ccc} 
L3 & $P($ T4 $)$ & $P($ T5 $)$ \\
\hline \hline A & 0.72 & .28 \\
$B$ & 0.66 & 0.34 \\
\hline \hline
\end{tabular}


Tabela 9B - Tabela de recompensas caso teste 4

\begin{tabular}{cccc} 
L4 & L5 & L6 & Recompensa \\
\hline \hline- & - & $A$ & 1 \\
- & - & $B$ & 2 \\
- & $A$ & - & 1 \\
- & $A$ & $A$ & 2 \\
- & $A$ & $B$ & 3 \\
- & $B$ & - & 2 \\
- & $B$ & $A$ & 3 \\
- & $B$ & $B$ & 4 \\
$A$ & - & - & 1 \\
$A$ & - & $A$ & 2 \\
$A$ & - & $B$ & 3 \\
$A$ & $A$ & - & 2 \\
$A$ & $A$ & $A$ & 3 \\
$A$ & $A$ & $B$ & 4 \\
$A$ & $B$ & - & 3 \\
$A$ & $B$ & $A$ & 4 \\
$A$ & $B$ & $B$ & 5 \\
$B$ & - & - & 2 \\
$B$ & - & $A$ & 3 \\
$B$ & - & $B$ & 4 \\
$B$ & $A$ & - & 3 \\
$B$ & $A$ & $A$ & 4 \\
$B$ & $A$ & $B$ & 5 \\
$B$ & $B$ & - & 4 \\
$B$ & $B$ & $A$ & 5 \\
$B$ & $B$ & $B$ & 6 \\
\hline \hline
\end{tabular}

Para o caso teste 5, deve-se considerar a mesma tabela de recompensas que 0 caso teste 1 (Tabela 2B), porém a tabela de probabilidades é a Tabela 10B. 
Tabela 10B - Tabela de probabilidades caso teste 5

\begin{tabular}{ccccc}
$\mathbf{L 1}$ & $\boldsymbol{P}_{\text {inf }}(\mathrm{T1})$ & $\boldsymbol{P}_{\text {sup }}(\mathrm{T1})$ & $\boldsymbol{P}_{\text {inf }}(\mathrm{T} 2)$ & $\boldsymbol{P}_{\text {sup }}(\mathrm{T} 2)$ \\
\hline \hline $\boldsymbol{A}$ & 0.4 & 0.8 & 0.3 & 0.5 \\
B & 0.5 & 0.66 & 0.4 & 0.44 \\
\hline \hline
\end{tabular}

Para o caso teste 6 , deve-se considerar a mesma tabela de recompensas que 0 caso teste 2 (Tabela B4), porém a tabela de probabilidades é a Tabela B11.

Tabela 11B - Tabela de probabilidades caso teste 6

\begin{tabular}{ccccc}
$L 1$ & $\boldsymbol{P}_{\text {inf }}(\mathbf{T 1})$ & $\boldsymbol{P}_{\text {sup }}(\mathbf{T 1})$ & $\boldsymbol{P}_{\text {inf }}(\mathrm{T2})$ & $\boldsymbol{P}_{\text {sup }}(\mathrm{T} 2)$ \\
\hline \hline $\boldsymbol{A}$ & 0.55 & 0.67 & 0.3 & 0.48 \\
$\boldsymbol{B}$ & 0.38 & 0.78 & 0.39 & 0.45 \\
$\boldsymbol{C}$ & 0.5 & 0.7 & 0.3 & 0.5 \\
\hline \hline
\end{tabular}

Para o caso teste 7 , deve-se considerar a mesma tabela de recompensas que 0 caso teste 3 (Tabela 6B), porém a tabela de probabilidades é a Tabela 12B.

Tabela 12B - Tabela de probabilidades caso teste 7

\begin{tabular}{ccccccc}
$\boldsymbol{L 1}$ & $\boldsymbol{P}_{\text {inf }}(\boldsymbol{T 1})$ & $\boldsymbol{P}_{\text {sup }}(\boldsymbol{T 1})$ & $\boldsymbol{P}_{\text {inf }}(\mathbf{T 2})$ & $\boldsymbol{P}_{\text {sup }}(\mathrm{T2})$ & $\boldsymbol{P}_{\text {inf }}(\mathbf{T 3})$ & $\boldsymbol{P}_{\text {sup }}(\boldsymbol{T} 3)$ \\
\hline \hline $\boldsymbol{A}$ & 0.65 & 0.716 & 0.3 & 0.334 & $\boldsymbol{D}$ & $\boldsymbol{D}$ \\
$\boldsymbol{A}$ & 0.6 & 0.95 & $\boldsymbol{D}$ & $\boldsymbol{D}$ & 0.2 & 0.25 \\
$\boldsymbol{A}$ & $\boldsymbol{D}$ & $\boldsymbol{D}$ & 0.41 & 0.81 & 0.35 & 0.43 \\
$\boldsymbol{A}$ & 0.55 & 0.702 & 0.25 & 0.334 & 0.05 & 0.104 \\
$\boldsymbol{B}$ & 0.6 & 0.666 & 0.334 & 0.4 & $\boldsymbol{D}$ & $\boldsymbol{D}$ \\
$\boldsymbol{B}$ & 0.2 & 0.4 & $\boldsymbol{D}$ & $\boldsymbol{D}$ & 0.5 & 0.9 \\
$\boldsymbol{B}$ & $\boldsymbol{D}$ & $\boldsymbol{D}$ & 0.5 & 0.66 & 0.3 & 0.54 \\
$\boldsymbol{B}$ & 0.5 & 0.592 & 0.1 & 0.194 & 0.212 & 0.4 \\
\hline \hline
\end{tabular}


Para o caso teste 8, deve-se considerar a mesma tabela de recompensas que 0 caso teste 4 (Tabela 9B), porém as tabelas de probabilidades são as Tabelas 13B e 14B.

Tabela 13B - Tabela de probabilidades caso teste 8

\begin{tabular}{ccccc} 
L1 & $\boldsymbol{P}_{\text {inf }}(\boldsymbol{T 1})$ & $\boldsymbol{P}_{\text {sup }}(\boldsymbol{T 1})$ & $\boldsymbol{P}_{\text {inf }}(\mathbf{T 2})$ & $\boldsymbol{P}_{\text {sup }}(\mathbf{T} 2)$ \\
\hline \hline $\boldsymbol{A}$ & 0.52 & 0.8 & 0.2 & .58 \\
$\boldsymbol{B}$ & 0.5 & 0.76 & 0.3 & 0.54 \\
\hline \hline
\end{tabular}

Tabela 14B - Tabela de probabilidades caso teste 8

\begin{tabular}{ccccc} 
L3 & $\boldsymbol{P}_{\text {inf }}($ T4 $)$ & $\boldsymbol{P}_{\text {sup }}($ T4 $)$ & $\boldsymbol{P}_{\text {inf }}($ T5) & $\boldsymbol{P}_{\text {sup }}($ T5 $)$ \\
\hline \hline $\boldsymbol{A}$ & 0.54 & 0.9 & 0.24 & 0.32 \\
B & 0.6 & 0.75 & 0.25 & 0.43 \\
\hline \hline
\end{tabular}




\section{APÊNDICE C}

Nesta seção há uma demonstração de como implementar a transformação. A transformação definida no Capítulo 4 é realizada descrevendo o MDP fatorado no formato dos SPUDD-IP. Para descrever este sistema, devem-se considerar algumas peculiaridades de representação da entrada deste sistema. Nesta seção é abordado como se representam os MDPs e MDPIPs fatorados de modo que possam ser resolvidos pelo método desenvolvido por Karina Valdivia [Delgado, Barros, Cozman \& Shirota (2009)].

\section{Transformação em MDP}

Nesta seção apresentam-se as etapas de modelagem na linguagem de entrada do método, que é composta por seis etapas:

1. Listagem das variáveis de estado

2. Definição das ações

3. Definição das funções de transição por estado e ação

4. Definição das recompensas

5. Definição do fator de desconto

6. Definição da tolerância

A primeira etapa consiste em listar as variáveis de estado. Porém esta listagem na linguagem (SPUDD-IP) não é tão trivial como demonstrada na Seção 4. O que dificulta esta listagem é o fato das variáveis deverem ser obrigatoriamente binárias. Para se garantir 0 atendimento desta restrição deve-se realizar a binarização das variáveis. 
No exemplo mostrado na Figura 18, foi estabelecido que o MDP fatorado possui três variáveis de estado $V_{1}, V_{2}$ e $V_{3}$. A variável $V_{3}$ pode possuir os valores $A$ ou vazio, ou seja, ela é facilmente binarizável, basta considerar uma equivalência entre ela e sua versão binarizada $V_{b 3}$. Se $V_{b 3}$ é igual a um, considera-se $V_{3}$ igual a $A$ e se $V_{b 3}$ é igual a zero, então $V_{3}$ é igual a vazio. Porém, $V_{1}$ e $V_{2}$ podem receber os valores $A, B, C$ e vazio, ou seja, caracterizando uma variável não binária. Deve-se aplicar uma binarização a estas variáveis.

O primeiro passo da binarização é calcular quantas variáveis binárias são necessárias para representar a variável original. E neste caso, quantas variáveis binárias são necessárias para representar todos os tipos de marcações disponíveis. Sendo $E_{i}$ o número de estados da variável não binária em questão e sendo este número uma potência de dois, ou seja, $E_{i}$ é igual a $2^{m i}$, e mi um número inteiro, o número de variáveis binárias que são necessárias para representar a variável em questão é mi. Cada combinação de estados destas variáveis corresponde a um estado da variável original não binária. No exemplo em questão, as variáveis $V_{1}$ e $V_{2}$ podem receber os valores $A, B, C$ ou vazio, ou seja, quatro valores possíveis. Neste caso $E_{i}$ é igual a 4 e, portanto $m i$ é igual a 2 , afinal, $2^{2}=4$. São necessárias duas variáveis para representar os quatro estados possíveis. Sendo assim, cada variável não binária é representada por duas binárias. $V_{1}$ é representada por $V_{b 11}$ e $V_{b 12}$ e $V_{2}$ por $V_{b 21}$ e $V_{b 22}$. A equivalência entre estas variáveis pode ser vista nas Tabelas $1 \mathrm{C}$ e $2 \mathrm{C}$, respectivamente. 
Tabela $1 \mathrm{C}$ - Equivalência de variáveis binarizadas de $V_{1}$

\begin{tabular}{ccc}
$V_{b 11}$ & $V_{b 12}$ & $V_{1}$ \\
\hline \hline 0 & 0 & Vazio \\
0 & 1 & $A$ \\
1 & 0 & $B$ \\
1 & 1 & $C$ \\
\hline \hline
\end{tabular}

Tabela 2C - Equivalência de variáveis binarizadas de $V_{2}$

\begin{tabular}{ccc}
$V_{b 21}$ & $V_{b 22}$ & $V_{2}$ \\
\hline \hline 0 & 0 & Vazio \\
0 & 1 & $A$ \\
1 & 0 & $B$ \\
1 & 1 & $C$ \\
\hline \hline
\end{tabular}

Porém, sabe-se que pode haver diferentes valores de conteúdo para as mesmas nos lugares, não necessariamente potências de dois. Nestes casos, a variável é dita não binarizável. Para estas variáveis deve-se realizar sua conversão em uma variável binarizável, ou seja, realizar a sua binarização de variáveis. Para tal, deve-se completar a sua lista de estados de modo a garantir que o número total de estados, $E_{i}$, seja uma potência de dois. Estes novos estados adicionados são os chamados estados impossíveis, ou seja, estados que não podem ser atingidos pelo sistema.

Suponha que para uma variável $V_{i}$ que possa ter os valores $A, B$ ou vazio, que são referidos como os estados da variável. Para binarizar esta variável, deve-se 
adicionar um estad impossível, para que haja quatro estados: $A, B$, vazio e inatingível. Como quatro é potência de dois elevado a dois, utiliza-se duas variáveis binárias para representá-la, conforme Tabela 3C.

Tabela 3C - Tabela de binarização de A, B e vazio

\begin{tabular}{ccc}
$\boldsymbol{V}_{\boldsymbol{b i 1}}$ & $\boldsymbol{V}_{\boldsymbol{b i 2}}$ & $\boldsymbol{V}_{\boldsymbol{4}}$ \\
\hline \hline 0 & 0 & Vazio \\
0 & 1 & $A$ \\
1 & 0 & $B$ \\
1 & 1 & Inatingível \\
\hline \hline
\end{tabular}

Podem-se criar tantos estados impossíveis quanto necessários. Supondo uma variável $V_{j}$, que possua cinco estados: $A, B, C, E$ e vazio. Para tornar esta variável binarizável, deve-se adicionar três estados inatingíveis: $I_{1}, I_{2}$ e $I_{3}$. Resultando em um total de oito estados, tornando esta variável binarizável por três variáveis binárias, $V_{v j 1}, V_{v j 2}$ e $V_{v j 3}$, com a equivalência representada na Tabela 4C.

Tabela 4C - Tabela de binarização de A, B, C, E e vazio

\begin{tabular}{cccc}
$\boldsymbol{V}_{\boldsymbol{b j 1}}$ & $\boldsymbol{V}_{\boldsymbol{b j 2}}$ & $\boldsymbol{V}_{\boldsymbol{b} \mathbf{3}}$ & $\boldsymbol{V}_{\mathbf{5}}$ \\
\hline \hline 0 & 0 & 0 & Vazio \\
0 & 0 & 1 & $A$ \\
0 & 1 & 0 & $B$ \\
0 & 1 & 1 & $C$ \\
1 & 0 & 0 & $E$ \\
1 & 0 & 1 & Inatingível I \\
1 & 1 & 0 & Inatingível I \\
1 & 1 & 1 & Inatingível I \\
\hline \hline
\end{tabular}

Definidas as variáveis é necessário declará-las. Para o caso do ultimo exemplo tem-se: 
$\operatorname{variables}\left(V_{b j}, V_{b j}, V_{b j 3}\right)$

A segunda etapa consiste na definição das ações. Conforme exposto na Seção 4, as ações resultam da combinação dos tipos de marcas que podem ser entrados por cada transição fonte. No exemplo exibido na Figura 19 pode haver as ações nenhuma, $B,{ }_{-} C, A_{-}, A B, A C, B_{-}, B B$ e $B C$ conforme descrito na Seção 4. Estas ações são listadas da seguinte forma na SPUDD-IP:

\section{action nenhuma}

*Função de transição das variáveis dada ação nenhuma*

endaction

action_B

${ }^{*}$ Função de transição das variáveis dada ação _ $B{ }^{*}$

endaction

action_C

*Função de transição das variáveis dada ação_C ${ }^{*}$

endaction

action $A$

*Função de transição das variáveis dada ação $A_{-}$*

endaction

action $A B$

*Função de transição das variáveis dada ação $A B$ *

endaction

action $A C$

${ }^{*}$ Função de transição das variáveis dada função $A C^{*}$

endaction

action $B$

${ }^{*}$ Função de transição das variáveis dada ação $B_{\text {_ }}$ *

endaction

action $B B$

*Função de transição das variáveis dada ação $B B^{*}$

endaction

action $B C$

${ }^{\star}$ Função de transição das variáveis dada função $B C$ *

endaction

Conforme exposto acima, a função de transição das variáveis deve ser inserida após a declaração de cada ação. Deve-se listar a função de transição de todas 
as variáveis para cada ação, mesmo que a variável em questão independa da ação.

A etapa seguinte consiste na definição das funções de transição de probabilidades que devem ser colocadas na posição marcada por "*Função de transição das variáveis dada função $X X^{*}$.' Os blocos destas funções são definidos por grupos de ações. A visão desta descrição é sempre a probabilidade da variável em questão ser um no estado seguinte, dados todos os possíveis estados configurados pelas variáveis das quais ela depende.

Considerando agora o exemplo da Figura 1C. Têm-se as dependências mostradas na Tabela $5 \mathrm{C}$, já considerando as variáveis binárias e seguindo a mesma lógica aplicada no exemplo da Figura 18.

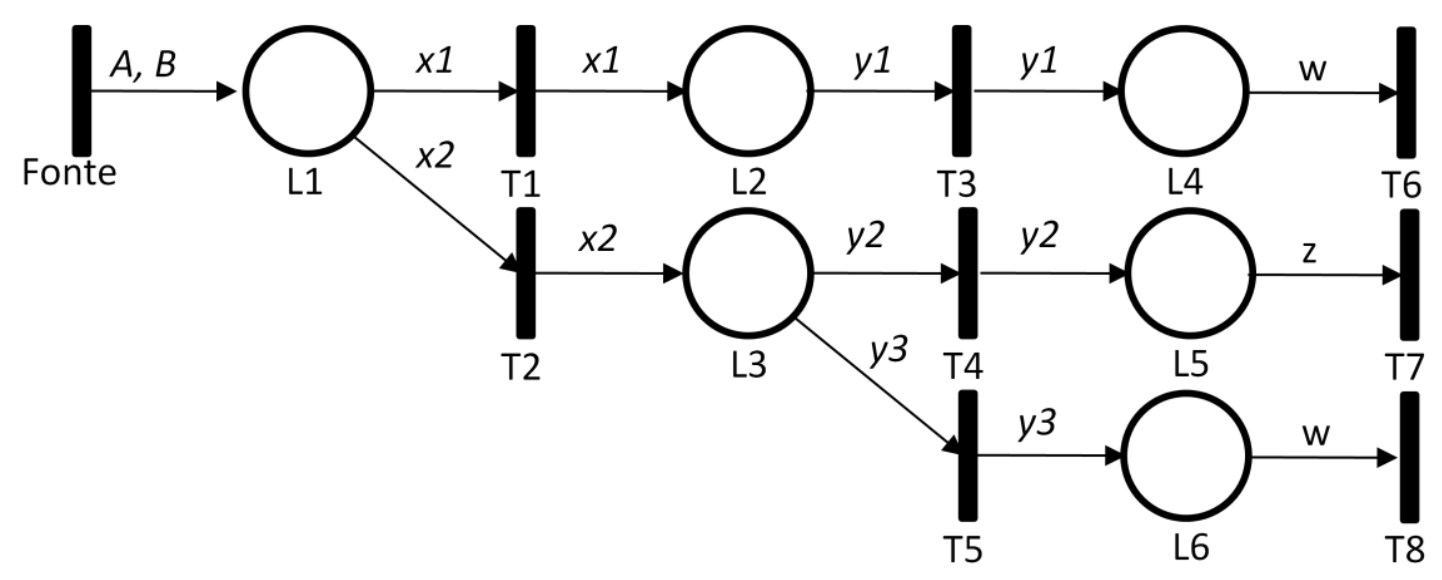

Figura 1C - Rede de Petri para exemplo de dependência entre variáveis. 
Tabela 5C - Tabela de dependência entre variáveis já binarizadas para exemplo da Figura 1C

Variável de estado Depende da ação? Variáveis da qual depende

\begin{tabular}{ccc}
\hline \hline$V_{b 11}$ & Sim & $V_{b 11}, V_{b 12}, V_{b 21}, V_{b 22}, V_{b 31}, V_{b 32}$ \\
$V_{b 12}$ & Sim & $V_{b 11}, V_{b 12}, V_{b 21}, V_{b 22}, V_{b 31}, V_{b 32}$ \\
$V_{b 21}$ & $N a ̃ o$ & $V_{b 11}, V_{b 12}, V_{b 21}, V_{b 22}, V_{b 31}, V_{b 32}, V_{b 41}, V_{b 42}$ \\
$V_{b 22}$ & $N a ̃ o$ & $V_{b 11}, V_{b 12}, V_{b 21}, V_{b 22}, V_{b 31}, V_{b 32}, V_{b 41}, V_{b 42}$ \\
$V_{b 31}$ & $N a ̃ o$ & $V_{b 11}, V_{b 12}, V_{b 21}, V_{b 22}, V_{b 31}, V_{b 32}, V_{b 51}, V_{b 52}, V_{b 61}, V_{b 62}$ \\
$V_{b 32}$ & $N a ̃ o$ & $V_{b 11}, V_{b 12}, V_{b 21}, V_{b 22}, V_{b 31}, V_{b 32}, V_{b 51}, V_{b 52}, V_{b 61}, V_{b 62}$ \\
$V_{b 41}$ & $N a ̃ o$ & $V_{b 21}, V_{b 22}, V_{b 41}, V_{b 42}$ \\
$V_{b 42}$ & $N a ̃ o$ & $V_{b 21}, V_{b 22}, V_{b 41}, V_{b 42}$ \\
$V_{b 51}$ & $N a ̃ o$ & $V_{b 31}, V_{b 32}, V_{b 51}, V_{b 52}, V_{b 61}, V_{b 62}$ \\
$V_{b 52}$ & $N a ̃ o$ & $V_{b 31}, V_{b 32}, V_{b 51}, V_{b 52}, V_{b 61}, V_{b 62}$ \\
$V_{b 611}$ & $N a ̃ o$ & $V_{b 31}, V_{b 32}, V_{b 51}, V_{b 52}, V_{b 61}, V_{b 62}$ \\
$V_{b 62}$ & $N a ̃ o$ & $V_{b 31}, V_{b 32}, V_{b 51}, V_{b 52}, V_{b 61}, V_{b 62}$ \\
\hline \hline
\end{tabular}

A representação em SPUDD-IP do estado futuro de $V_{b 51}$, por exemplo, é exibida abaixo, onde não foram preenchidos os valores de probabilidades que por enquanto são indicados por "prob".

VB51

(VB51

(VB52

(VB31

(VB32

(VB61

(VB61

(VB62 [prob] [prob] )

(VB62 [prob] [prob] ) )

(VB62 [prob] [prob] )

(VB62 [prob] [prob] ) ) )

(VB32

(VB61

(VB61

(VB62 [prob] [prob])

(VB62 [prob] [prob] ) )

(VB62 [prob] [prob] )

(VB62 [prob] [prob] ) ) ) )

(VB31

(VB32

(VB61

(VB62 [prob] [prob] ) 


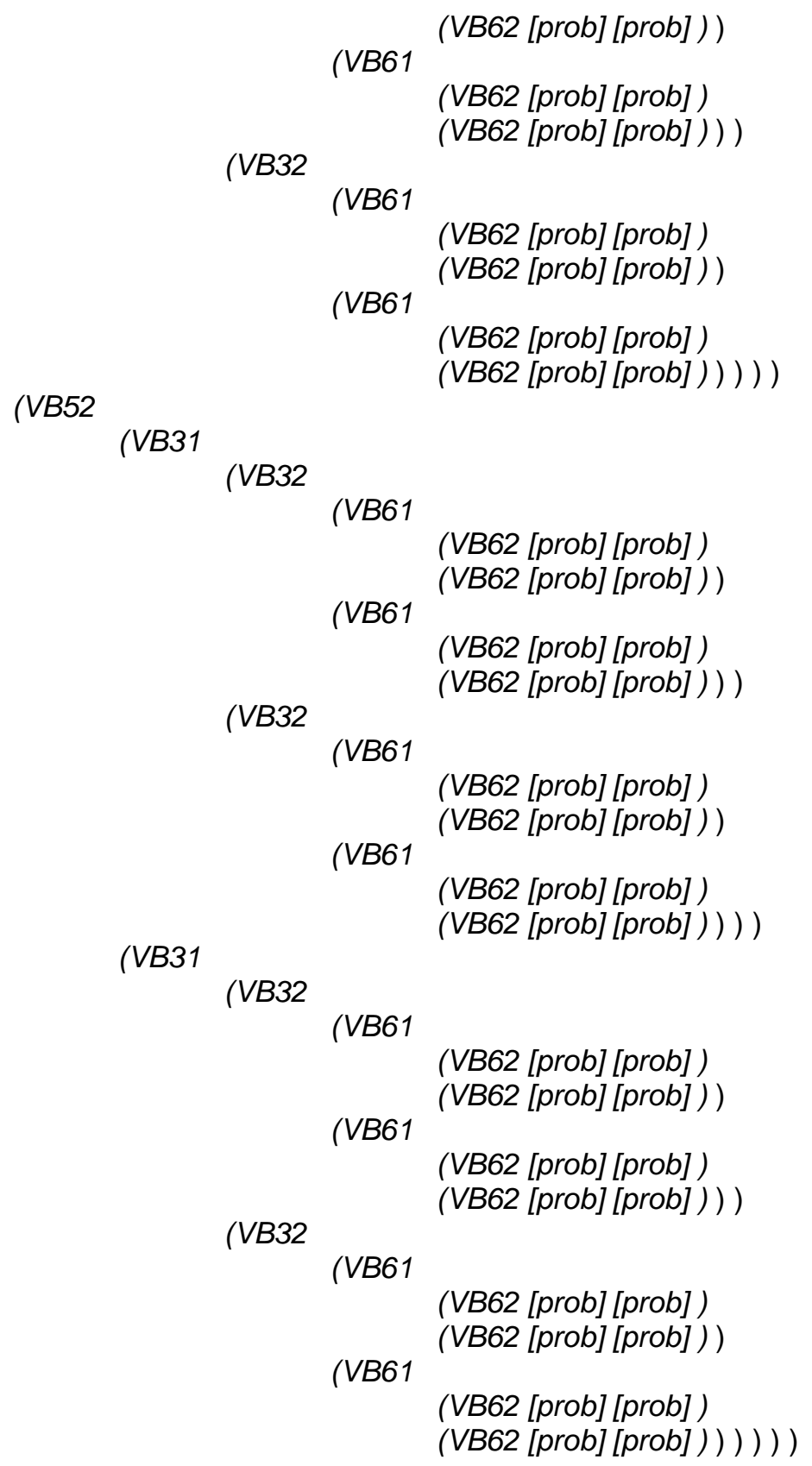

Os valores de "prob" podem ser determinados de três formas:

- Os estados impossíveis recebem valor "zero"

- Os estados que eram probabilidades absolutas (transições habilitadas que não estão em conflitos ou desabilitadas) recebem os valores zero ou um 
- Probabilidades determinadas por conflitos devem ser obtidas a partir das tabelas de probabilidades.

Neste caso só há uma probabilidade associada a um conflito, que é a probabilidade de $V_{b 51}$ ' ser igual a um, dado que $V_{b 51}, V_{b 52}, V_{b 61}, V_{b 62}$ e $V_{b 32}$ são iguais a zero e $V_{b 31}$ é igual a um. $V_{b 51}, V_{b 52,}, V_{b 61}$ e $V_{b 62}$ representam as transições $T_{4}$ e $T_{5}$ habilitadas, e $V_{b 31}$ igual a um e $V_{b 32}$ igual a zero representam o conteúdo $A$ em $L 3$. Esta probabilidade pode ser obtida na tabela do segundo grupo de conflito, representado na Tabela $6 \mathrm{C}$, primeira linha e segunda coluna (pois o valor de $V_{51}$ em $L_{5}$ é resultado do disparo de T4).

Tabela $6 \mathrm{C}$ - Tabela de probabilidades do segundo grupo de conflitos do exemplo da Figura $1 \mathrm{C}$

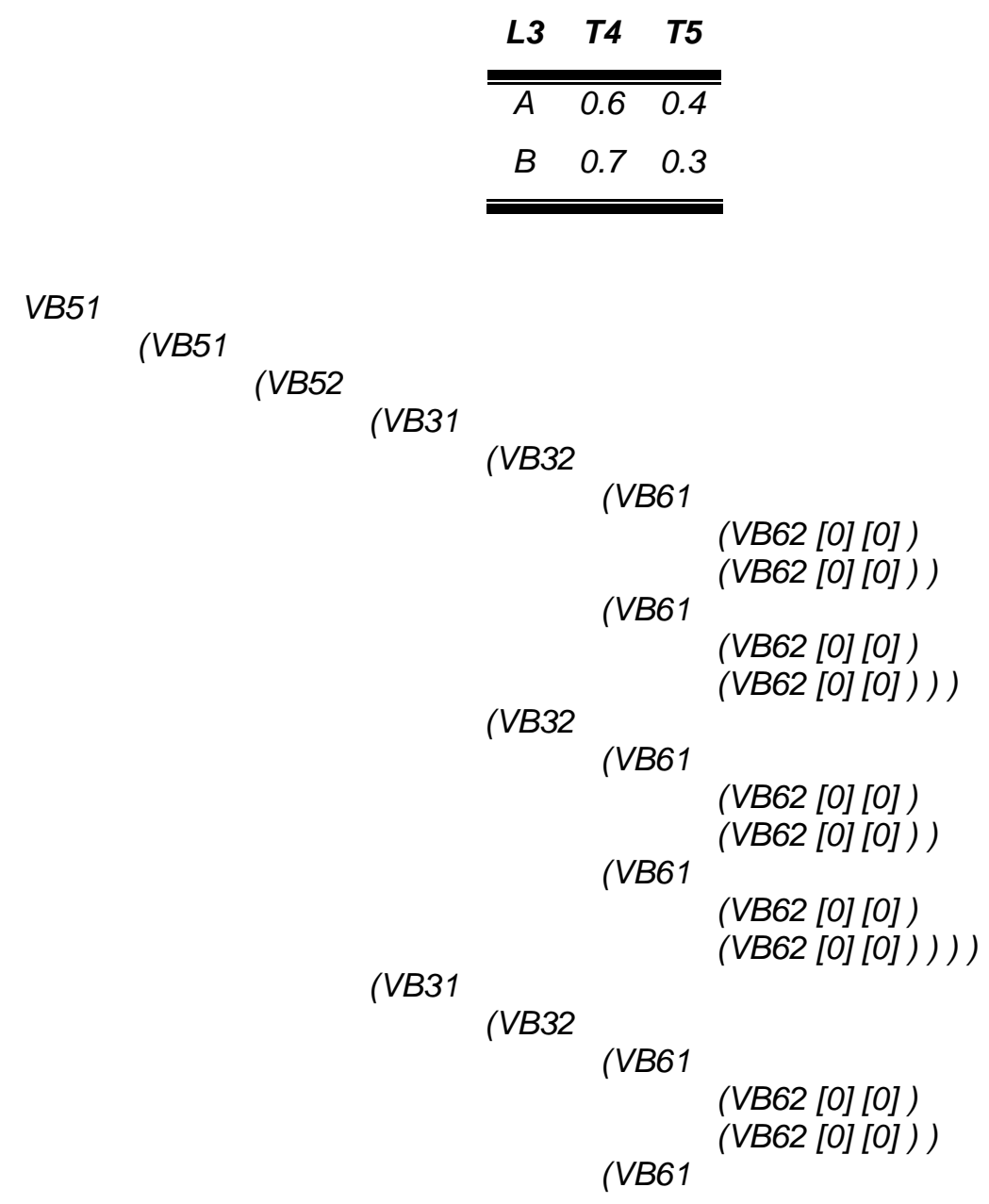




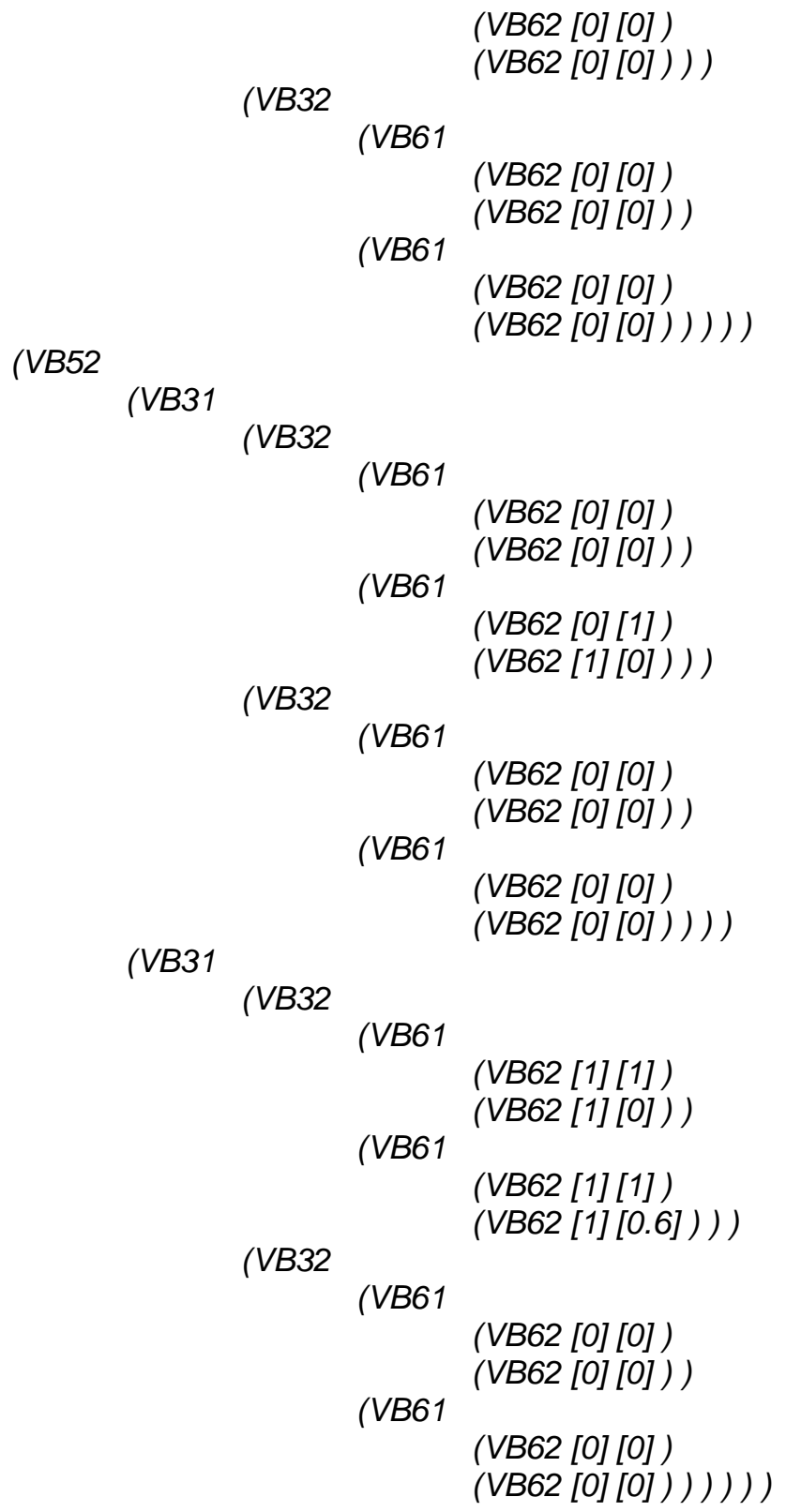

A próxima etapa consiste na definição das recompensas. Por definição, as recompensas são determinadas por uma tabela que é criada junto com a modelagem em FPN, portanto o trabalho desta terceira etapa é a conversão desta tabela. Para o exemplo da Figura 20, suponha a tabela de recompensas da Tabela 7C. 
Esta tabela deve ser convertida para a versão binarizada das variáveis do MDP, observada na Tabela $8 \mathrm{C}$. Note que da mesma forma que a tabela de recompensas original lista apenas as variáveis que a afetam, ao converter também se considera apenas estas variáveis, não precisando listar as demais.

\begin{tabular}{|c|c|c|}
\hline$L 3$ & $L 4$ & Recompensa \\
\hline$\overline{D D}$ & $\bar{A}$ & $\overline{3}$ \\
\hline$D$ & $B$ & 4 \\
\hline$D$ & $C$ & 5 \\
\hline$D$ & Vazia & 2 \\
\hline Vazia & $A$ & 1 \\
\hline Vazia & $B$ & 2 \\
\hline Vazia & C & 3 \\
\hline
\end{tabular}

Tabela 8C - Tabela de recompensas da rede da Figura 20 utilizando variáveis binarizadas do MDP

\begin{tabular}{cccc}
$\boldsymbol{V}_{\boldsymbol{b} 31}$ & $\boldsymbol{V}_{\boldsymbol{b} 41}$ & $\boldsymbol{V}_{\boldsymbol{b} 42}$ & Recompensa \\
\hline \hline 1 & 0 & 1 & 3 \\
1 & 1 & 0 & 4 \\
1 & 1 & 1 & 5 \\
1 & 0 & 0 & 2 \\
0 & 0 & 1 & 1 \\
0 & 1 & 0 & 2 \\
0 & 1 & 1 & 3 \\
\hline \hline
\end{tabular}

Ao representar as recompensas em SPUDD-IP, também deve-se levar em consideração apenas estas variáveis, não necessitando listar as demais. Os estados que não foram listados na tabela devem receber o valor zero, como por exemplo, o estado que combina $V_{b 31}, V_{b 41}$ e $V_{b 42}$. 


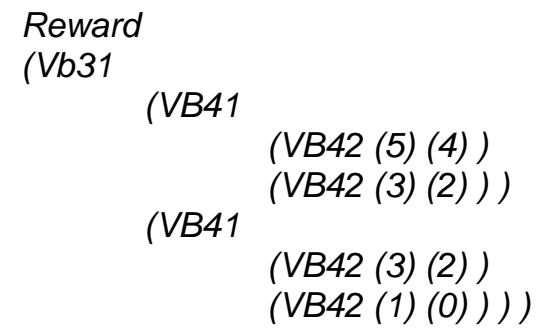

Para que a resolução não se dê em um número infinito de interações e não encontre política ótima, define-se um fator de desconto, quanto maior, mais se valoriza os primeiros estados em relação aos seguintes.

discount 0.025

E por último é determinada a tolerância, que representa a tolerância a ser considerada nos cálculos.

tolerance 0.01

\section{Transformação em MDPIP}

Todas as etapas de transformação de FPN em MDP e FPNIP em MDPIPs são iguais, exceto a terceira etapa, na qual há a associação das probabilidades. Neste caso, como os valores não são fixas, a função de transição de probabilidades deve possuir uma variável onde houver intervalo de probabilidades. Os limites superiores e inferiores desta variável são listados em seguida. 
Considerando para o exemplo da Figura 19 a Tabela $9 \mathrm{C}$ ao invés da Tabela $6 \mathrm{C}$ indicando probabilidades, caracteriza-se uma FPNIP. Neste caso, ao invés de inserir o valor da probabilidade, coloca-se uma variável, chamada arbitrariamente de $p 45 A$. A descrição da função de transição para a variável $V_{51}$ fica:

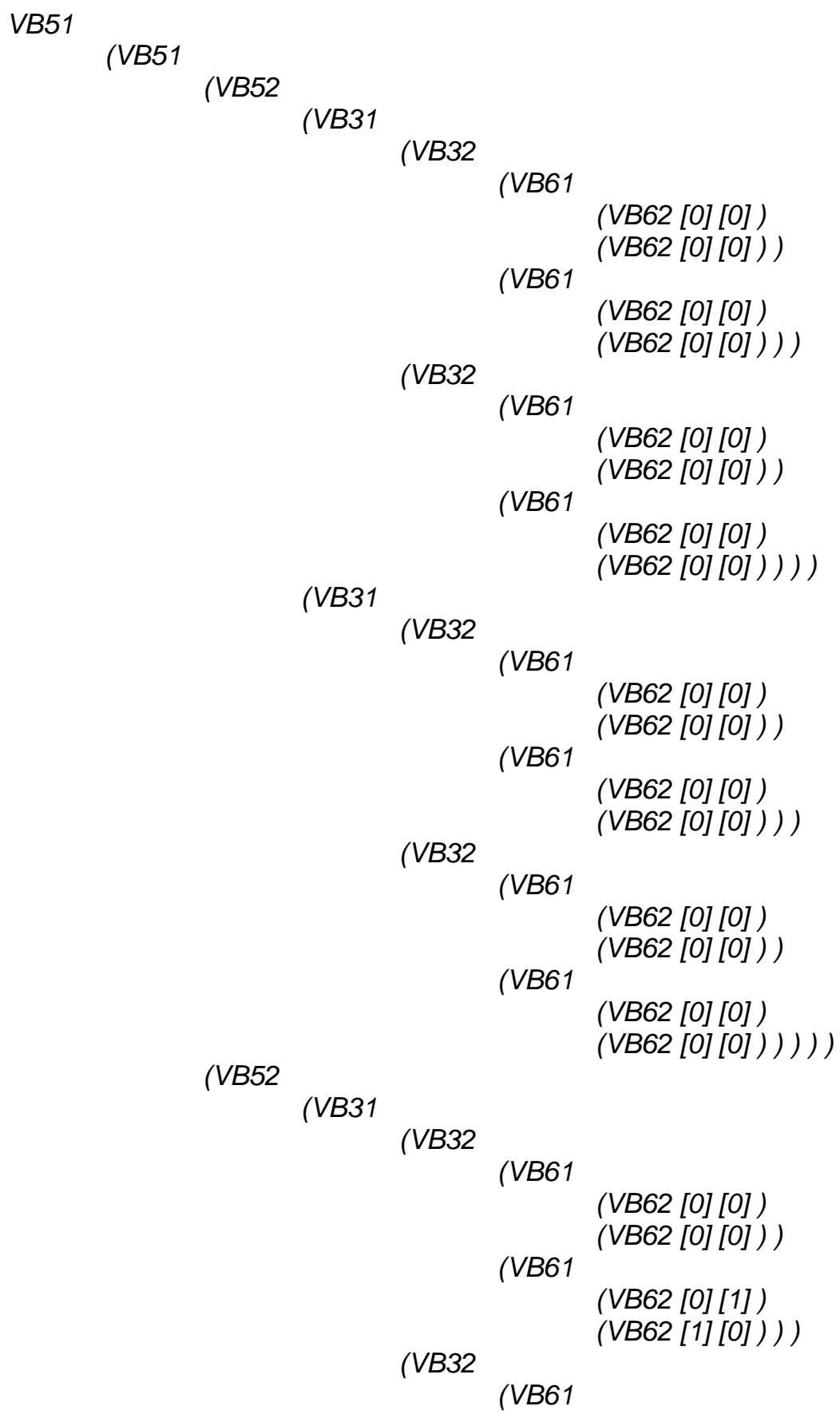




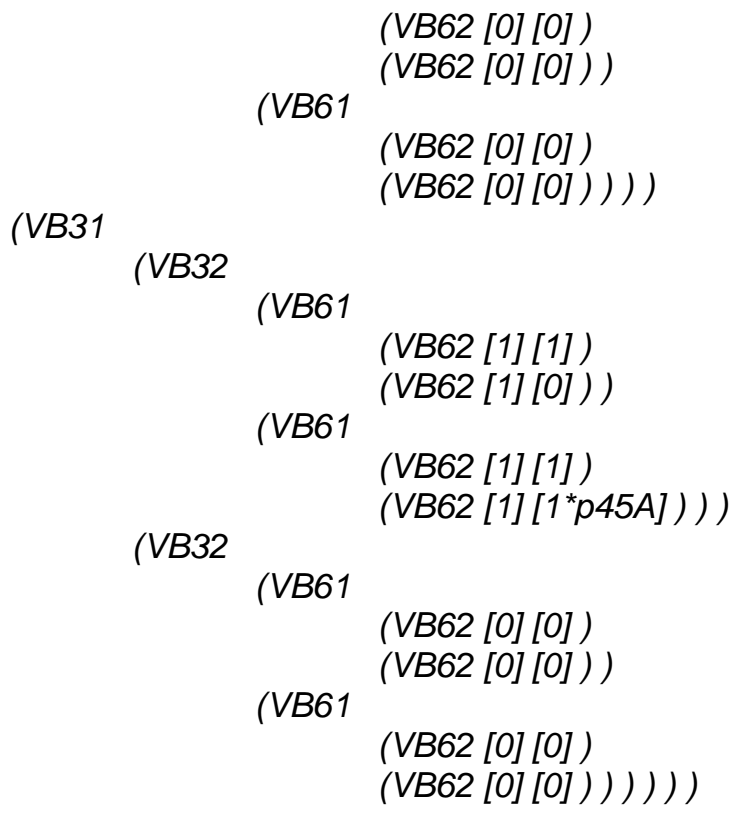

Tabela 9C - Tabela de probabilidades do segundo grupo de conflitos do exemplo da Figura $1 \mathrm{C}$

\begin{tabular}{ccccc} 
L3 & $\mathbf{T 4}_{\text {inf }}$ & $\mathbf{T 4}_{\text {sup }}$ & $\mathbf{T 5}_{\text {inf }}$ & $\mathbf{T 5}_{\text {sup }}$ \\
\hline \hline$A$ & 0.55 & 0.65 & 0.3 & 0.5 \\
$B$ & 0.65 & 0.75 & 0.2 & 0.4 \\
\hline \hline
\end{tabular}

Após a listagem de todas as funções de transição de probabilidades de todas as variáveis e ações, deve-se definir os limites inferiores e superiores das probabilidades que foram indicadas por variáveis. Supondo que a Tabela $10 \mathrm{C}$ represente as probabilidades do primeiro grupo de conflito, e a Tabela $9 \mathrm{C}$ do segundo para o exemplo da Figura 1C, obtém-se a seguinte listagem de variáveis que representam probabilidades imprecisas:

$$
\begin{aligned}
& \text { constraints } \\
& (\quad(p 23 A>=0.45) \\
& (p 23 A<=0.55) \\
& (p 23 B>=0.35) \\
& (p 23 B<=0.45) \\
& (p 32 A>=0.35)
\end{aligned}
$$




$$
\begin{aligned}
& (p 32 A<=0.65) \\
& (p 32 B>=0.4) \\
& (p 32 B<=0.8) \\
& (p 45 A>=0.55) \\
& (p 45 A<=0.65) \\
& (p 45 B>=0.65) \\
& (p 45 B<=0.75) \\
& (p 54 A>=0.3) \\
& (p 54 A<=0.5) \\
& (p 54 B>=0.2) \\
& (p 54 B<=0.4) \\
& )
\end{aligned}
$$

Tabela 10C - Tabela de probabilidades do primeiro grupo de conflitos do exemplo da Figura 1C

\begin{tabular}{ccccc}
$\mathbf{L 1}$ & $\boldsymbol{T 2}_{\text {inf }}$ & $\boldsymbol{T 2}_{\text {sup }}$ & $\boldsymbol{T 3}_{\text {inf }}$ & $\boldsymbol{T 3}_{\text {sup }}$ \\
\hline \hline$A$ & 0.45 & 0.55 & 0.35 & 0.65 \\
$B$ & 0.35 & 0.45 & 0.4 & 0.8 \\
\hline \hline
\end{tabular}




\section{APÊNDICE D}

Nesta seção há uma descrição do programa desenvolvido que realiza a transformação de FPNs em FMDPs. Este programa foi desenvolvido em Excel (VBA) e sua finalidade foi verificar o tempo necessário para tais transformações.

Esta seção está dividida em duas partes, primeiro uma explicação de como utilizar o programa e em seguida os resultados (tempos) de conversão de FPNs em FMDPs.

\section{Utilização do programa}

Os dados da PN devem ser entrados em uma planilha Excel como mostrado na Figura 1D. São listados os lugares, transições, transições fonte, transições sorvedouros e arcos.

Para a listagem de lugares (coluna B), transições (coluna D), transições fonte (coluna $\mathrm{F}$ ) e transições sorvedouros (coluna $\mathrm{H}$ ), o procedimento é apenas listar seus nomes. Para facilitar a programação, foi estabelecido que lugares deveriam ser iniciados por "L" e transições por "T". A listagem dos arcos é mais complicada, devendo conter na primeira coluna o lugar ou transição de onde o arco parte (coluna J), na segunda coluna o lugar ou transição onde 0 arco chega (coluna K) e na terceira (coluna L) o tipo de marca processada pela transição associada ao arco (variável ou fixo). É importante notar que caso o valor do arco seja uma variável, a mesma deverá ter seu nome iniciado por "var", que foi um artifício utilizado para facilita a programação. 


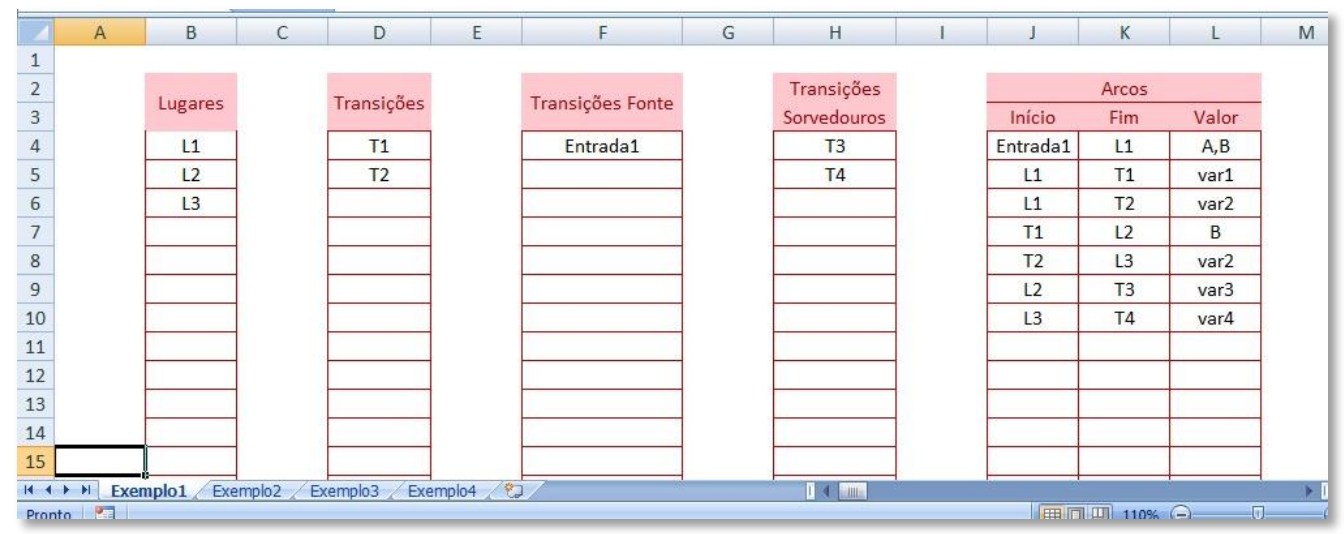

Figura 1D - Entrada da rede de Petri no programa

Em seguida, devem ser listadas as tabelas de probabilidades, deixando-se sempre uma coluna vazia entre uma tabela e outra. Na Figura 2D pode-se ver um exemplo de declaração de tabelas de probabilidades.

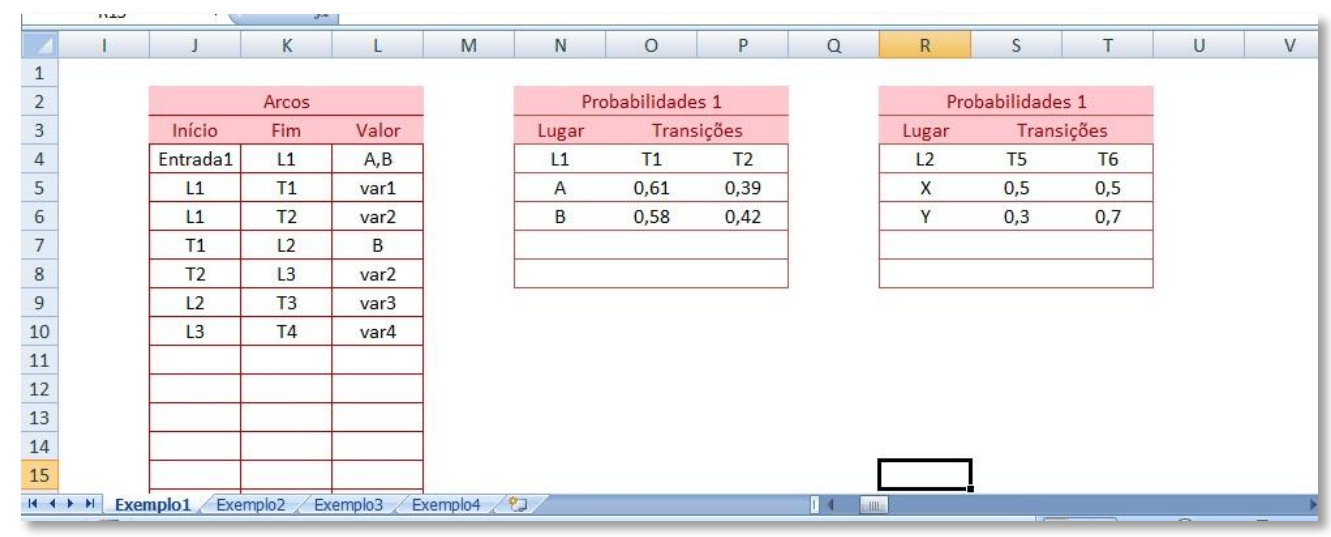

Figura 2D - Entrada das tabelas de probabilidades no programa

\section{Tempos de conversão}

Realizou-se quatro testes para medir tempo de conversão, para os Exemplos de MDP 1, 2, 3 e 4. Para todos os casos o tempo de conversão foi inferior a um minuto, demonstrando eficiência na conversão, além de sua viabilidade de utilização imaginando uma aplicação na industria com 100 lugares que deve ser resolvida em menos de quatro horas.. 